\title{
3D Simulator for Wind Interferometer Data-Model Comparison
}

\author{
Md. Nurul Huda
}

Thesis submitted to the Faculty of the

Virginia Polytechnic Institute and State University

in partial fulfillment of requirements for the degree of

Master of Science

in

Aerospace Engineering

Scott L. England, Chair

Scott M. Bailey

Colin S. Adams

September 27, 2019

Blacksburg, Virginia

Keywords: ICON, MIGHTI, WINDII, Airglow, LOS. 
3D Simulator for Wind Interferometer Data-Model Comparison

Md. Nurul Huda

\begin{abstract}
The connection between earth and space weather has numerous impacts on spacecraft, radio communications and GPS signals. Thus, predicted \& modeling this region is important, yet models (both empirical and first principles) do a poor job of characterizing the variability of this region. One of the main objectives of the NASA ICON mission is to measure the variability of the ionosphere and thermosphere at low-mid latitudes. The MIGHTI instrument on ICON is a Doppler Interferometer that measures the horizontal wind speed and direction with 2 discrete MIGHTI units, separated by $90^{\circ}$, mounted on the ICON Payload Interface Plate. This work focuses on building a simulation of wind interferometer data, similar to MIGHTI, using a first-principles model as the input dataset, which will be used for early validation and comparison to the MIGHTI data. Using a ray-tracing approach, parameters like $\mathrm{O}, \mathrm{O} 2, \mathrm{O}+, \mathrm{O} 2+$, $\mathrm{T}$, wind, solar $\mathrm{F} 10.7$ index will be read for every point along every ray from the model and brightness and Line of Sight (LOS) wind will be calculated as functions of altitude and time. These data will be compared to the MIGHTI observations to both to establish the limitation of such models, and to validate the ICON data. ICON will help determine the physics of our space environment and pave the way for mitigating its effects on our technology, communications systems and society. However, ICON is yet to launch and due to the unavailability of MIGHTI data, we have selected another instrument called WINDII (Wind Imaging Interferometer) from a different mission UARS (Upper Atmosphere Research Satellite) to demonstrate the utility of this data-model comparison. Similar to MIGHTI, WINDII measures Doppler shifts from a suite of visible region airglow and measures zonal and meridian winds, temperature, and VER (Volume Emission rate) in the upper mesosphere and lower thermosphere $(80$ to $300 \mathrm{~km}$ ) from observations of the Earth's airglow. We will use a similar approach discussed for MIGHTI to calculate vertical profile of Redline airglow, Wind velocity, emission rate and compare them with our simulated results to validate our algorithm. We initially thought asymmetry calculation along the Line of Sight (LOS) would be the limiting factor. We believe there are other things going on such as variability in the winds associated with natural fluctuations in the thermosphere, atmospheric waves, inputs from the sun and the atmosphere below etc., appear to be bigger factor than just asymmetry along the line of sight.
\end{abstract}


3D Simulator for Wind Interferometer Data-Model Comparison

Md. Nurul Huda

\section{GENERAL AUDIENCE ABSTRACT}

The upper Earth atmosphere host's most of the valuable spacecraft's and almost all the communication signals go through this portion of the atmosphere. Yet we do not understand what causes variation in the upper atmosphere. In order to answer what's causing these changes and to understand this complicated region, NASA has developed the ICON mission. ICON we will mainly study the Ionosphere ranging from 90 to $450 \mathrm{~km}$ above the earth surface. In this study have developed a tool able to simulate thermospheric wind profiles, $\mathrm{O}, \mathrm{O}_{2}, \mathrm{O}_{+}, \mathrm{O}_{2+}$ densities, Volume emission rate (VER) of green and red line airglow from measurements on the NASA Ionospheric Connection Explorer (ICON) mission from an instrument on board called MIGHTI. However, ICON is yet to launch so do not have MIGHTI to test our algorithm. We chose an instrument which is similar to MIGHTI called Wind Imaging Interferometer (WINDII), from a different mission called Upper Atmosphere Research Satellite (UARS) to test our algorithm. We initially thought asymmetry calculation along the Line of Sight (LOS) would be the limiting factor. We believe there are other things going on such as variability in the winds associated with natural fluctuations in the thermosphere, atmospheric waves, inputs from the sun and the atmosphere below etc., appear to be bigger factor than just asymmetry along the line of sight. 


\section{Acknowledgements}

I would like to express my gratitude towards Dr. Scott England for his guidance and patience throughout this project. I would also like to give thanks to Dr. Scott Bailey and Dr. Colin Adams for helping me with their inputs throughout my research work.

The ICON Level 2 MIGHTI data files used in this study were generated for testing purposes and made available by the ICON team. ICON is supported by NASA's Explorers Program through contracts NNG12FA45C and NNG12FA42I. 


\section{Table of Contents}

1. Chapter 1: Introduction ...............................................................................

1.1 Earth Atmosphere

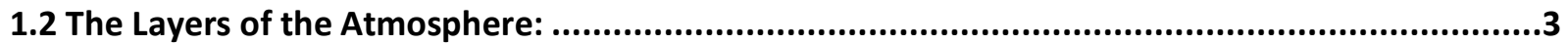

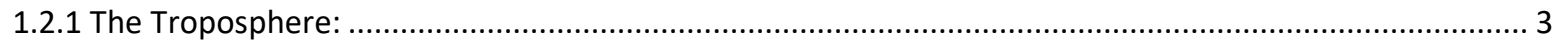

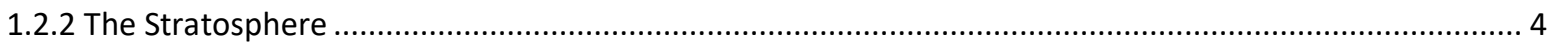

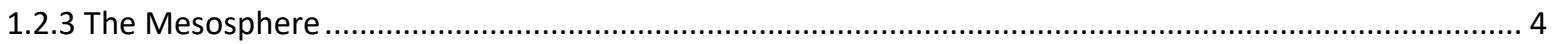

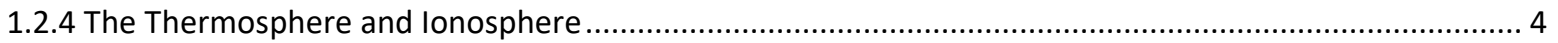

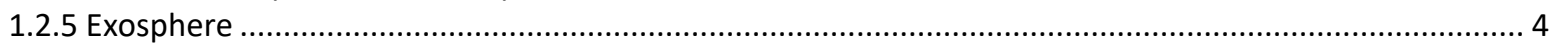

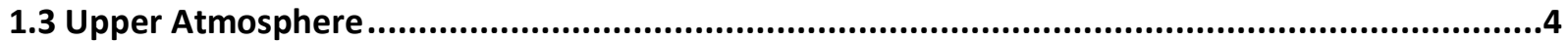

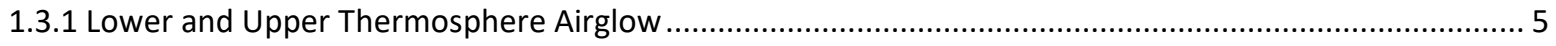

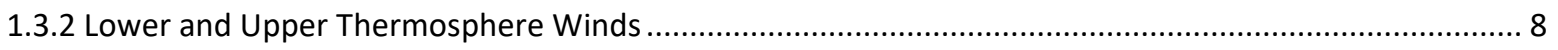

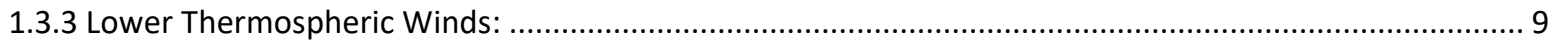

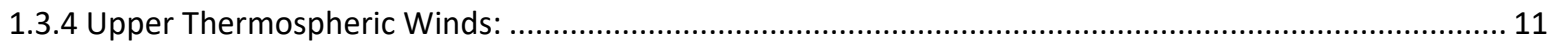

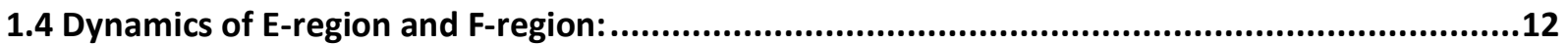

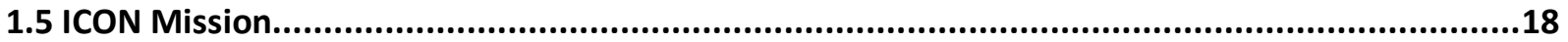

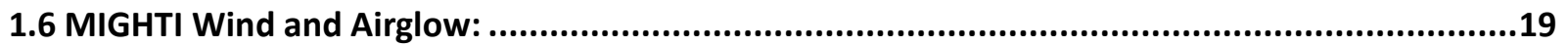

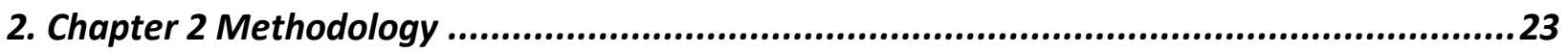

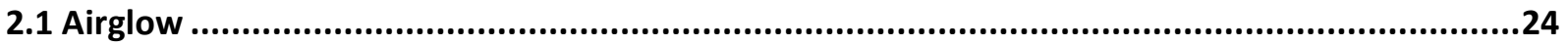

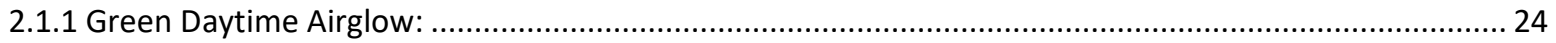

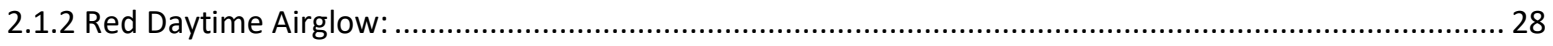

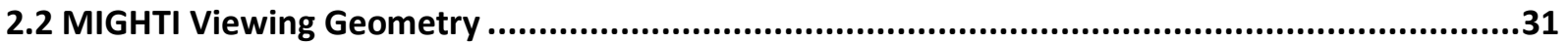

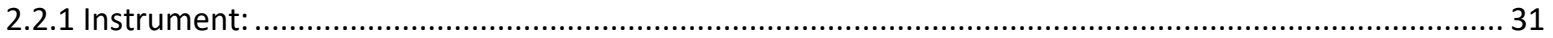

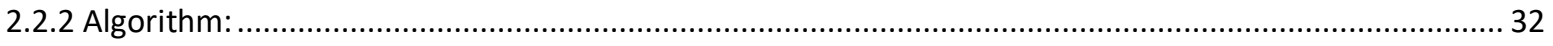

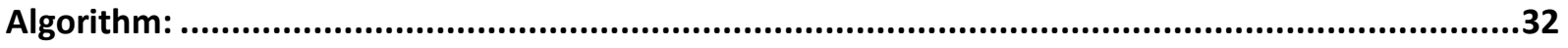

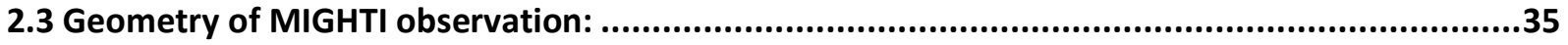

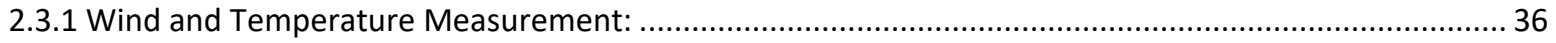

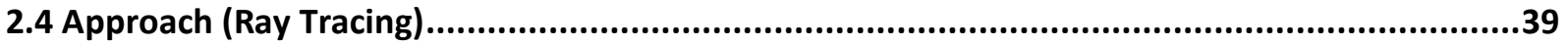

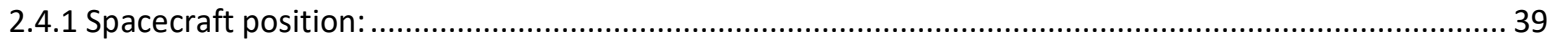

2.4.2 Coordinate Conversion:

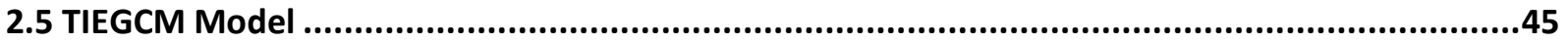

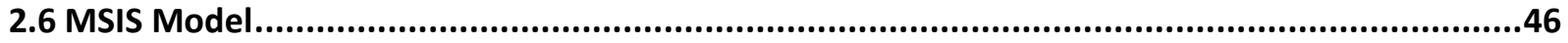

2.6.1 Inputs of MSIS Model (from en.wikipedia.org/wiki/NRLMSISE-00):...................................................... 46

2.6.2 Outputs of MSIS Model (from en.wikipedia.org/wiki/NRLMSISE-00):................................................... 47

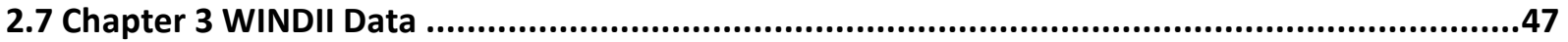

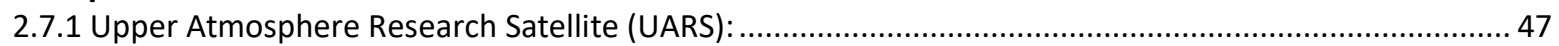

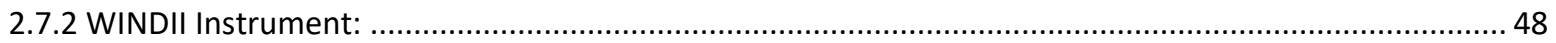

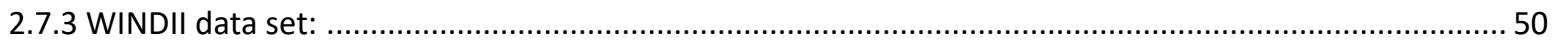

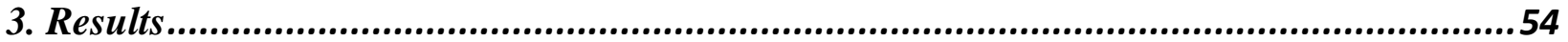




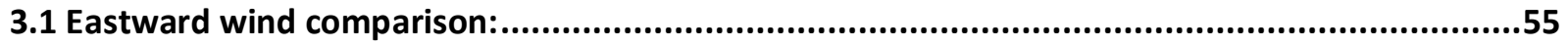

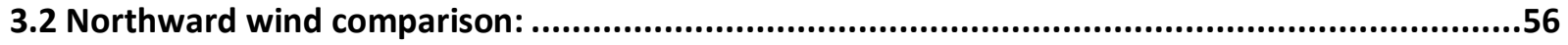

3.3 Mean of WINDII and TIEGCM east and north winds: ...........................................................57

3.4 Mean East and North wind comparison with Latitude: ..........................................................62

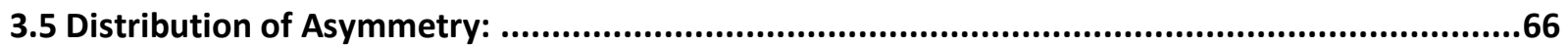

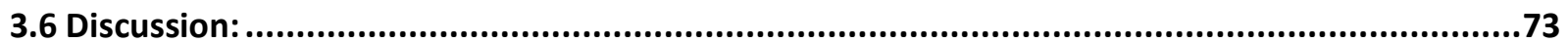

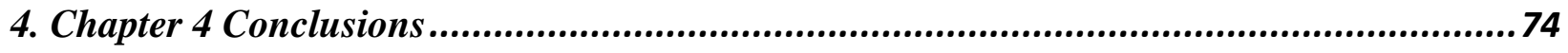

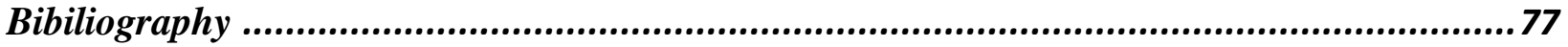




\section{List of Figures}

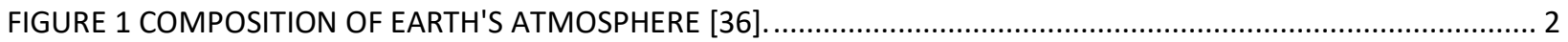

FIGURE 2 LAYERS OF EARTH'S UPPER ATMOSPHERE. CREDIT: JOHN EMMERT/NRL [29] ....................................... 3

FIGURE 3 ENERGY INPUT, CONVERSION AND TRANSPORT PROCESSES RELEVANT TO THE IONOSPHERE-

THERMOSPHERE (IT) SYSTEM FROM (FORBES, 2007).............................................................................. 5

FIGURE 4 EARTH'S AIRGLOW SHOWS VARIATIONS IN BRIGHTNESS WHICH PROVIDE CLUES TO THE MYSTERY OF THE EARTH-SPACE CONNECTION. PHOTO TAKEN FROM [22] ................................................................... 6

FIGURE 5 THE SEASONALLY AVERAGED GREEN LINE VOLUME EMISSION RATE (PHOTON CM-3 S -1) AT LOCAL TIME 8,10, 12, 14, AND 16 HOURS DURING FOR PERIODS IN THE LOCAL TIME DOMAIN. ZHANG ET AL, 2005......... 7

FIGURE 6 THE SEASONALLY AVERAGED GREEN LINE VOLUME EMISSION RATE (PHOTON CM-3 S -1) AT 400N, THE EQUATOR, AND 400S FOR SEP92, DEC92, MAR93, AND JUN93 PERIODS IN THE LOCAL TIME DOMAIN (ZHANG

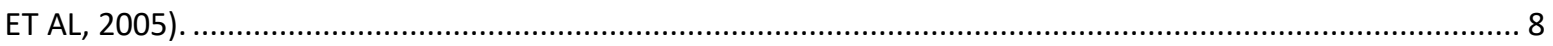

FIGURE 7 TWO SAMPLES OF THE MEASURED RED LINE PROFILE AND GAUSSIAN FITTING CURVE (SHENGPAN P. ZHANG ET AL, 2004).

FIGURE 8 SCHEMATIC ILLUSTRATING THE ZONAL MEAN MERIDIONAL CIRCULATION DRIVEN BY DIFFERENTIAL SOLAR HEATING IN THE THERMOSPHERE (BLUE ARROWS), THE TRANSPORT OF O AND N $\mathrm{N}_{2}$ (LABELED ARROWS), THE LATITUDINAL VARIATION OF R[O/N $\left.\mathrm{N}_{2}\right]$ (FORBES, 2007).

FIGURE 9 ZONAL MEAN ZONAL (LEFT) AND MERIDIONAL (RIGHT) WINDS INDUCED BY DISSIPATION OF SEMIDIURNAL TIDES FOR THE MONTH OF JANUARY AS CALCULATED IN THE MODELING WORK OF ANGELATS AND FORBES (2002).

FIGURE 10 GLOBAL PRESSURE AND WIND DISTRIBUTION FOR AN ALTITUDE OF 300 KM DURING THE SPRING EQUINOX (21 MARCH). THE DISTRIBUTION WAS COMPUTED FOR THE TIME12 UT, MODERATE SOLAR ACTIVITY ( $\mathrm{Cl}=100)$ AND WEAK GEOMAGNETIC ACTIVITY (KP=2). THE CONTOURS ARE LINES OF CONSTANT PRESSURE (ISOBAR). THE HIGHEST PLOTTED PRESSURE OF THE HIGH-PRESSURE REGION (H) CORRESPONDS TO A VALUE OF $9 \mu$ PA; THE LOWEST LEVEL OF THE LOW-PRESSURE REGION (L) TO A VALUE OF $5 \mu$ PA. THE DIFFERENCE BETWEEN ISOBARS DRAWN AWAY FROM THE POINT IN QUESTION. THE WIND SPEED SCALE IS SHOWN BELOW THE MODELS MSIS 86 (HEDIN, 1987) AND HWM 93 (HEDIN 1996). FIGURE TAKEN FROM "PHYSICS OF THE EARTH'S SPACE ENVIRONMENT"- PRÖLSS 2004.

FIGURE 11 THE ABOVE FIGURE IS A BLOCK DIAGRAM THAT EXPLAINS THE E AND F REGION DYNAMOS. THE FIGURE IS TAKEN FROM (HEELIS ET AL. 2001).

FIGURE 12 REPRESENTATIVE PROFILES OF THE TOTAL ION CONCENTRATION DURING DAYTIME AND NIGHTTIME SHOWING THE PEAK AND LEDGE OF THE F- AND E-REGIONS, RESPECTIVELY. (FROM HEELIS ET AL., 2004).... 14

FIGURE 13 CURRENT LOOP DRIVEN BY ZONAL NEUTRAL WINDS IN THE F-REGION (HEELIS ET AL., 2004)................ 15 FIGURE 14 POLARIZATION CHARGES AND ASSOCIATED ELECTRIC FIELDS RESULTING FROM AN EASTWARD ZONAL WIND IN THE F-REGION (HEELIS ET AL., 2004).

FIGURE 15 LOCAL TIME VARIATIONS OF THE ZONAL DRIFTS (UPPER PANEL) AND VERTICAL DRIFTS (LOWER PANEL) OBSERVED AT THE DIP EQUATOR BY THE JICAMARCA RADAR (FROM FEJER ET AL., 1991)............................ 17

FIGURE 16 IONOSPHERIC CONNECTION EXPLORER PHOTO TAKEN FROM [22].................................................... 18

FIGURE 17 VARIATIONS IN VERTICAL PLASMA DRIFTS MEASURED AT THE MAGNETIC EQUATOR FROM THE JICAMARCA RADIO OBSERVATORY DURING PERIODS OF LOW SOLAR ACTIVITY (AFTER ALKEN ET AL., 2009). 19

FIGURE 18 THE ICON MIGHTI INSTRUMENT FROM PHOTO TAKEN FROM (IMMEL ET AL, 2018)............................. 20 FIGURE 19 SCHEMATIC INTERFEROGRAM FROM AN ISOLATED THERMALLY BROADENED EMISSION LINE (HARLANDER ET AL., 2007).

FIGURE 20 VOLUME EMISSION RATES OF THE OXYGEN GREEN (GL) AND RED (RL) LINE EMISSIONS USED FOR THE MIGHTI INSTRUMENT MODEL FROM (ENGLERT, ET AL.,2017).

FIGURE 21 AVERAGE VOLUME EMISSION RATES OF THE OXYGEN A-BAND USED FOR THE MIGHTI INSTRUMENT MODEL FROM (ENGLERT, ET AL.,2017).

FIGURE 22 RESULT OF THE VERIFICATION SIMULATION WITHOUT NOISE. (TOP) A DEPICTION OF THE SIMULATED ICON ORBIT IN BLACK, OVERLAID ON A MAP OF THE TOTAL VERTICAL COLUMN BRIGHTNESS OF THE SIMULATED RED EMISSION, FOR REFERENCE. FOR TWO EXAMPLE FINDINGS AT T $=1200 \mathrm{~S}$ AND T $=2150 \mathrm{~S}$, THE LINES OF SIGHT OF MIGHTI A AND B ARE SHOWN IN WHITE. (BOTTOM) THE FINDING ERRORS FOR THE 
ZONAL AND MERIDIONAL WIND AND THE RED AND GREEN EMISSIONS ARE SHOWN AS A FUNCTION OF ALTITUDE AND TIME, FOLLOWING ICON'S ORBIT. THE TWO EXAMPLE FINDINGS ARE REPRESENTATIVE OF THE LARGEST SOURCES OF ERROR: SPHERICAL ASYMMETRY NEAR THE TERMINATOR AND THE EDGE OF THE EQUATORIAL IONIZATION ANOMALY FROM (HARDING ET AL., 2017).

FIGURE 23 FOUR SAMPLES OF THE MEASURED GREEN LINE EMISSION RATE PROFILES (DOTS) AND FITTING CURVES (DASHED CURVES FOR THE TWO CHAPMAN FUNCTION FITTINGS, AND SOLID CURVES FOR THE COMBINED FITTING) FROM (ZHANG ET AL.,2005)

FIGURE 24 VOLUME EMISSION RATE (VER) OF DAY AIRGLOW FOR GREEN LINE. ................................................... 27

FIGURE 25 VOLUME EMISSION RATE (VER) OF DAY AND NIGHT AIRGLOW COMBINED FOR GREEN LINE. ................ 28 FIGURE 26 TWO SAMPLES OF THE MEASURED RED LINE PROFILE AND GAUSSIAN FITTING CURVE FROM (ZHANG ET

AL.,2004). 29

FIGURE 27 VOLUME EMISSION RATE (VER) OF DAY AIRGLOW FOR RED LINE. .................................................. 30

FIGURE 28 VOLUME EMISSION RATE (VER) OF DAY AND NIGHT AIRGLOW COMBINED FOR GREEN LINE. ............... 30

FIGURE 29 (MIGHTI) INSTRUMENT SOURCE (HARDING, ET AL. 2017). ................................................................ 31

FIGURE 30 OBSERVATION GEOMETRY FOR A MIGHTI INTERFEROGRAM (SOURCE: HARDING, ET AL. 2017). ........... 32

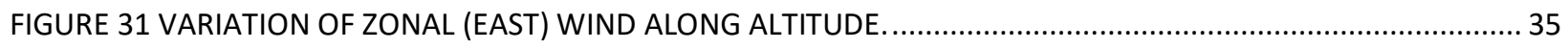

FIGURE 32 VARIATION OF MERIDIAN (NORTH) WIND ALONG ALTITUDE.

FIGURE 33 ICON'S OBSERVATIONAL GEOMETRY ALLOWS SIMULTANEOUS IN SITU AND REMOTE SENSING OF THE

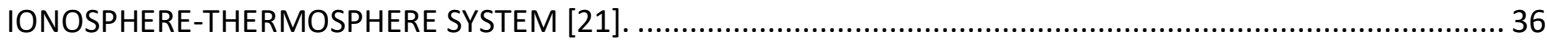

FIGURE 34 EXAMPLE 1D ‘IMAGE’ OF THE WIND \& BRIGHTNESS (SOURCE: HARDING, ET AL. 2017)....................... 37

FIGURE 35 VARIATION OF TIEGCM ION, ELECTRON, NEUTRAL TEMPERATURE.................................................. 37

FIGURE 36 SCHEMATIC ILLUSTRATION OF THE SOLAR ZENITH ANGLE (SZA) AND VIEWING ZENITH ANGLE (VZA) FOR

OBSERVATIONS FROM SATELLITE-BASED INSTRUMENT. [IMAGE TAKEN FROM A NASA PAGE] ..................... 38

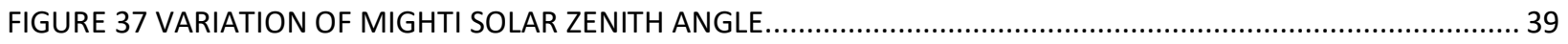

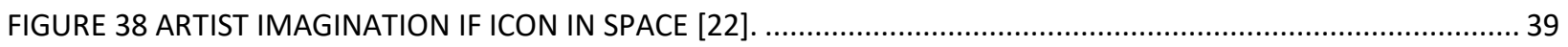

FIGURE 39 THE CARTESIAN (RECTANGULAR) COORDINATE SYSTEM SOURCE: (HTTP://WWW.COOLMATH.COM/). 40

FIGURE 40 ECI (EARTH CENTERED INERTIAL) SYSTEM [4] ............................................................................... 41

FIGURE 43 COORDINATE CONVERSION PHOTO TAKEN FROM (COLORADO.EDU)................................................ 42

FIGURE 44 UPPER ATMOSPHERE RESEARCH SATELLITE (UARS) FROM (HTTPS://UARS.GSFC.NASA.GOV). .............. 48

FIGURE 45 FROM (SHEPHERD ET AL., 2012) (A) WINDII OPTICAL SCHEMATIC LAYOUT; THE ARROWS SHOW THE TWO DIRECTIONS OF WINDII MOTION CORRESPONDING TO FORWARD AND BACKWARD UARS FLIGHT. (B) WINDII PHOTO SHOWING THE BAFFLE, THE RADIATOR PLATE, AND THE OPTICS WHICH ARE DEEP INSIDE THE

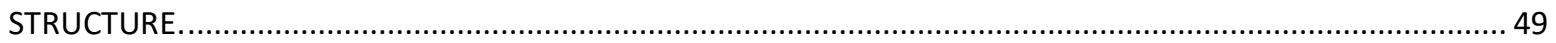

FIGURE 46 ALTITUDE VARIATION FOR WINDII VERTICAL PROFILE. ................................................................. 51

FIGURE 47 WINDII LATITUDE VARIATION WITH LOCAL TIME - FOR YEAR 1992 DAY 015..................................... 52

FIGURE 48 WINDII LONGITUDE VARIATION WITH LOCAL TIME- FOR YEAR 1992 DAY 015...................................... 52

FIGURE 49 ALTITUDE VARIATION FOR TOP AND BOTTOM RAYS - FROM YEAR 1992 DAY 015.............................. 53

FIGURE 50 GLOBAL PRESSURE AND WIND DISTRIBUTION FOR AN ALTITUDE OF 300 KM DURING THE SPRING EQUINOX (21 MARCH). THE DISTRIBUTION WAS COMPUTED FOR THE TIME12 UT, MODERATE SOLAR ACTIVITY (CI=100) AND WEEK GEOMAGNETIC ACTIVITY (KP=2). THE CONTOURS ARE LINES OF CONST ANT PRESSURE (ISOBAR). THE HIGHEST PLOTTED PRESSURE OF THE HIGH-PRESSURE REGION (H) CORRESPONDS TO A VALUE OF $9 \mu$ PA; THE LOWEST LEVEL OF THE LOW-PRESSURE REGION (L) TO A VALUE OF $5 \mu$ PA. THE DIFFERENCE BETWEEN ISOBARS DRAWN AWAY FROM THE POINT IN QUESTION. THE WIND SPEED SCALE IS SHOWN BELOW THE MODELS MSIS 86 (HEDIN, 1987) AND HWM 93 (HEDIN 1996). FIGURE TAKEN FROM "PHYSICS OF THE EARTH'S SPACE ENVIRONMENT"- PRÖLSS 2004........................................................ 55 FIGURE 51 COMPARISON OF EASTWARD WIND BETWEEN TIEGCM MODEL AND WINDII FOR AN ALTITUDE OF NEAR

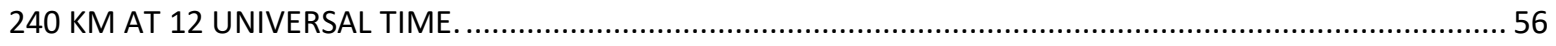
FIGURE 52 COMPARISON OF EASTWARD WIND BETWEEN TIEGCM MODEL AND WINDII FOR AN ALTITUDE OF NEAR

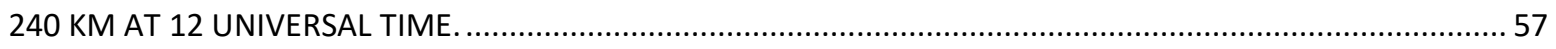

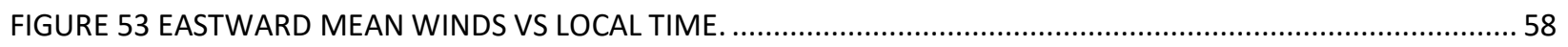
FIGURE 54 EASTWARD MEAN WINDS WITH STANDARD DEVIATION VS LOCAL TIME. .......................................... 59

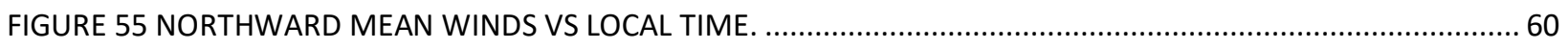

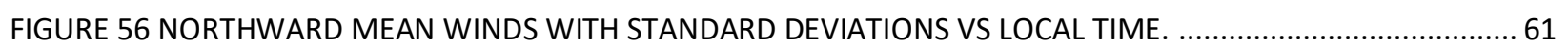


FIGURE 57 EASTWARD MEAN WINDS VS LATITUDE. 62

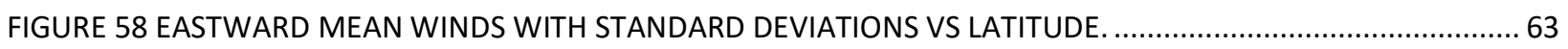

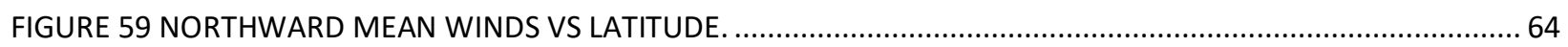

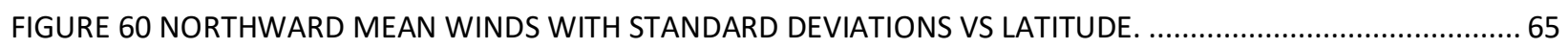

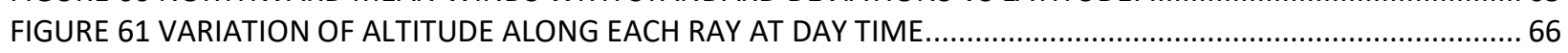

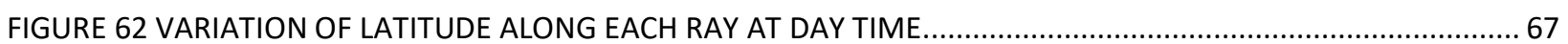

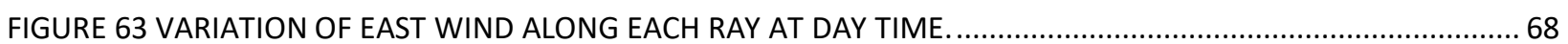

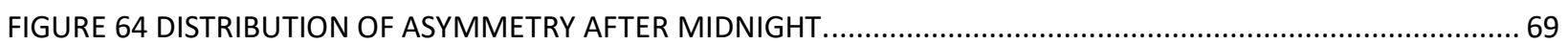

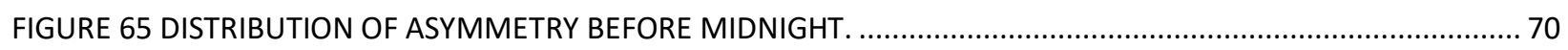

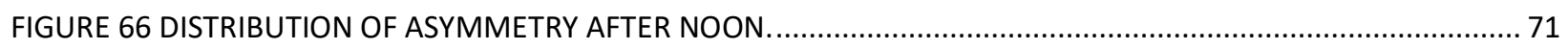

FIGURE 67 DISTRIBUTION OF ASYMMETRY BEFORE NOON. ..................................................................... 72 


\section{List of Tables}

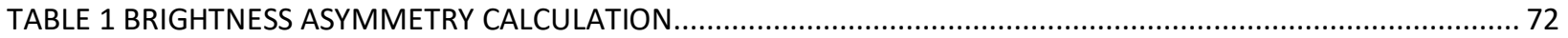

TABLE 2 WIND*BRIGHTNESS ASYMMETRY CALCULATION..... 


\section{Chapter 1: Introduction}

For navigation and precise positioning of satellites, aircraft, vehicles, missiles and many other space carats, global positioning system (GPS) signals, radio frequency interference (RFI) are used almost every day. GPS signals can also be used to help farmers harvest their fields, by mapping their fields where they need to harvest depending on different seasons. Further, GPS signals can be very handy in mining, surveying. Our modern life has become so dependent on these that, we cannot imagine a world without these at for a single day. At present, there are 31 active GPS satellites orbiting earth at a height of $20000 \mathrm{~km}$ above earth's surface to support this huge need. Yet, the success of GPS based data depends on a number of attributes (e.g accuracy of receiver, satellite position at current time, and most importantly the medium through which the signal passes), where minimum GPS signal levels have threatened GPS radio frequency interference (RFI). The transmitted waves from GPS satellite penetrates through the upper atmosphere by the time it reaches to the receiver, atmospheric charged particles, atoms and electrons in the atmosphere curve the radio signals and decelerate the wave propagation That's why it's important to understand our ionosphere and what causes disruption, which if not answered might lead to catastrophic consequences like communication loss with aircrafts and others satellites, giving wrong location to aircrafts or missiles, providing wrong weather prediction. Understanding the variation of the charged particles, plasmas, densities of atmospheric particles of the upper atmosphere will help us unraveling the mystery of lost GPS signal.

So, we need a better understanding of the Earth's upper atmosphere, it's air particles and atoms (e.g O, $\mathrm{O}_{2}, \mathrm{O}_{+}, \mathrm{O}_{2}+, \mathrm{N}_{2+}$ ). Absorption of solar ultraviolet and X-radiation and chemical reactions result in excited state of parameters such as $\mathrm{O}, \mathrm{O}_{2}, \mathrm{O}_{+}, \mathrm{O}_{2+}$ and cause the emission at $630 \mathrm{~nm}$ from the $\mathrm{O}\left({ }_{1} \mathrm{D}\right)$ level of atomic oxygen (Red line) or emission at $557.7 \mathrm{~nm}$ from $\mathrm{O}\left({ }_{1} \mathrm{D}-1 \mathrm{~S}\right)$ (Green line) (Zhang et al., 2004). We will describe Earth's upper atmosphere and its composition in this section.

Chapter 1 will introduce the motivation and goal for this thesis. 1.1 Introduces the common characteristics of Earth's atmosphere, what region of the atmosphere we are looking at? 1.2 Discusses the different Layers of the Earth Atmosphere; 1.3 Upper atmosphere of Earth Atmosphere and previous observations of the upper atmosphere, what types of parameters likes wind, upper atmosphere, temperature? 1.4 discusses the upper and lower thermosphere; 1.5 describes the airglow specially 630. $\mathrm{nm}$ (red line) and $557.7 \mathrm{~nm}$ (green line) which data has been acquired for analysis in this thesis; 1.6 discusses observations of airglow from different models.

\subsection{Earth Atmosphere}

Earth is the only solar system planet with a life - sustaining atmosphere. The Earth's atmosphere is the most essential part of the life of Earth. The Earth's atmosphere (Ozone Layer) prevents some of the hazardous solar rays of the sun from spreading to the Earth's surface. It confines solar heat and makes Earth a pleasant temperature compared to other planets to sustain life. The Earth's atmosphere extends approximately 300-350 miles $(480-550 \mathrm{~km})$, however almost all of the earth's 
atmosphere (about $75 \%$ by mass) is $10-14$ miles $(16-20 \mathrm{~km})$ from the surface of the Earth. There is no exact ending of the atmosphere; it only gets thinner and thinner until it merges with outer space or becomes essentially collision less in the exosphere. The atmospheric density reduces with altitude due to the gravitational force of the Earth, which attracts the gasses and aerosols on the inside, is closest to the surface [28].

The evolution of the current atmosphere on Earth is not fully understood. The current atmosphere is thought to have originated from the periodic release of gasses from the interior of the planet as well as from life forms - unlike the primordial atmosphere [28]. About $85 \%$ of volcanic emissions are in water vapor form. By contrast, carbon dioxide accounts for about $10 \%$ of effluent. Earth's atmospheric composition consists of nitrogen $\left(N_{2}\right)$, 78.08\%; oxygen $\left(\mathrm{O}_{2}\right)$ 20.95\%; $\operatorname{argon}(A)$, 0.93\%; water $\left(\mathrm{H}_{2} \mathrm{O}\right), 0$ to 4\%; and carbon dioxide $\left(\mathrm{CO}_{2}\right), 0.04 \%$ [28]. Inert gasses like neon $(\mathrm{Ne})$, helium $(\mathrm{He})$, crypton $(\mathrm{Kr})$ and other components such as nitrogen oxides, sulfur compounds and ozone compounds are found in smaller quantities. It is important to note that this composition is most representative of the lower atmosphere and is not relevant to the thermosphere.

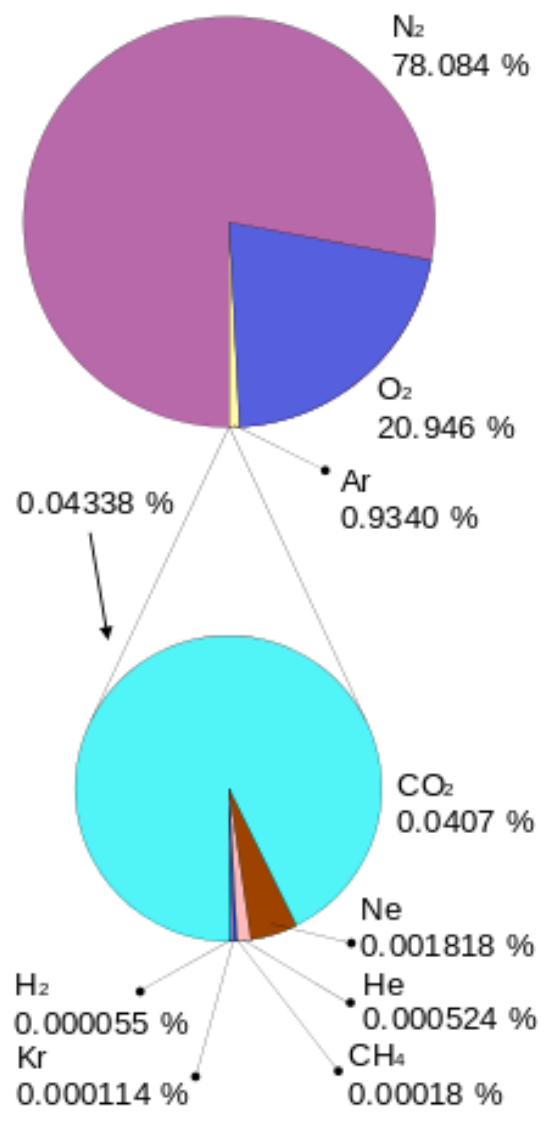

Figure 1 Composition of Earth's atmosphere [36]. 


\subsection{The Layers of the Atmosphere:}

The Earth's atmosphere is divided based on its temperature with altitude, where we also find differences in composition and other such properties into five main layers.

- The Troposphere

- The Stratosphere

- The Mesosphere

- The Thermosphere

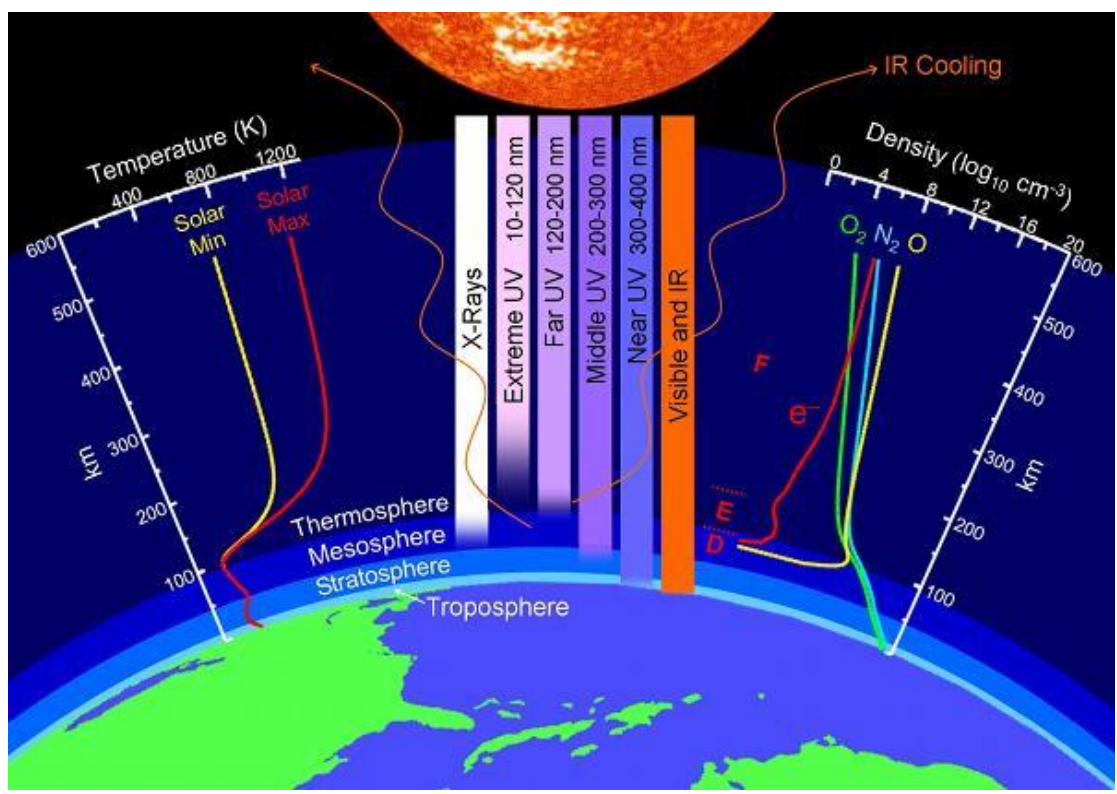

Figure 2 Layers of Earth's upper atmosphere. Credit: John Emmert/NRL [29].

\subsubsection{The Troposphere:}

The part of the atmosphere closest to the Earth's surface is known as the troposphere. It mostly extends up to 7 to $20 \mathrm{~km}$ from the Earth's surface and considered thickest part of the Earth's atmosphere. At the Earth's surface the air is warm, however the temperature gets colder as the altitude increases, by about $6.5^{\circ} \mathrm{C}$ per kilometer. The troposphere is believed to hold about $75 \%$ of the atmospheric air and almost all the water vapor (which forms clouds and rain). Earth's surface acts like the heat source, so the decrease in temperature is the result of going away from the heat source.

The boundary layer is the lower part of the troposphere. The air motion in this region is governed by the characteristics of the surface of the earth. Turbulence in the troposphere is originated by the wind blowing over the surface of the earth and the thermal convection soaring from the earth when the sun is heated. This spiraling disturbance carries heat and humidity within the limiting layer, 
pollutants and other atmospheric components. The troposphere's top is called the tropopause, the lowest in the poles, $7-10 \mathrm{~km}$ above the surface of the earth. It's the highest near the equator (about $17-18 \mathrm{~km})$.

\subsubsection{The Stratosphere}

The Stratosphere starts from the tropopause and stretch to about $50 \mathrm{~km}$. It contains a lot of the atmospheric ozone. The temperature growth with height is caused by the absorption by this ozone of ultraviolet (UV) radiation from the sun. Stratosphere temperatures are highest over the summer pole. The top of the stratosphere is called the stratopause.

\subsubsection{The Mesosphere}

Atmosphere above our planet that extends from the stratopause. up to a height of about $85 \mathrm{~km}$ (53 miles) is called the mesosphere. Unlike stratosphere the temperature drops with height, reaching a minimum of about $-90^{\circ} \mathrm{C}\left(-130^{\circ} \mathrm{F}\right)$, are found near the top of this layer, called the mesopause.

\subsubsection{The Thermosphere and Ionosphere}

The thermosphere and the ionosphere are the region where most of the High-energy UV radiation from the Sun and almost all the ionized particles, plasmas being absorbed. This portion of the atmosphere is the main attraction of our research, that's why we will discuss elaborately in the later section under upper atmosphere. This is discussed in more detail in Section 1.3 below.

\subsubsection{Exosphere}

The most upper most layer of earth's atmosphere, where the thermosphere gives way to exosphere, in this region atoms and molecules escape into space. Basic property of the exosphere includes constant temperature with altitude, very low density and mostly dominated by $\mathrm{He}, \mathrm{H}$ a bit of $O$. Due to the very low-density number of collisions are very little. The transition between thermosphere is called exobase.

\subsection{Upper Atmosphere}

The Thermosphere, and Ionosphere together comprises Earth's upper atmosphere. The thermosphere is the realm of High-energy X-rays, UV radiation from the Sun, ionized particles, plasmas, meteors, auroras and satellites extends from an altitude from about $90-1000 \mathrm{~km}$. Earth's upper atmosphere is extremely important if you want to understand the variability of the composition of the atmosphere and account for the causes of these changes.

We can divide the thermosphere in 3 categories

- Lower Thermosphere: Which extends from 90-120 km above the surface of the earth. Sometimes lower thermosphere is compared with mesosphere. In this section of the earth's 
atmosphere the temperature increases slowly with altitude, highest temperature in this region is about $300 \mathrm{~K}$.

- Middle Thermosphere: Which extends from 120-200 km above the earth's atmosphere. In this region, the temperature rapidly increases with altitude, highest temperature in this region is $1000 \mathrm{~K}$.

- Upper Thermosphere: Which extends from 200-1000 km above the earth's atmosphere. In this region of the earth's atmosphere the temperature almost remains constant with altitude.

Understanding the thermosphere is most important as the thermosphere hosts ionosphere, and the ionosphere impacts global positioning system (GPS) signals, radio frequency interference (RFI). "The thermosphere is an intermediate atmospheric region strongly coupled to the lower-middle atmosphere by gravity waves, planetary waves, thermal tides, dust storms etc. and also coupled from above with the energy inputs from the Sun by Solar X-ray, EUV and UV fluxes and solar wind particles." - (Haberle et al., 2017). Therefore, to answer the question what drives all the flow of energy and change in ion, electron density we need to understand different sources of external forcing to the earth's upper atmosphere, also known as the Ionosphere-Thermosphere (IT) system.

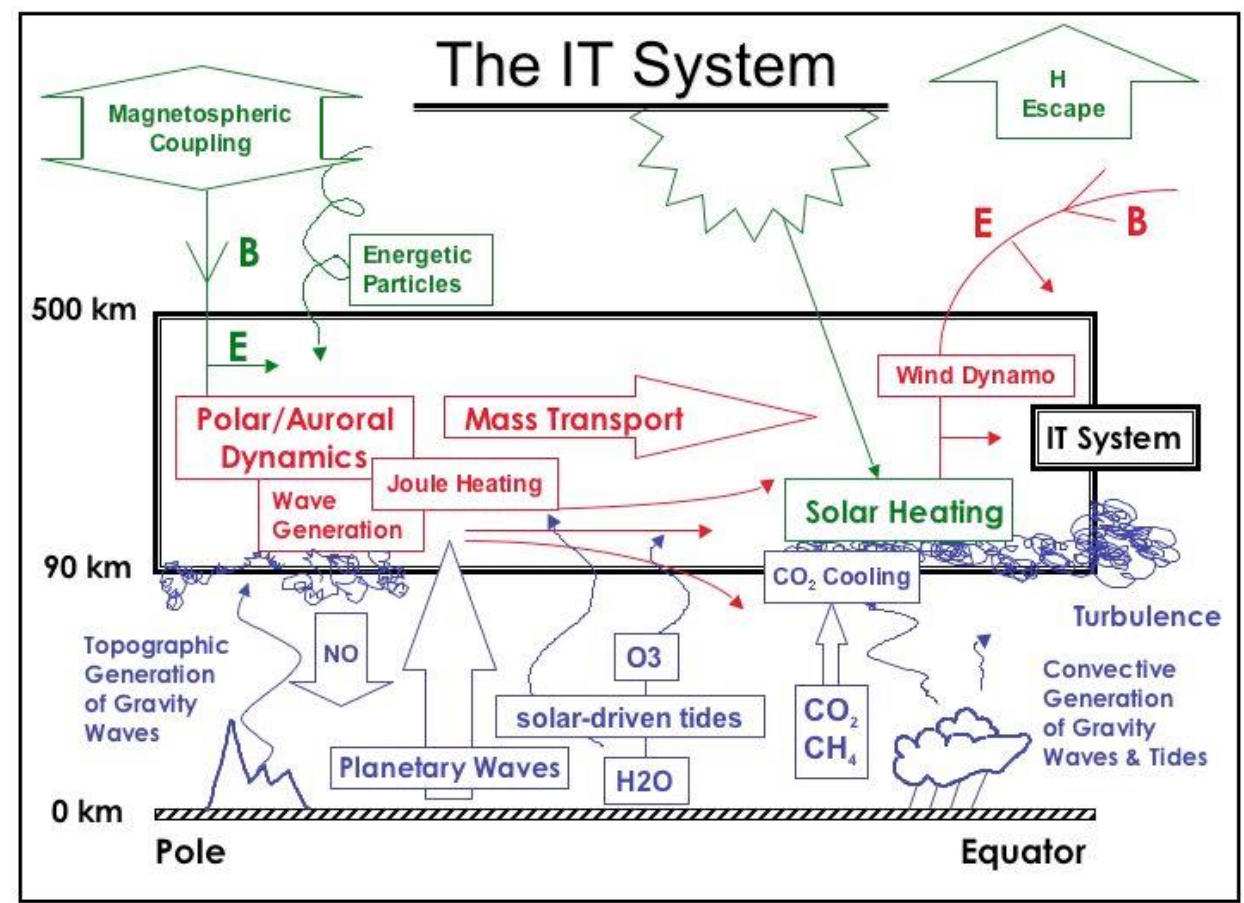

Figure 3 Energy input, conversion and transport processes relevant to the Ionosphere-Thermosphere (IT) system from (Forbes, 2007).

\subsubsection{Lower and Upper Thermosphere Airglow}

Airglow, faint luminescence of Earth's upper atmosphere that is caused by air molecules and atoms (e.g O, $\mathrm{O}_{2}, \mathrm{O}_{+}, \mathrm{O}_{2+}, \mathrm{N}_{2+}$ ) selective absorption of solar ultraviolet and X-radiation and chemical reactions resulting in excited states of these species (from britannica.com/science/airglow). There has been extensive evidence from observations from different studies showing that parameters such as $\mathrm{O}, \mathrm{O}_{2}, \mathrm{O}_{+}, \mathrm{O}_{2+}$, temperature and wind are the key factors contributing to atmospheric 
features like emission at $630 \mathrm{~nm}$ from the $(\mathrm{O}(1 \mathrm{~S} \rightarrow 1 \mathrm{D}))$ level of atomic oxygen (Red line) or emission at $557.7 \mathrm{~nm}$ from $\left(\mathrm{O}\left(1 \mathrm{D} \rightarrow{ }_{3} \mathrm{P}\right)\right.$ ) (Green line) (Zhang et al., 2004). We need a deep knowledge of the temperature profile of the lower and upper thermosphere to account for the density variance of the air molecules and atoms (e.g O, $\left.\mathrm{O}_{2}, \mathrm{O}_{+}, \mathrm{O}_{2+}, \mathrm{N}_{2+}\right)$ in this region because of many processes like molecular diffusion, atmospheric chemical reaction depends on temperature. Mentioned above we are mostly interested in the emission at $630 \mathrm{~nm}$ from the $\mathrm{O}\left({ }_{1} \mathrm{D}\right)$ level of atomic oxygen (Red line) or emission at $557.7 \mathrm{~nm}$ from $\mathrm{O}(1 \mathrm{D}-1 \mathrm{~S})$ (Green line) in this study, also known as $\mathrm{O}_{2}$ Atmospheric band, or "A-band" (Zhang et al., 2004). These emissions originate in a broad altitude region between $80 \mathrm{~km}$ and $200 \mathrm{~km}$ in the day-glow and from a thin layer between 80 and $100 \mathrm{~km}$ in the nightglow (Yee et al., 2012).

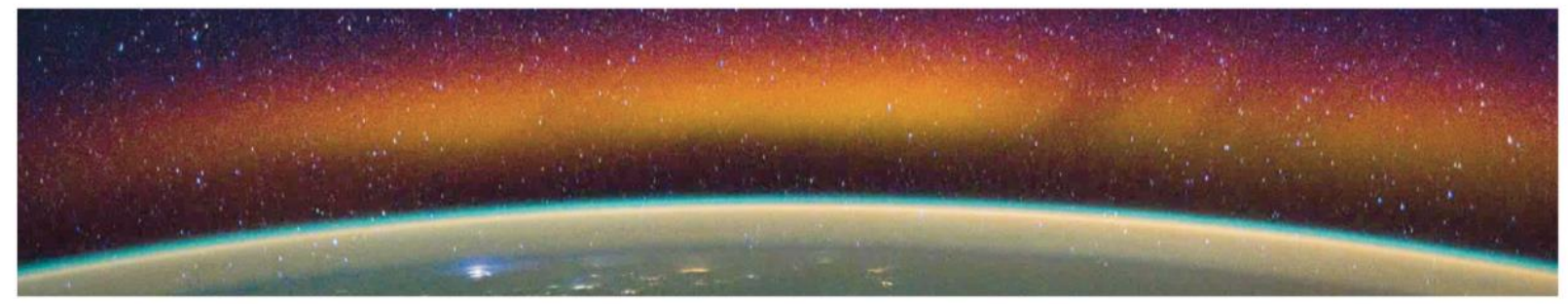

Figure 4 Earth's airglow shows variations in brightness which provide clues to the mystery of the Earthspace connection. Photo taken from [22].

From previous observations like, (MacDade et al., 1986 ) used Volume emission profiles of the $\mathrm{O}_{2}\left(\mathrm{~b}_{1} \sum \mathrm{g}^{+}-\mathrm{X}_{3} \sum \mathrm{g}-\right)(0-0)$ Atmospheric Band and the $0(1 \mathrm{~S} \rightarrow 1 \mathrm{D})$ green line, from the rocket measurements they shown that emission of the $\mathrm{O}_{2}\left(\mathrm{~b} 1 \sum \mathrm{g}+\right)$ Atmospheric Band, the $0\left({ }_{1} \mathrm{~S}\right)$ green line and the atomic oxygen concentrations in the nightglow emissions may be explained by exchange of thermal energy between atoms and altitude profiles for the quenching of the precursor states. Christensen et al 2012 observed airglow emission using the RAIDS (Remote Atmospheric and Ionospheric Detection System) instruments Launched in Sept. 2009, RAIDS performed routine observations of the $\mathrm{O}_{2}\left(\mathrm{~b}_{1} \sum \rightarrow \mathrm{X}_{3} \sum\right)$ Atmospheric band $\left(\mathrm{O}_{2}\right.$ A-band) transition during solar minimum conditions from October 2009 to December 2010. Model developed by (Yee, et al., 2012) permits us to study the atmosphere from 40 up to $200 \mathrm{~km}$, a region where the strongest coupling between the lower atmosphere and upper atmosphere occurs (Heller, et al., 1991) presented some rocket-born Ebert-Fastie spectrometer experiment to measure the day-glow $\left.\mathrm{O}_{2}\left(\mathrm{~b}_{1} \sum \mathrm{g}+\right)\right)$ atmosphere $(0,0)$ band centered at $761.9 \mathrm{~nm}$.

(Zhang et al., 2005) studied more than 520,000 emission rate profiles of the $\mathrm{O}(1 \mathrm{~S})$ dayglow (557.7 $\mathrm{nm}$, the atomic oxygen green line) from the Wind Imaging Interferometer (WINDII) on the Upper Atmospheric Research Satellite (UARS) providing an unprecedented and unique resource for studying the $\mathrm{O}(1 \mathrm{~S})$ emission layer, its related physics and chemistry, and the response of the mesosphere and thermosphere to the solar input. (Zhang et al., 2005), also measured global morphology of the green line emission rate structures at $40^{\circ} \mathrm{N}$, the equator, and $40^{\circ} \mathrm{S}$ in the local time and altitude domain are depicted in the Figure below at four seasons (first day of March, June, September, and December). They produced an empirical model of this which is used in this study. 

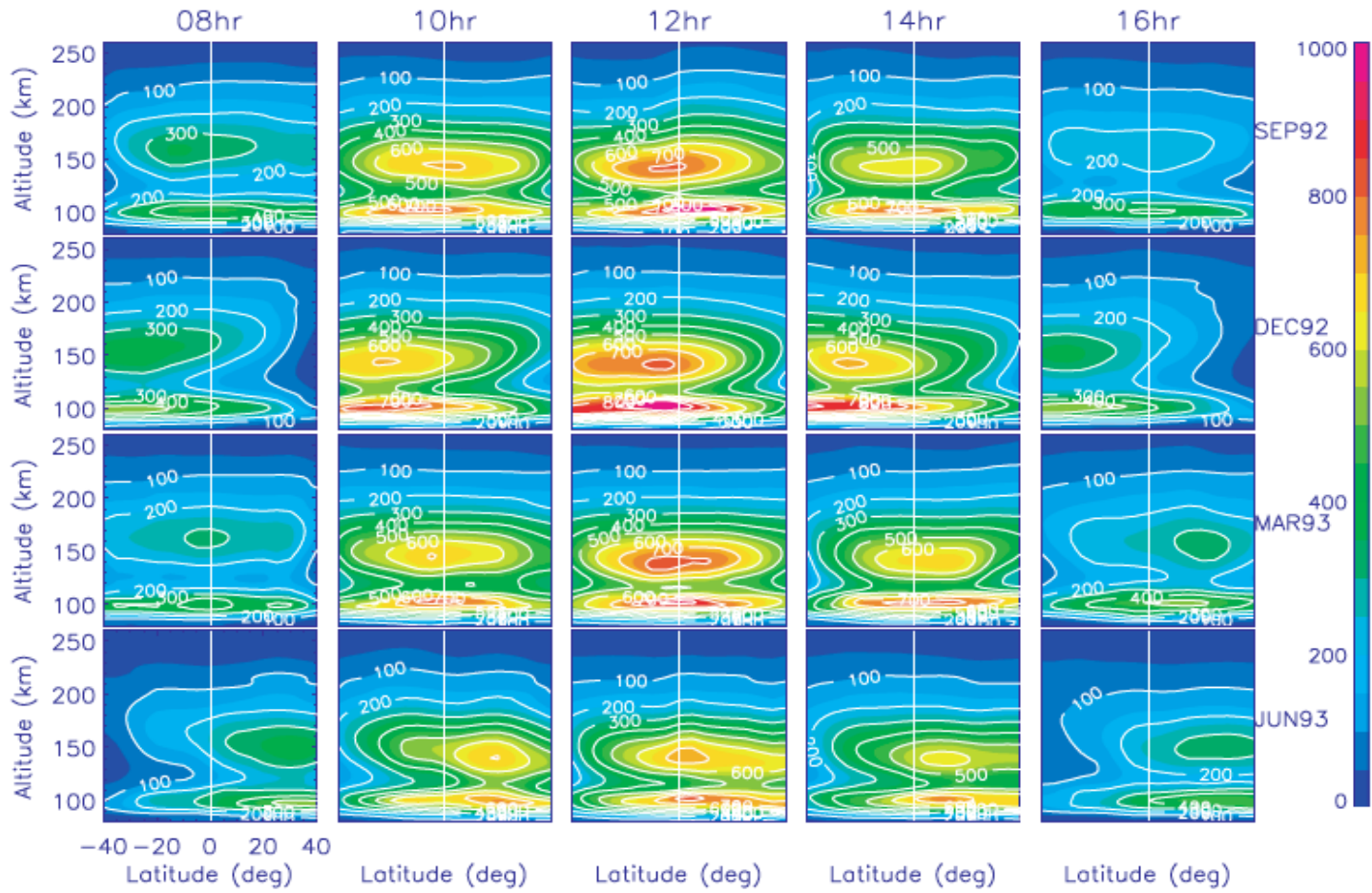

Figure 5 The seasonally averaged green line volume emission rate (photon $\mathrm{cm}-3 \mathrm{~s}-1$ ) at local time 8,10, 12, 14, and 16 hours during for periods in the local time domain. Zhang et al, 2005.
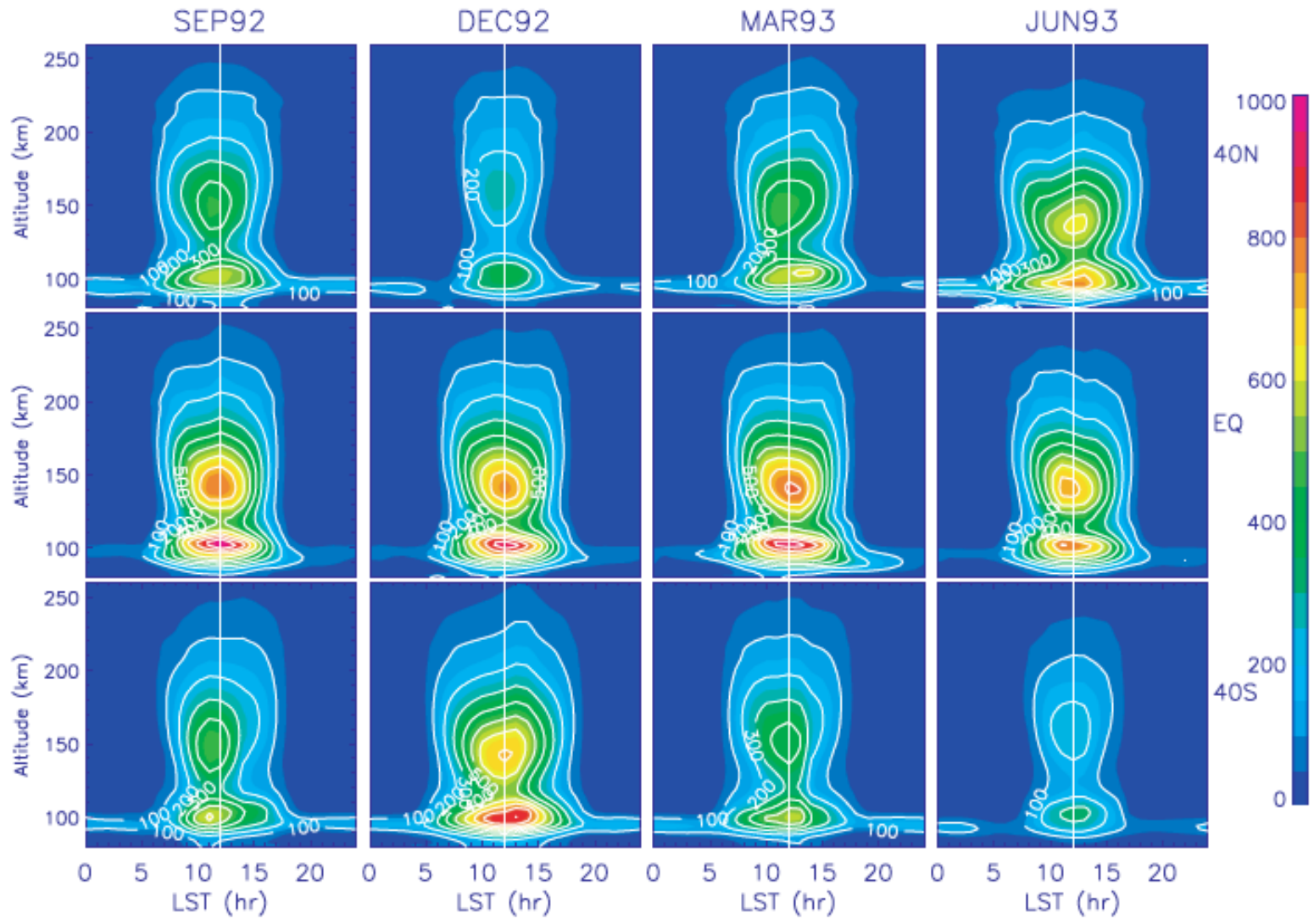
Figure 6 The seasonally averaged green line volume emission rate (photon cm-3 s-1) at 400N, the equator, and 400S for SEP92, DEC92, MAR93, and JUN93 periods in the local time domain (Zhang et al, 2005).

(Zhang et al., 2004) studied more than 130,000 emission rate profiles of the $\mathrm{O}\left({ }_{1} \mathrm{~S}\right)$ dayglow (630 $\mathrm{nm}$, the atomic oxygen red line) from the Wind Imaging Interferometer (WINDII) on the Upper Atmospheric Research Satellite (UARS) providing an unprecedented and unique resource for studying the $\mathrm{O}\left({ }_{1} \mathrm{~S}\right)$ emission layer, its related physics and chemistry, and the response of the mesosphere and thermosphere to the solar input. (Zhang et al., 2004) further studied two profiles of the daytime $\mathrm{O}\left({ }_{1} \mathrm{D}\right)$ atomic oxygen red line volume emission rate (V) in (photon $\mathrm{cm}-3 \mathrm{~s}-1$ ) as examples of WINDII measurements. We can see that most of the change in the Volume emission rate occurs at altitude between $90-250 \mathrm{~km}$, and for both the $\mathrm{O}(1 \mathrm{D})$ atomic oxygen profiles the peak is around $210 \mathrm{~km}$. This study inspires us to study the altitude range from $90-250 \mathrm{~km}$.

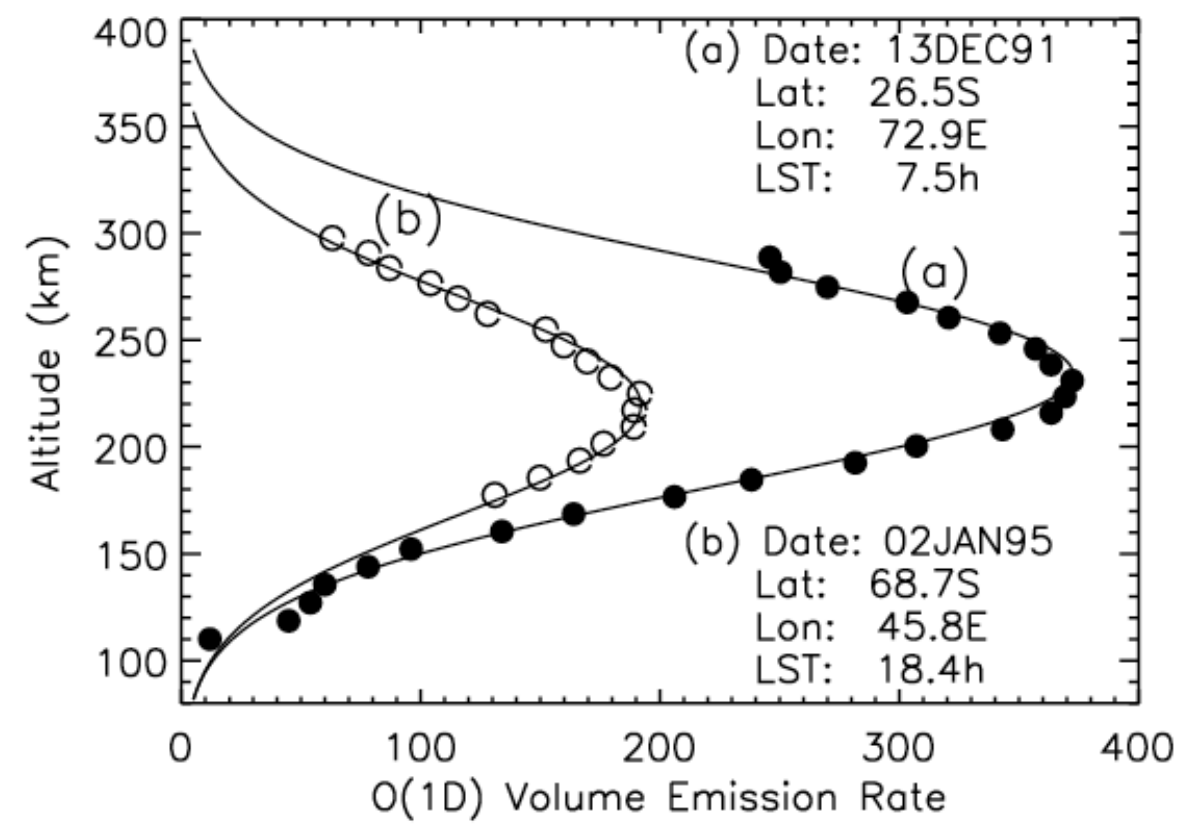

Figure 7 Two samples of the measured red line profile and Gaussian fitting curve (Shengpan P. Zhang et al, 2004).

\subsubsection{Lower and Upper Thermosphere Winds}

It is much familiar that most of the sun's X-rays and UV radiations are absorbed in the Earth's upper atmosphere between $90 \mathrm{~km}-800 \mathrm{~km}$. This results in a rise in temperature with increasing altitude in the thermosphere, unlike the mesosphere. These radiations, in addition to ionizing radiations from outer space, ionize neutral species in the mesosphere and thermosphere forming the ionosphere which extends from about 60 to $800 \mathrm{~km}$, and using electron density is subdivided into; the D region (70-90 km), E-region $(90-150 \mathrm{~km})$ and F-region $(150-700 \mathrm{~km})$ (Sivla, 2012). This radiation heating, latitudinal variations of neutral gas heating then combines with coriolis effect, generate meridional and zonal winds in the earth's upper atmosphere. 
The circulation plays an important effect on the distribution of the major chemical species (e.g O and $\mathrm{N}_{2}$ ) of the thermosphere between about 120 and $500 \mathrm{~km}$, (Forbes, 2007). Processes such as lower thermosphere heating and upwelling can carry $\mathrm{N}_{2}$-rich air to higher altitudes, drive the thermosphere from its diffusive equilibrium state, and in addition enhance the loss of ionosphere plasma and the N2-rich air can be transported by horizontal winds, thus affecting latitude regions outside the heating zone (Sivla, 2012).

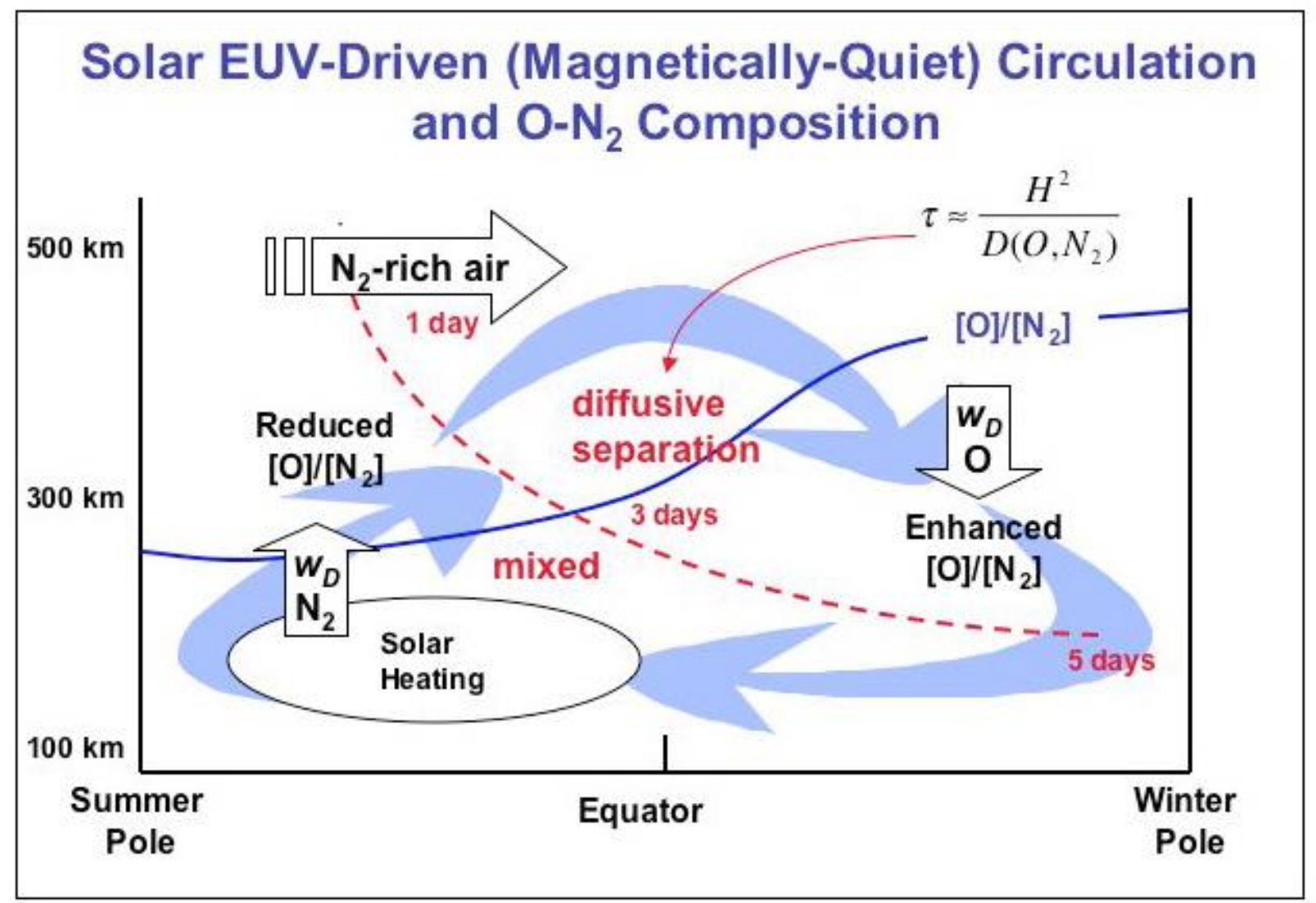

Figure 8 Schematic illustrating the zonal mean meridional circulation driven by differential solar heating in the thermosphere (blue arrows), the transport of $\mathrm{O}$ and $\mathrm{N}_{2}$ (labeled arrows), the latitudinal variation of $\mathrm{R}\left[\mathrm{O} / \mathrm{N}_{2}\right]$ (Forbes, 2007).

Due to the solar Wind-Driven Circulation IT system at high latitudes, the flow is influenced by momentum transfer from the convecting ions to the neutrals, and winds attain amplitudes up to $\approx$ 500 ms-1. At middle and low latitudes, the flow is less intense $(\approx 50-150 \mathrm{~ms}-1)$ (Forbes, 2007).

\subsubsection{Lower Thermospheric Winds:}

In this section we will discuss the lower thermospheric winds along with both migrating tides (sunsynchronous tidal components) and non-migrating tides (non sun-synchronous tidal components) which refers to the absorption of solar fluxes in the thermosphere and the resulting global temperature, density and wind patterns. In the lower thermosphere we expect more rotating wind patterns around high/low pressure areas and varies with altitude. This geostrophic force balance and the thermal winds can be related by following set of equations, 


$$
\begin{gathered}
\Delta \rho=2 \rho \vec{u} \times \vec{\Omega}_{E} \\
u_{x}=-\frac{1}{2 \rho \Omega_{E} \sin \varphi} \frac{\partial p}{\partial y} \\
u_{y}=+\frac{1}{2 \rho \Omega_{E} \sin \varphi} \frac{\partial p}{\partial x} \\
f \frac{\partial u_{x}}{\partial z}=-\frac{g}{T} \frac{\partial T}{\partial y} \\
f \frac{\partial y}{\partial z}=+\frac{g}{T} \frac{\partial T}{\partial x} \\
f=2 \rho \Omega_{E} \sin \varphi
\end{gathered}
$$

From studies from (Forbes, 2007) we know that the altitude ranges particularly $(\approx 80-120 \mathrm{~km})$ or the mesosphere-lower thermosphere (MLT) region, the dynamics of the atmosphere is largely dominated by the solar thermal tides. For a given altitude and latitude, the local time structure of the atmosphere is heavily dependent on longitude in response to the solar absorbed heating (Forbes, 2007).

Solar thermal tidal fields are represented in the form

$$
A_{n, s} \cos \left(n \Omega t+s \lambda-\emptyset_{n, s} \quad\right. \text { (Forbes, 2007). }
$$

where $\mathrm{t}=$ time (days), $\Omega$ rotation rate of the earth $=2 \pi$ day- $1, \lambda=$ longitude, $\mathrm{n}(=1,2, \ldots)$ denotes a sub harmonic of a solar day, $\mathrm{s}(=\ldots .-3,-2, \ldots 0,1,2, \ldots$.$) is the zonal wavenumber, and the$ amplitude $A_{n, s}$ and phase $\varphi_{n, s}$ are functions of height and latitude (Forbes, 2007). From work done by (Hagan and Roble,2001; Yamashita et al., 2002; Angelats i Coll and Forbes, 2002; Lieberman et al., 2004; Grieger et al., 2004; Oberheide et al., 2002) suggests that nonlinear interactions between the stationary planetary wave with $\mathrm{s}=1$ and migrating tides lead to significant non migrating diurnal and semidiurnal tidal signatures above about $80 \mathrm{~km}$ altitude. 

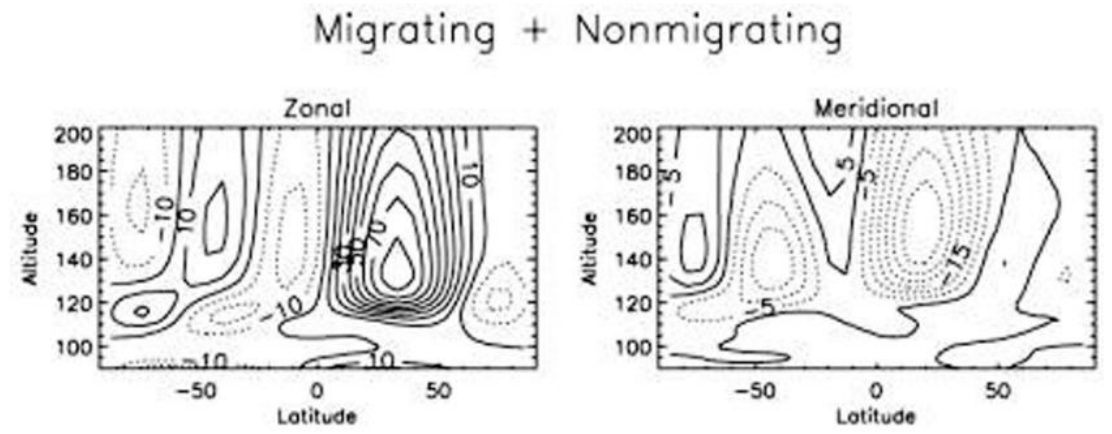

Migrating
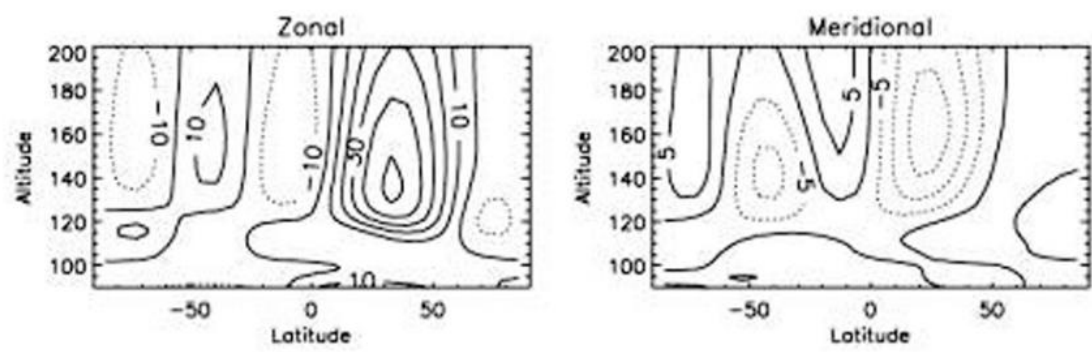

\section{Difference}
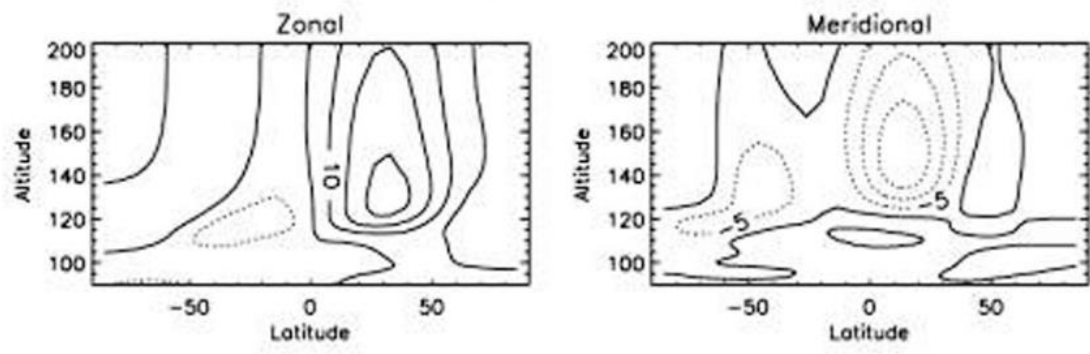

Figure 9 Zonal mean zonal (left) and meridional (right) winds induced by dissipation of semidiurnal tides for the month of January as calculated in the modeling work of Angelats and Forbes (2002).

From the discussion above we can tell that lower thermosphere holds a complex dynamic that draws a number of conclusions. First, we can see that tides propagating from the lower thermosphere are the major driver at low and mid-latitudes.

\subsubsection{Upper Thermospheric Winds:}

Two dominant forces in the upper thermosphere are pressure gradient and friction (ion-neutral collision). In this section, we will discuss the equations that describes the pressure balancing the ion drag force in the upper thermosphere.

$$
\begin{aligned}
& u_{x}=-\frac{1}{\rho v_{n, i}} \frac{\partial p}{\partial x} \\
& u_{y}=-\frac{1}{\rho v_{n, i}} \frac{\partial p}{\partial y}
\end{aligned}
$$


But in some places, it's more complex, such as polar regions. It's also been found that a combination of forcing terms of commensurate magnitude, nonlinear advection term, the Coriolis term, and the pressure gradient term and the polar cap thermospheric thermal balance plays a major role in the small changes in wind velocity and direction within the polar cap (Killeen et al,1995).

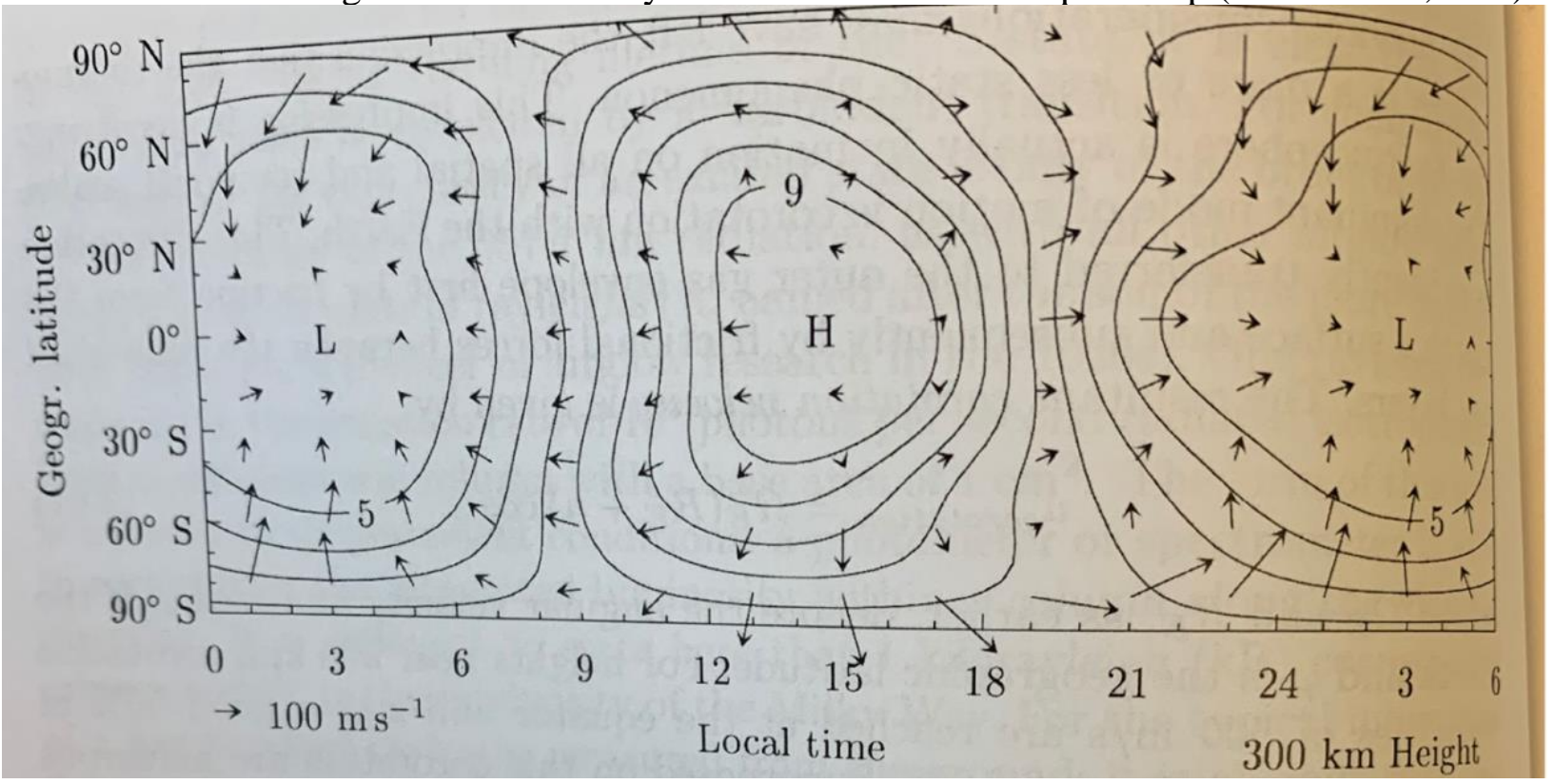

Figure 10 Global pressure and wind distribution for an altitude of $300 \mathrm{~km}$ during the spring equinox (21 march). The distribution was computed for the time12 UT, moderate solar activity (CI=100) and weak geomagnetic activity $(\mathrm{Kp}=2)$. The contours are lines of constant pressure (isobar). The highest plotted pressure of the high-pressure region $(\mathrm{H})$ corresponds to a value of $9 \mu \mathrm{Pa}$; the lowest level of the low-pressure region (L) to a value of $5 \mu \mathrm{Pa}$. The difference between isobars drawn away from the point in question. The wind speed scale is shown below the models MSIS 86 (Hedin, 1987) and HWM 93 (Hedin 1996). Figure taken from "Physics of the Earth's Space Environment"Prölss 2004.

However, the wind oscillation at the upper thermosphere is yet to fully understand. On the other hand, at solar minimum the typical upper thermospheric wind speed varies from $200 \mathrm{~ms}-1$, rising to up to about 800 ms-1 during high geomagnetic activity owing to the geomagnetic polar cap diurnal effect.

\subsection{Dynamics of E-region and F-region:}

One of the prominent factors in the upper thermosphere along with airglow is the winds, responsible for causing the GPS signal loss in the upper thermosphere - where we will actually look when you get to Chapter 3. This change in the winds in the upper atmosphere can be explained by F-region dynamo (for upper thermosphere), E-region (for lower thermosphere). 
The basic principles of E-region and F-region dynamo can be explained by the forces of that drives currents in this region like collisions with neutral particles, Lorentz force, gravity, pressure gradient.

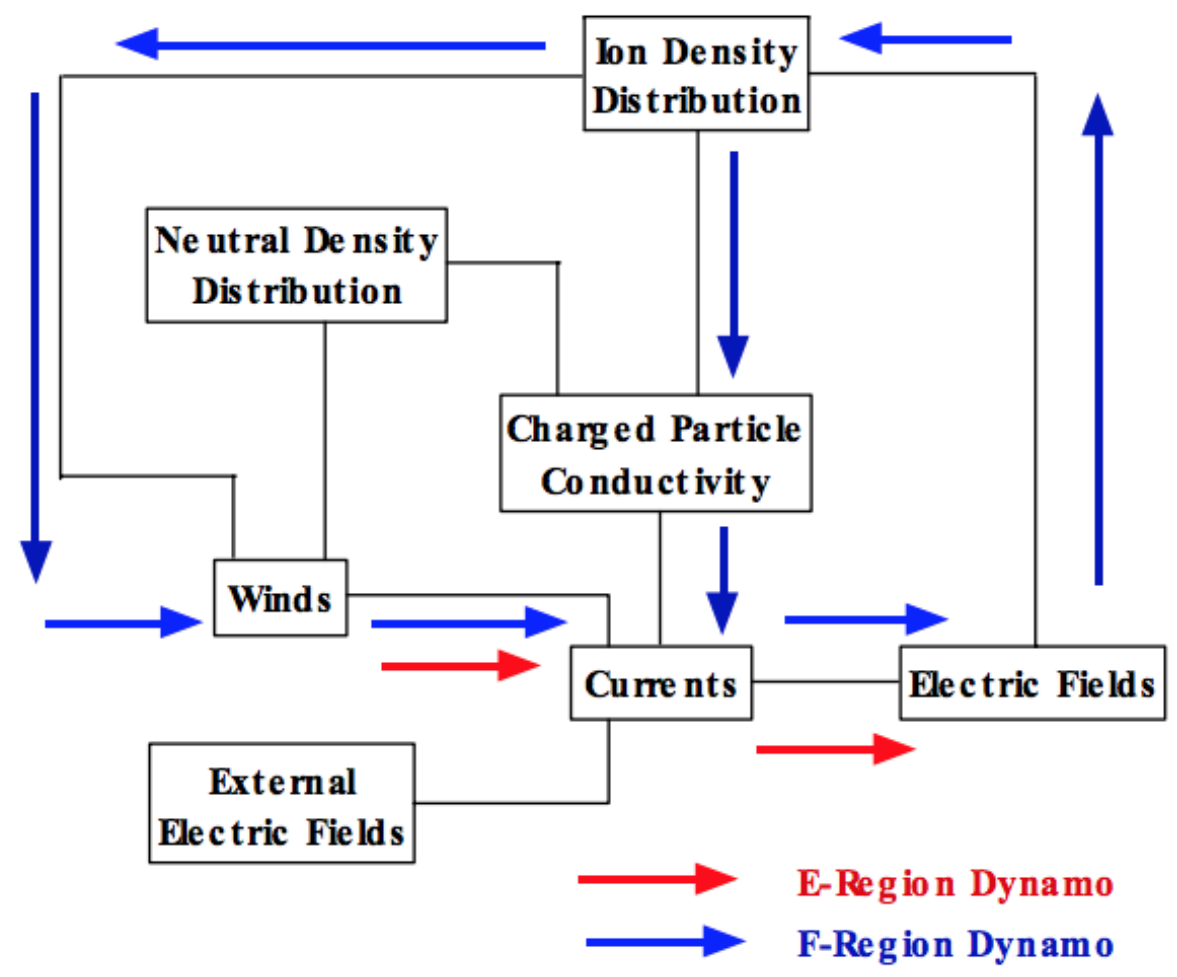

Figure 11 The above figure is a block diagram that explains the $\mathrm{E}$ and $\mathrm{F}$ region dynamos. The figure is taken from (Heelis et al. 2001).

For our study we are mostly interested in the F-region dynamo, as we are looking at only Red airglow which gives us information about the winds in this region. To understand the F-region dynamo, we need to look at the neutral winds and the conductivity. Hall conductivity can be found in the layer near $120 \mathrm{~km}$, most of this conductivity vanishes at nighttime. Where Pederson conductivity are divided in two regions in the F-region and E-region. Pederson conductivity is much greater at the E-region in the daytime compared to F-region. However, at nighttime the Fregion portion of the Pederson conductivity is much greater than the E-region. These changes in the conductivity are initiated by solar ionization balanced by chemical losses and diffusion (Heelis et al. 2004). 


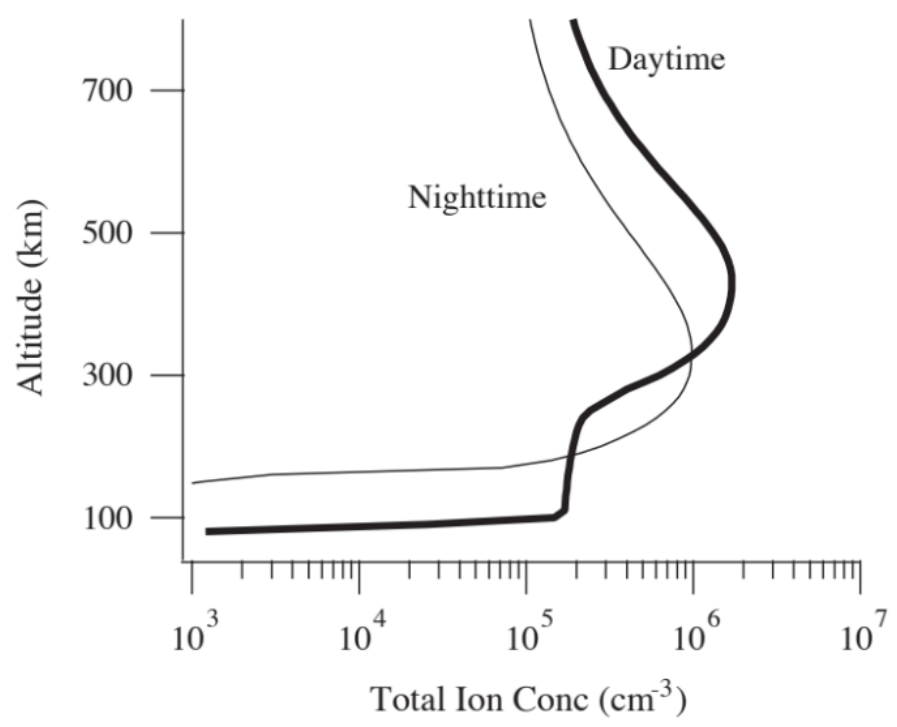

Figure 12 Representative profiles of the total ion concentration during daytime and nighttime showing the peak and ledge of the F- and E-regions, respectively. (From Heelis et al., 2004).

The most important driver of the current related to F-region dynamo is the zonal winds which drive a current perpendicular to the wind and the magnetic field (Heelis et al., 2004). In the F-region winds drive ions in direction $U \times B$ and the current is therefore upwards. The E-region is a highly conductive region in the daytime. So, in the day, this current closes via the E-region shown in the figure. In the day, this leads to no polarization charge building up. 


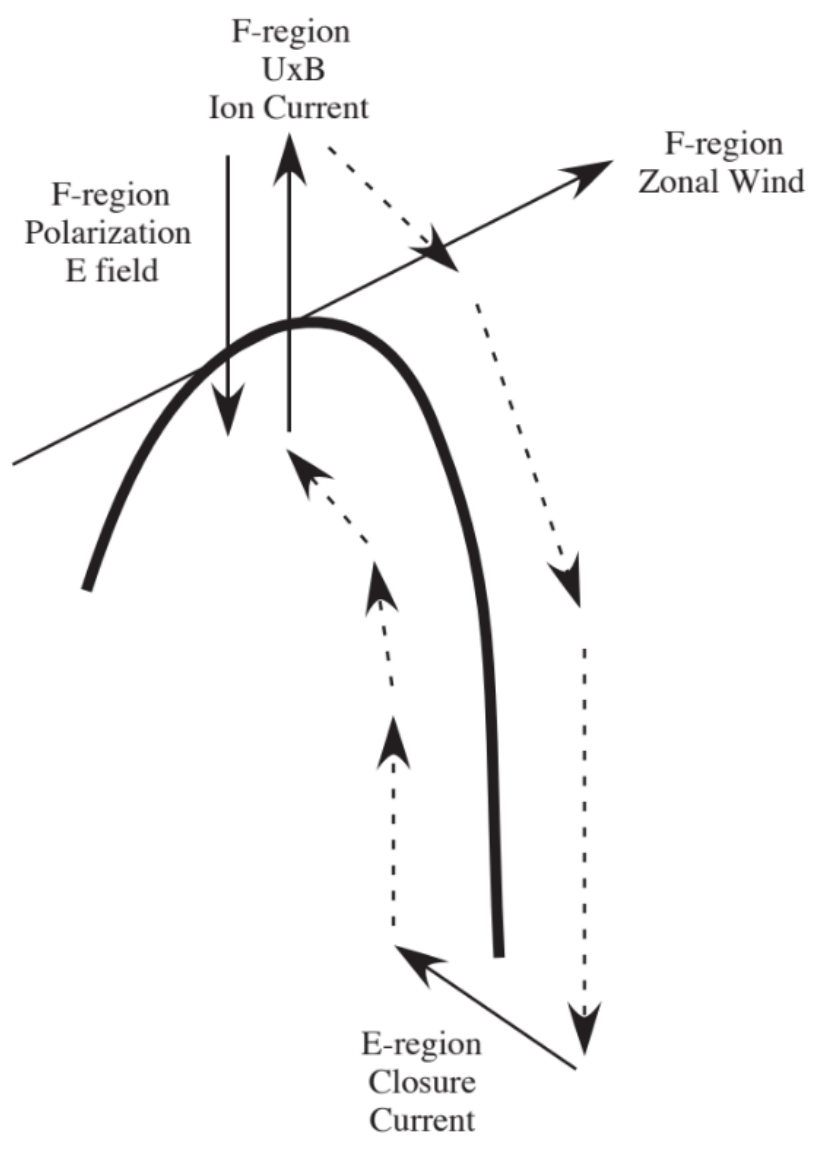

Figure 13 Current loop driven by zonal neutral winds in the F-region (Heelis et al., 2004).

After sunset, we get the same upward current, but now it doesn't close in the E-region, so we build up a polarization charge. The polarized fields created in the F-region by differences in ion and electron numbers of 1 in 108. If we look now, we have E-fields in 2 directions. One is vertical this drives an East-west motion of the plasma that we don't need to care about here. The other is daylight - darkness E-field, which drives the plasma upwards at sunset. This is important because it's move plasma higher; its lifetime increases. This is called the pre-reversal enhancement. 


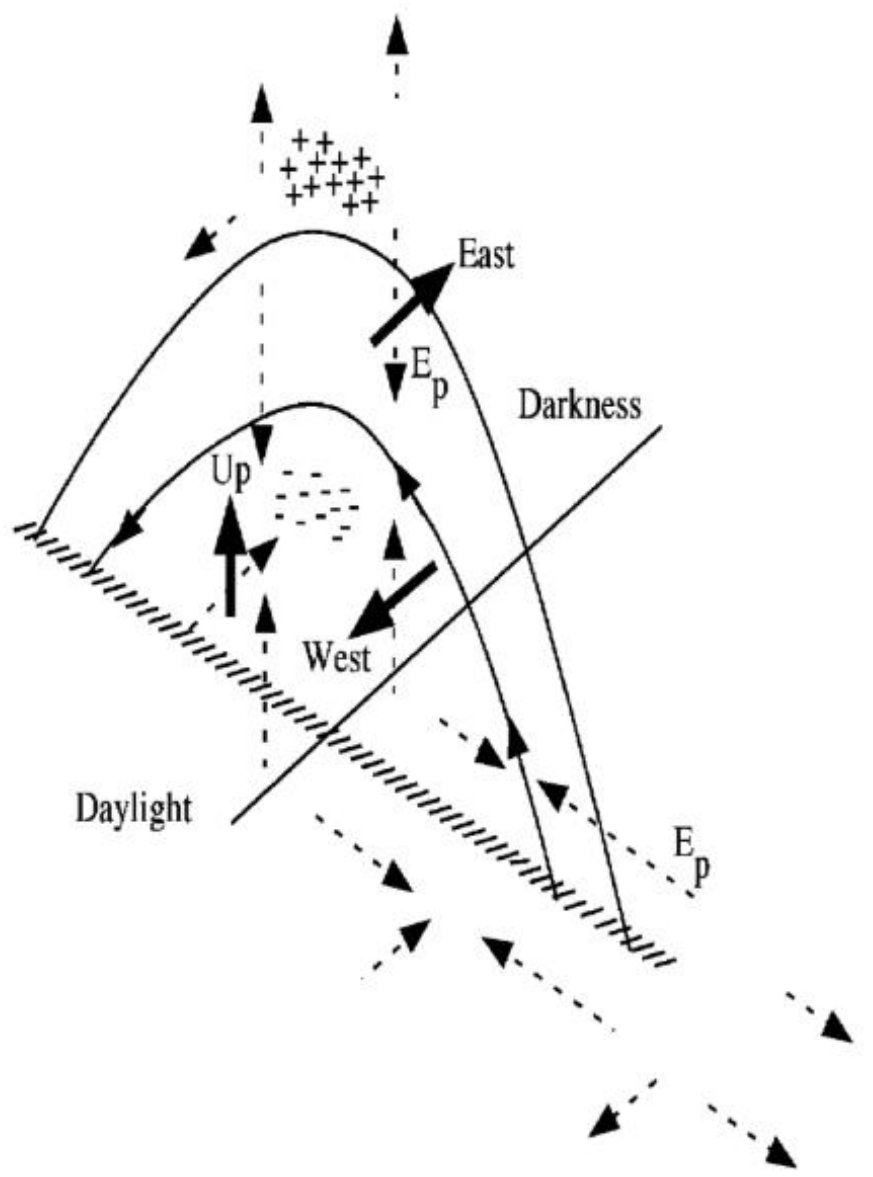

Figure 14 Polarization charges and associated electric fields resulting from an eastward zonal wind in the F-region (Heelis et al., 2004).

Figure 15 shows the ion drifts or most importantly east-west drifts in near the magnetic equator region (Heelis et al., 2004). One of the main differences in the F-region is the change in magnitude of east-west drifts during daytime and nighttime region (Heelis et al., 2004). This bottom side Fregion polarization charges produce pre-sunset eastward field otherwise known as pre -reversal enhancement reversal enhancement (Heelis et al., 2004). 

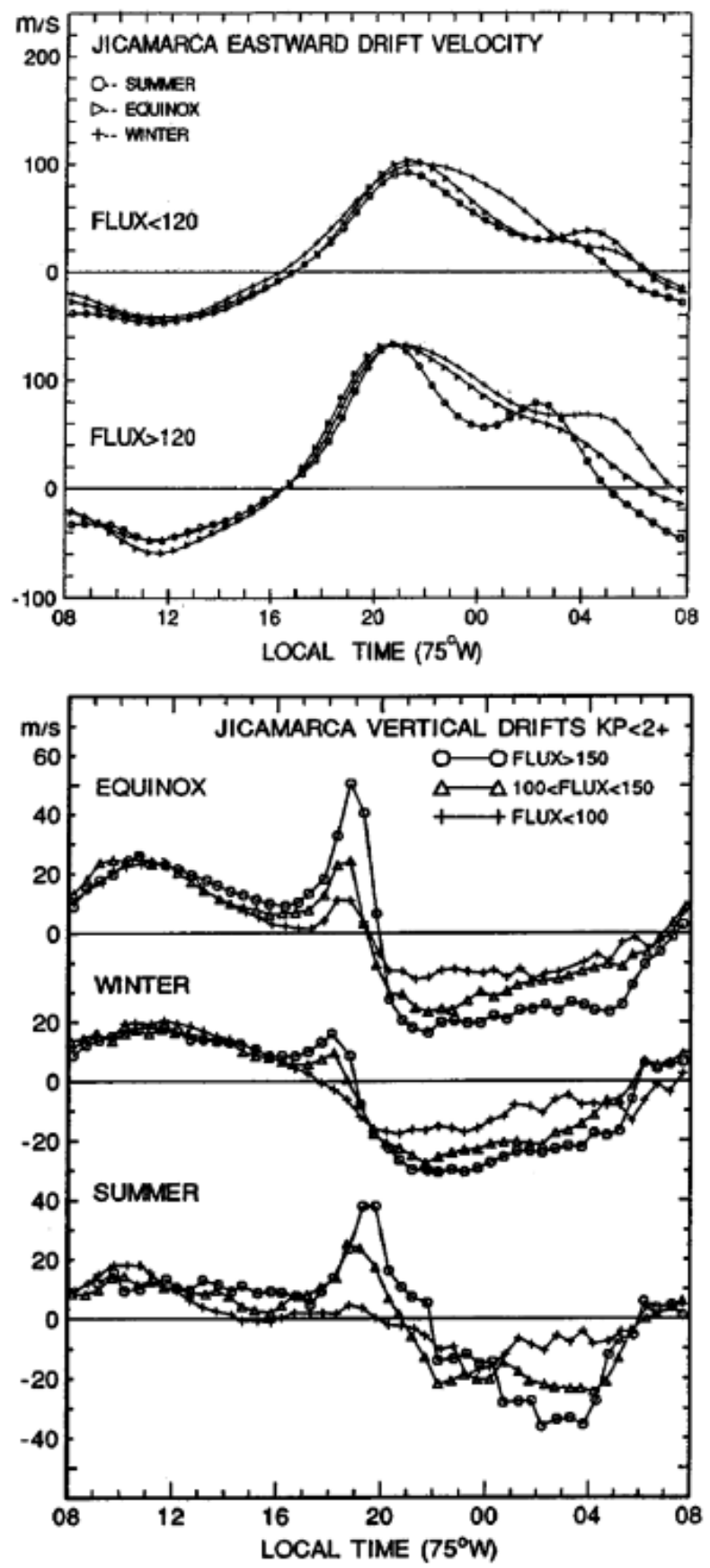

Figure 15 Local time variations of the zonal drifts (upper panel) and vertical drifts (lower panel) observed at the dip equator by the Jicamarca radar (from Fejer et al., 1991).

We have seen how important neutral winds are in driving the F-region dynamo, and in creating motion of the F-region plasma. These wind motions are driven by tidal oscillations that propagate from below (Forbes, 1995) and by in situ heating. It is no mystery to us that we need to understand information regarding local time variations of the neutral winds in the F-region or low and middle latitude ionosphere to answer shortcomings of ionospheric observations. 


\subsection{ICON Mission}

The Ionospheric Connection Explorer otherwise ICON is a heliophysics satellites sponsored by NASA to study the Earth's upper atmosphere between 60 and 300 miles above the Earth's surface to investigate the dynamic changes in Earth's ionosphere due to the weather below the ionosphere and weather above it. ICON is developed and managed by Space Sciences Laboratory (SSL) at the University of California, Berkeley and will be launched in a circular at $575 \mathrm{~km}$ altitude, 270 inclination orbit (Immel et al, 2018).

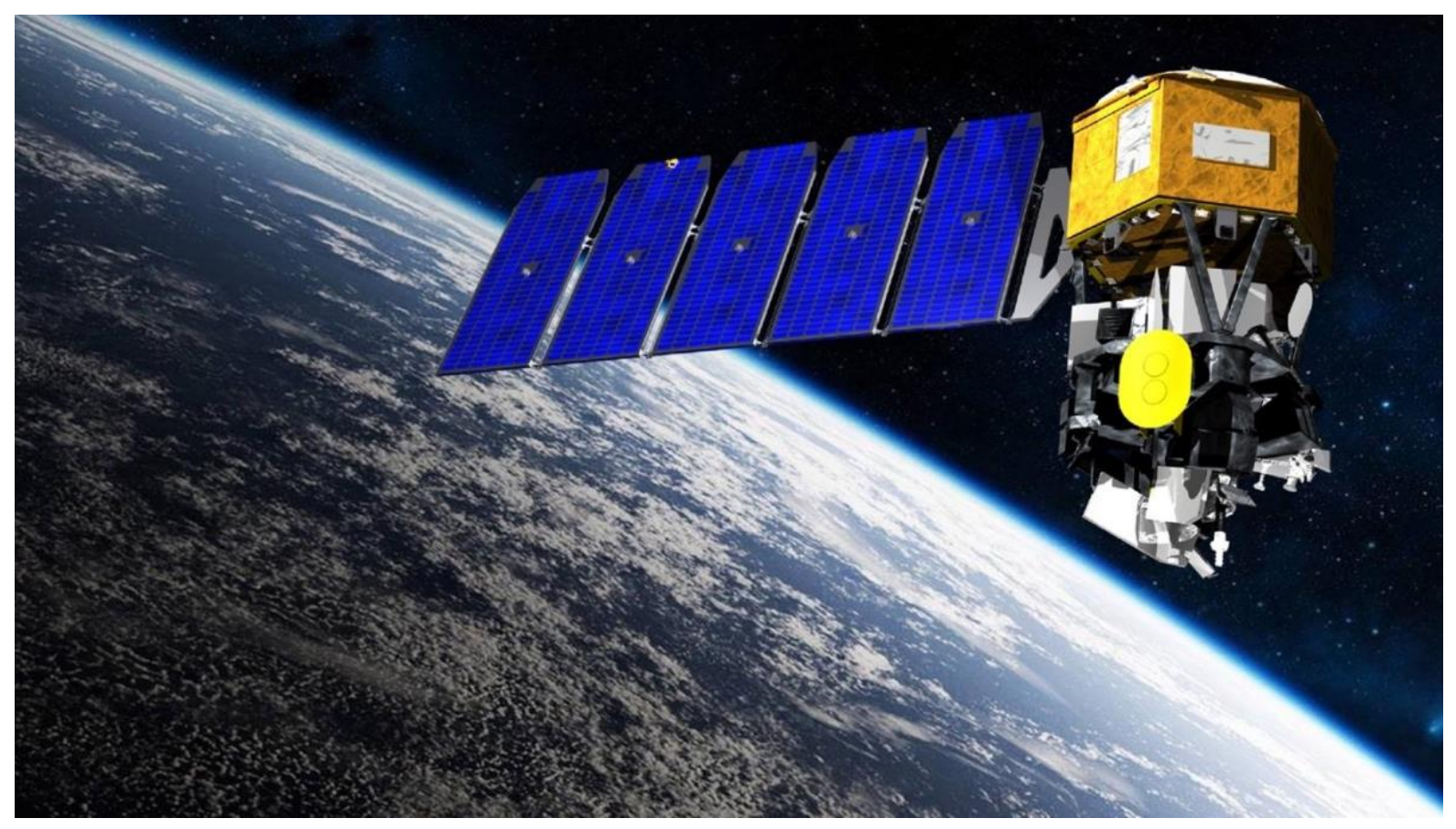

Figure 16 Ionospheric Connection Explorer photo taken from [22].

ICON is set to find the answers of atmosphere-ionosphere coupling from (Immel et al, 2018) we have ICON's science fundamental objectives are to understand:

- The sources of strong Ionospheric variability.

- The transfer of energy and momentum from our atmosphere into space.

- How solar wind and magnetospheric effects modify the internally driven atmospherespace system.

Figure below motivates scientists to study the ionosphere, shows the variation of electric field and associated $\mathrm{F}$ region ion drifts in the ionosphere, and under all geophysical conditions (Immel, 2018). 

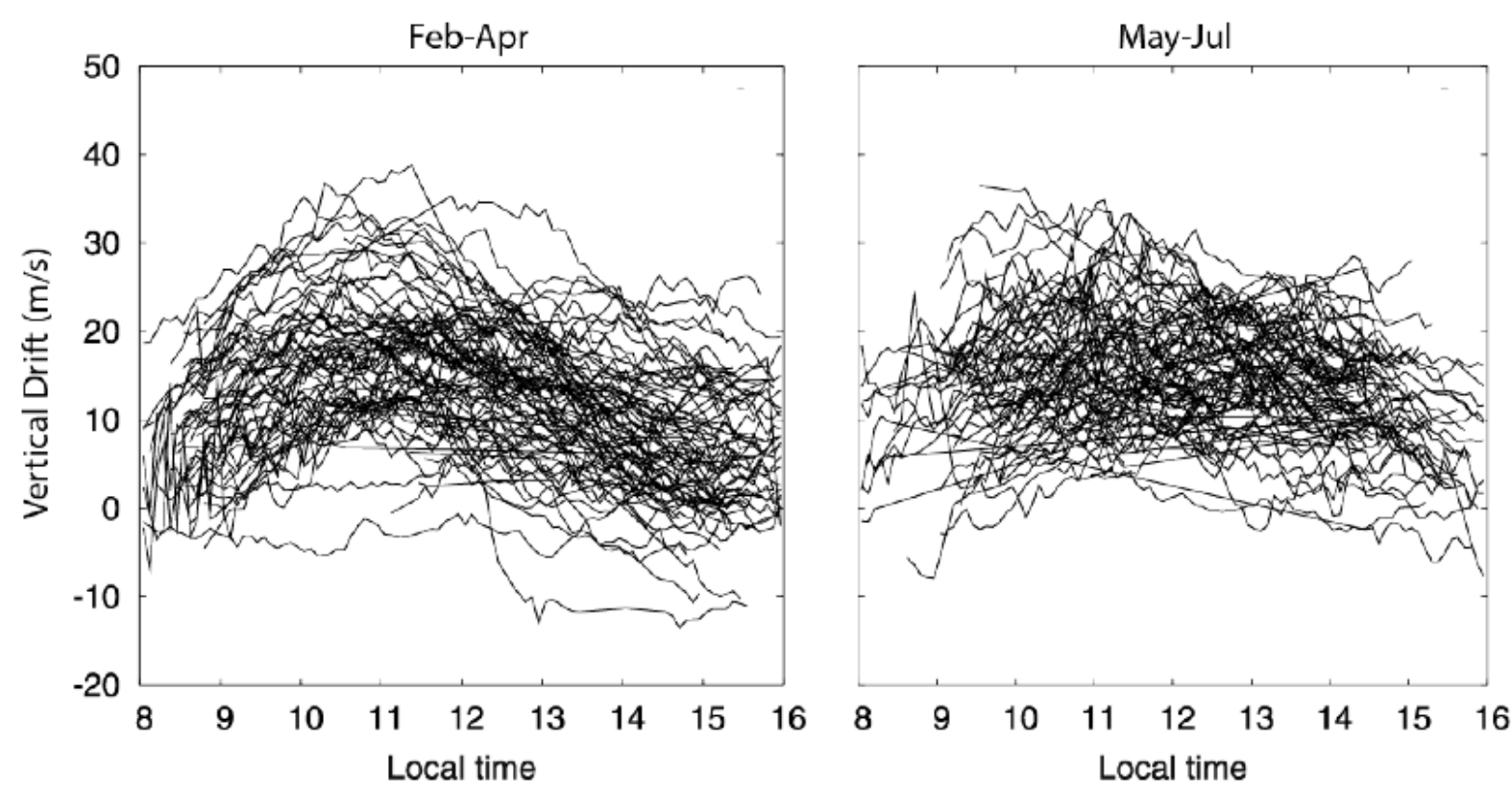

Figure 17 Variations in vertical plasma drifts measured at the magnetic equator from the Jicamarca Radio Observatory during periods of low solar activity (After Alken et al., 2009).

Scientists found that owing to other factors as well the neutral wind and the ionospheric conductance plays the most prolific role in creating variability in the ionosphere. The UV solar radiation absorbed by ions and electrons interplay with Earth's magnetic fields around the globe, especially at the equator where the variability is believed to the greatest. (see Section 1.4)

Following that ICON has been designed to measure the wind and ionospheric $\mathrm{O}+$ density at low latitudes for comparison with the recently gathered electric field close to the magnetic equator to determine the source of this variability (Immel et al, 2018). To fulfill the science requirements for all three objectives discussed above ICON will be equipped with four instruments (Immel et al, 2018):

1. MIGHTI (Michelson Interferometer for Global High-resolution Thermospheric Imaging)

2. IVM (Ion Velocity Meter)

3. FUV (Far-Ultraviolet Imager)

4. EUV (Extreme-Ultraviolet Imager)

Our focus will be limited to MIGHTI in this research and discussed below.

\subsection{MIGHTI Wind and Airglow:}

The Michelson Interferometer for Global High-resolution imaging of the Thermosphere and Ionosphere otherwise called (MIGHTI), was built on the NASA Ionospheric Connection Explorer (ICON) mission by Naval Research Laboratory (NRL) (Immel et al, 2018). 


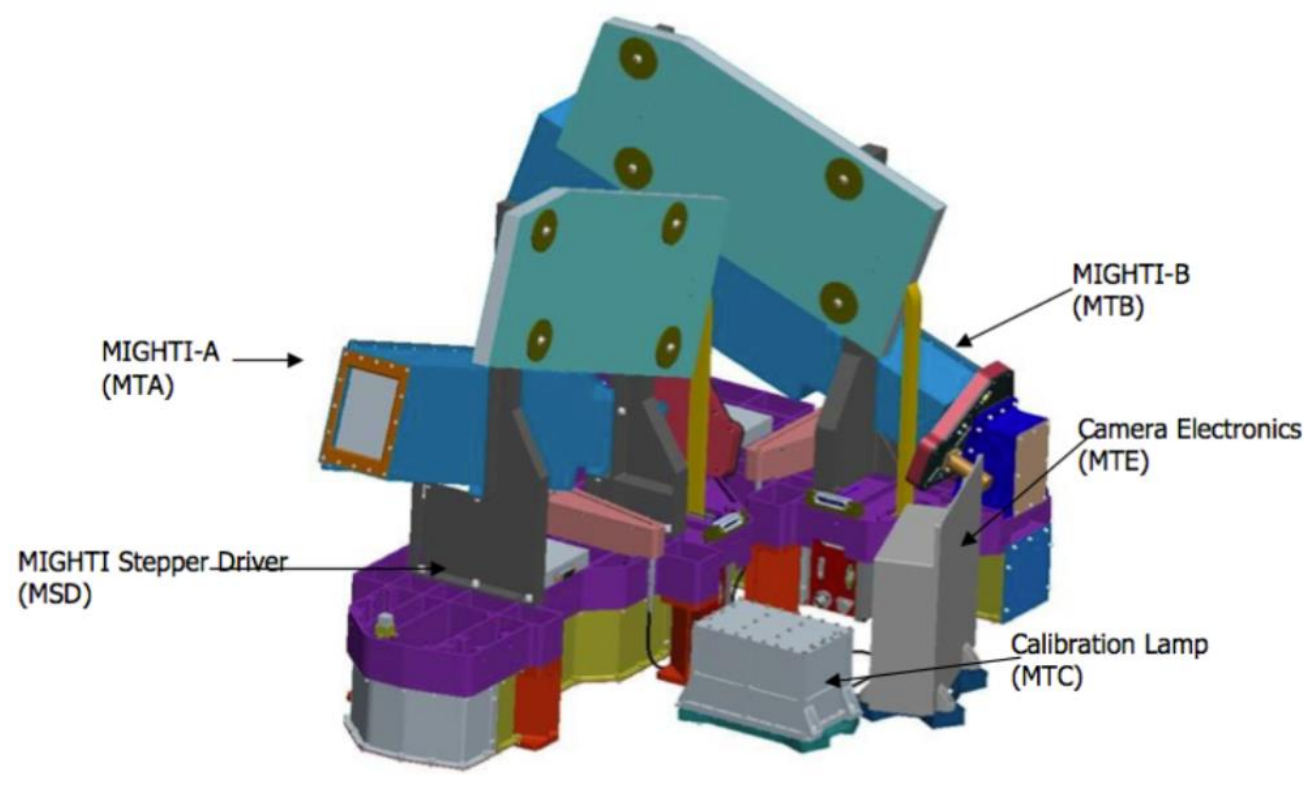

Figure 18 The ICON MIGHTI Instrument from photo taken from (Immel et al, 2018).

Its main focus is to measure the wind speed by interpreting the Doppler shift of the atomic oxygen red line (from the $\mathrm{O}\left(1 \mathrm{D} \rightarrow{ }_{3} \mathrm{P}\right)$ ) transition, centered at $\left.630.0 \mathrm{~nm}\right)$ and green line (from the $(\mathrm{O}(1 \mathrm{~S}$ $\left.\rightarrow{ }_{1} \mathrm{D}\right)$ ) transition, centered at $557.7 \mathrm{~nm}$ )) (Harding et al., 2017) and temperature of the upper atmosphere from the spectral shape of the molecular oxygen band at $762 \mathrm{~nm}$ (Stevens et al., 2017).

MIGHTI uses the DASH (Doppler Asymmetric Spatial Heterodyne) technique calculate for the thermospheric winds by monitoring instrument drifts. In the figure below is a demonstration of the DASH technique, where we have two emissions with the same temperature but different signal, which indicates two interferograms is an expanding phase shift with path difference due to the two-wind driven Doppler shift (Harlander et al., 2007). 


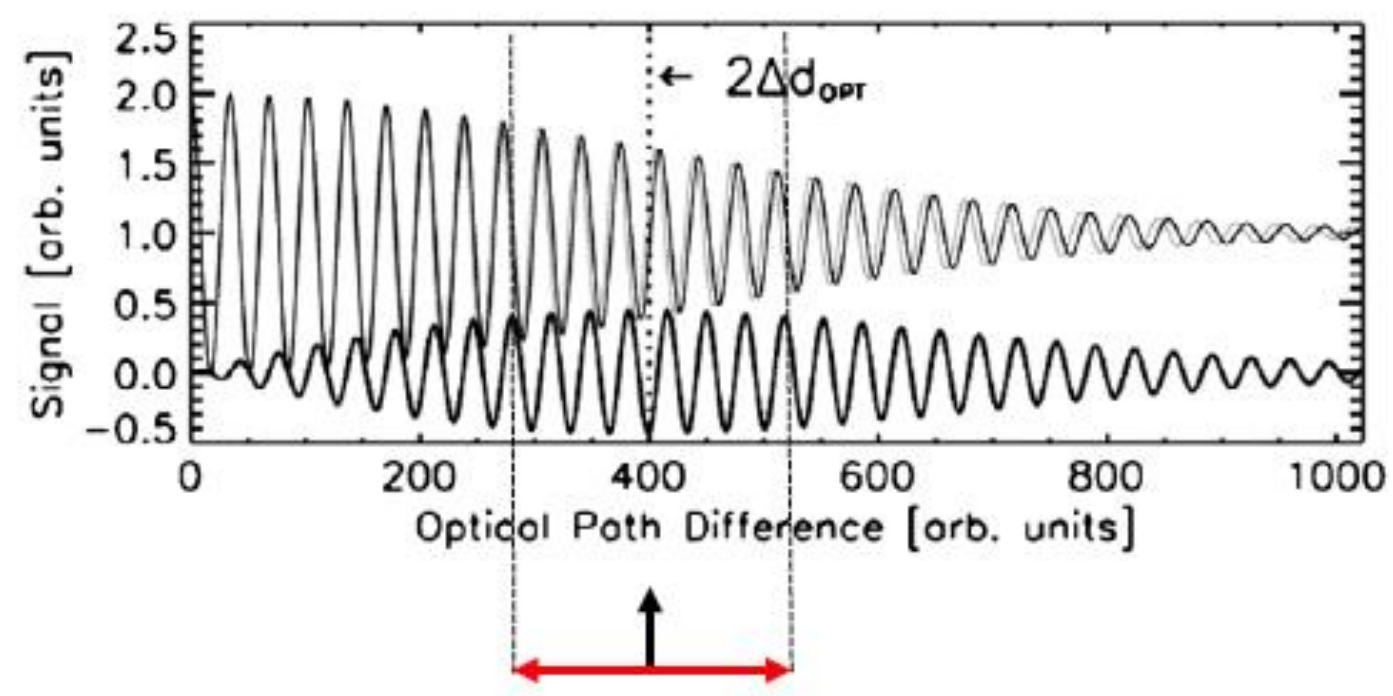

Figure 19 Schematic interferogram from an isolated thermally broadened emission line (Harlander et al., 2007).

MIGHTI calculates green and red line emission rate at different altitude range $90-300 \mathrm{~km}$ for green and 150-300 km for, however at daytime this altitude profile of the winds changes from below 170 $\mathrm{km}$ for green line and red will be used above $170 \mathrm{~km}$ (Harding et al., 2017). At nighttime, the atmospheric emission profiles will limit measurements to the range 90-105 km (green) and 210$300 \mathrm{~km}$ (red) respectively (Harding et al., 2017).

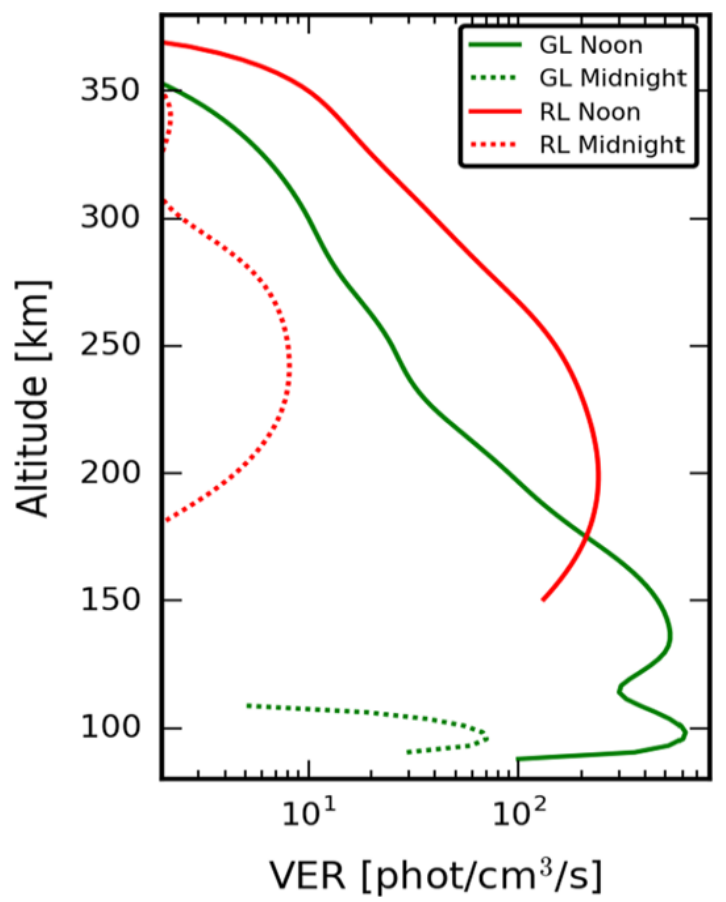

Figure 20 Volume emission rates of the oxygen green (GL) and red (RL) line emissions used for the MIGHTI instrument model from (Englert, et al.,2017). 
The molecular oxygen A-band spectral shape is one of the brightest emissions in the visible and near infrared airglow, MIGHTI will use a radiometric measurement of the A-band for temperature measurements (Englert, et al.,2017).

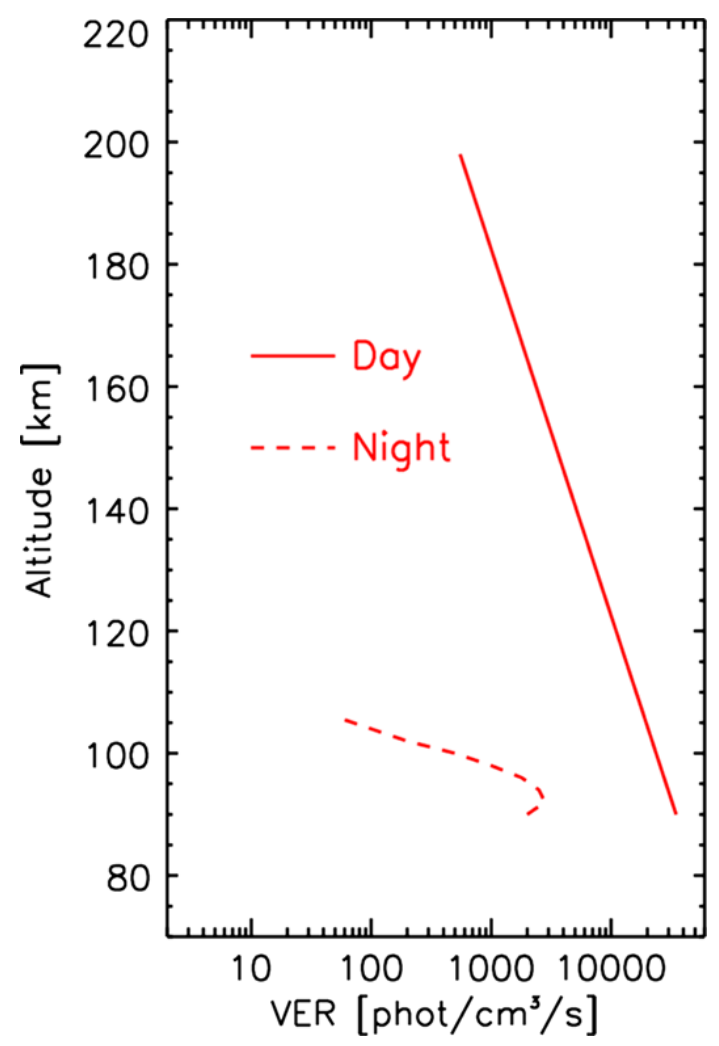

Figure 21 Average volume emission rates of the oxygen A-band used for the MIGHTI instrument model from (Englert, et al.,2017).

We can summarize that the MIGHTI instrument measures thermospheric horizontal wind velocity profiles. It uses two perpendicular fields of view pointed at the Earth's limb, observing the Doppler shift of the atomic oxygen red and green lines at $630.0 \mathrm{~nm}$ and $557.7 \mathrm{~nm}$ wavelength and thermospheric temperature by a multichannel photometric measurement of the spectral shape of the molecular oxygen A-band around $762 \mathrm{~nm}$ wavelength in various altitude regions between 90 $\mathrm{km}$ and $300 \mathrm{~km}$, during the day and night from (Englert, et al.,2017). 


\section{Chapter 2 Methodology}

We need a new tool to help us to compare MIGHTI with a model to interpret the MIGHTI observations of the variability of the ionosphere and thermosphere at low-mid latitudes. While it is expected that the MIGHTI observations will reveal new features in the upper atmosphere, it is uncertain whether the data or its findings will be understood fully at the start of the mission. Comparing these data to an atmospheric model is a good way to being to understand the MIGHTI data, and later on, to identify places where it significantly deviates from this model, which could reveal new features in the upper atmosphere. We need this tool to account for the geometry of the observation and variations in parameters like $\mathrm{O}, \mathrm{O}_{2}, \mathrm{O}+, \mathrm{O}_{2}+$, Temperature, wind etc. This chapter describes the geometry, sampling of the model and airglow profiles e.g. the atomic oxygen red line (from the $\mathrm{O}\left(1 \mathrm{D} \rightarrow{ }_{3} \mathrm{P}\right)$ ) transition, centered at $\left.630.0 \mathrm{~nm}\right)$ and green line (from the $\left(\mathrm{O}\left(1 \mathrm{~S} \rightarrow{ }_{1} \mathrm{D}\right)\right.$ ) transition, centered at $557.7 \mathrm{~nm}$ )) (Harding et al., 2017).

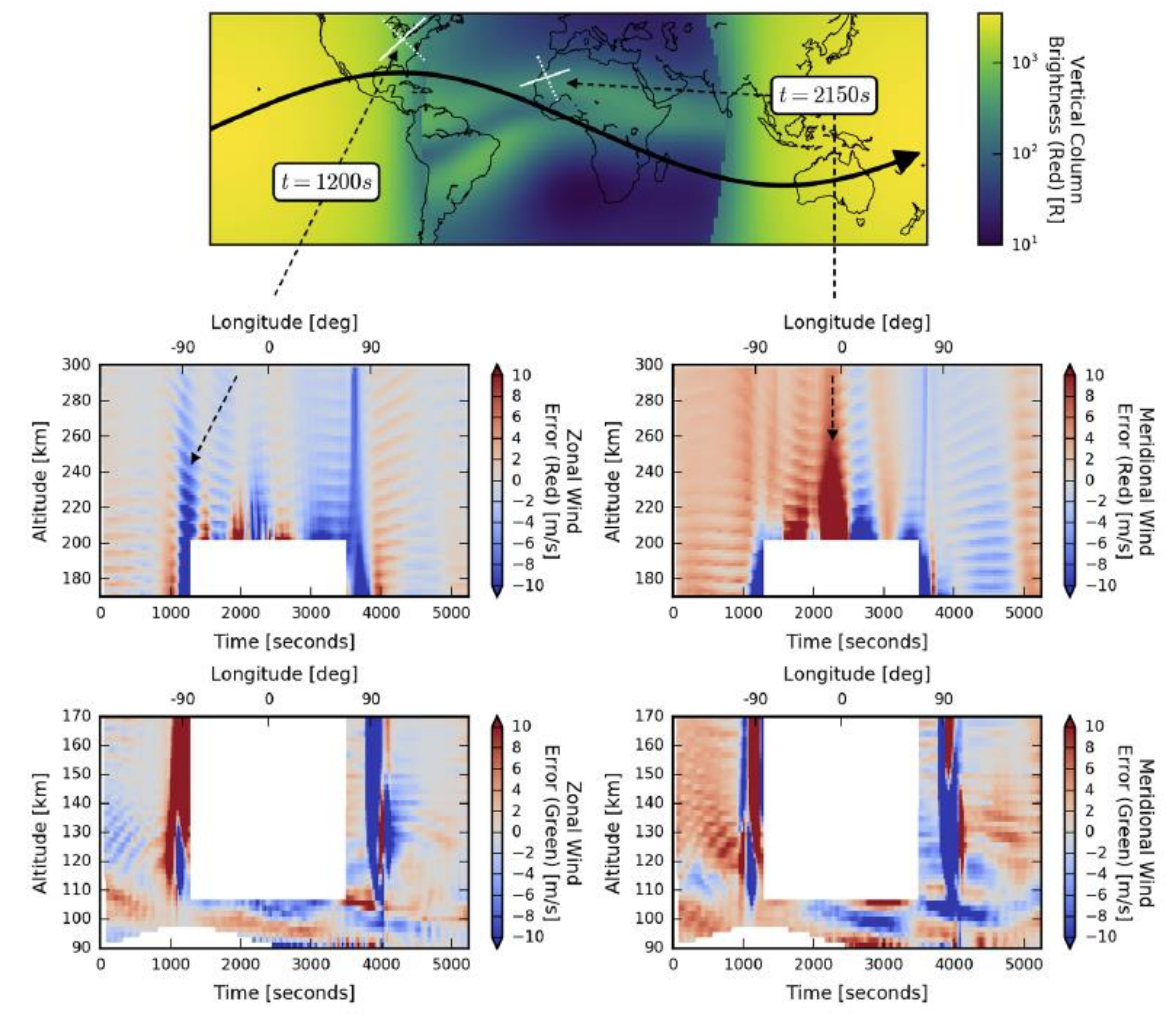

Figure 22 Result of the verification simulation without noise. (Top) A depiction of the simulated ICON orbit in black, overlaid on a map of the total vertical column brightness of the simulated red emission, for reference. For two example findings at $t=1200 \mathrm{~s}$ and $\mathrm{t}=2150 \mathrm{~s}$, the lines of sight of MIGHTI A and B are shown in white. (Bottom) The finding errors for the zonal and meridional wind and the red and green emissions are shown as a function of altitude and time, following ICON's orbit. The two example findings are representative of the largest sources of error: spherical asymmetry near the terminator and the edge of the equatorial ionization anomaly from (Harding et al., 2017). 
(Harding et al., 2017) showed error due to asymmetry (Figure 22) is in the brightness or in the wind, this is why we will run the experiment to calculate the asymmetry along the ray to find where the error is significant. We see from (Figure 22) that there is a lot of error due to asymmetry at night rather than the day and the greatest error due to asymmetry at sunset and sunrise. The error is most likely to depend on latitude as well - as the ionosphere varies with latitude at night and the 630.0 brightness varies with the $\mathrm{O}_{+}$density. However, we don't have MIGHTI, so we looked at WINDII (discussed in Section 2.7.3). WINDII does not give us the day/night boundary data, so we can't investigate Green line as well as we can Red line. We do have WINDII redline in the night and day - during the night we can look for asymmetry, during the day we can look at other parameters. This is why we use WINDII and why we focus on redline, but we can look at winds \& how they compare to the model, and if there is a correspondence between asymmetry along the ray and disagreement.

\subsection{Airglow}

Airglow, faint luminescence of Earth's upper atmosphere that is caused by air molecules and atoms (e.g O, $\mathrm{O}_{2}, \mathrm{O}_{+}, \mathrm{O}_{2}+, \mathrm{N}_{2+}$ ) selective absorption of solar ultraviolet and X-radiation and chemical reactions resulting in excited states of these species (from britannica.com/science/airglow). From different studies it has been found that parameters such as $\mathrm{O}, \mathrm{O}_{2}, \mathrm{O}_{+}, \mathrm{O}_{2}+$ are the dominant features in the ionosphere, and the emission at $630 \mathrm{~nm}$ from the $\mathrm{O}(1 \mathrm{D})$ level of atomic oxygen (Red line) or emission at $557.7 \mathrm{~nm}$ from $\mathrm{O}\left({ }_{1} \mathrm{D}-1 \mathrm{~S}\right)$ (Green line) can be used to calculate the temperature and wind in the upper atmosphere (Zhang et al.,2004). To better understand these anomalies and to create different model that can predict these phenomena, we need to better understand the composition and the mechanism of these airglow. This section will describe the production rate and production rate the of this species. The production reactions can be divided in sections i.e Dissociative recombination, Photoelectron excitation, Photodissociation of $\mathrm{O}_{2}$ molecules, Collisional deactivation of $\mathrm{N}_{2}$, The three-body recombination of the Barth mechanism. The loss rate has been explained in three process.

\subsubsection{Green Daytime Airglow:}

The green line airglow produced by the atomic oxygen transition $\mathrm{O}\left({ }_{1} \mathrm{D}-1 \mathrm{~S}\right)$ and resulting in photon emission at $557.7 \mathrm{~nm}$, (Zhang et al.,2005) the daytime $\mathrm{O}(1 \mathrm{~S})$ is one of the most remarkable and persistent phenomena in the Earth's atmosphere and has two components, peaking at 140-180 km and 94-104 km. 
(a) 11JAN92

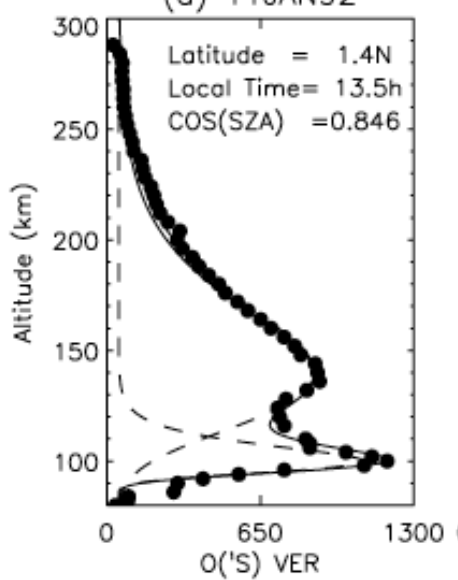

(b) 28APR92

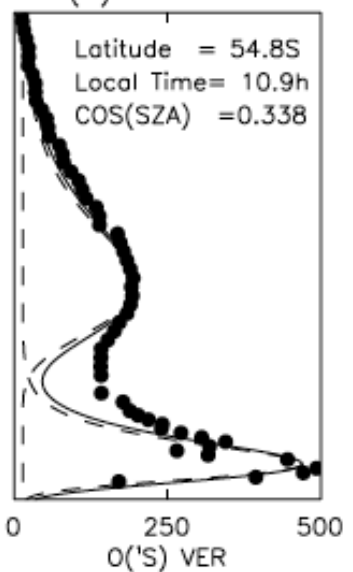

(c) 07JUL93

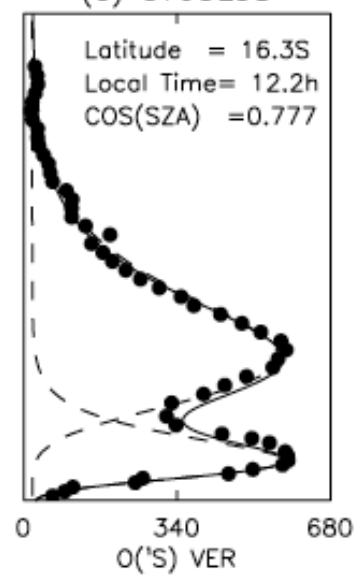

(d) 25APR97

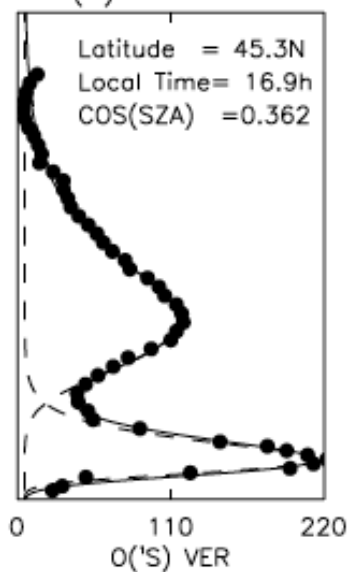

Figure 23 Four samples of the measured green line emission rate profiles (dots) and fitting curves (dashed curves for the two Chapman function fittings, and solid curves for the combined fitting) from (Zhang et al.,2005).

We will discuss the production reactions below, following the description of (Zhang et al.,2005). Production Reactions:

(1) Dissociative recombination:

$$
\mathrm{O}_{2}^{+}+e \rightarrow O(1 \mathrm{~S})+O \text { (Zhang et al.,2005) }
$$

where e is an electron. This reaction depends on the molecular oxygen ion density, the electron density and temperature, and the quantum yield of $\mathrm{O}(1 \mathrm{~S})$.

(2) Photoelectron excitation:

$$
O+e_{p h} \rightarrow O\left({ }^{1} S\right)+e_{p h} \quad \text { (Zhang et al.,2005) }
$$

where $e_{p h}$ is a photoelectron, produced through the ionization of atmospheric constituents. (Zhang et al., 2005) This reaction depends on the atomic oxygen density, the photoelectron flux, and the excitation cross section of $O\left({ }^{1} S\right)$.

(3) Photodissociation of $\mathrm{O} 2$ molecules:

and

$$
\mathrm{O}_{2}+h v(<242.1 \mathrm{~nm}) \rightarrow O+O \text { (Zhang et al.,2005) }
$$

$$
\mathrm{O}_{2}+h v(<133.3 \mathrm{~nm}) \rightarrow O\left({ }^{1} \mathrm{~S}\right)+O \text { (Zhang et al.,2005) }
$$

(Zhang et al.,2005) The production mechanism of equation (3) produces atomic oxygen in the thermosphere mostly below $200 \mathrm{~km}$. Since the lifetime of atomic oxygen in this region can be as long as a few weeks, atomic oxygen is effectively a permanent atmospheric constituent, and is then a source for other production reactions of $\mathrm{O}(1 \mathrm{~S})$.

(4) Collisional deactivation of $\mathrm{N}_{2}$ : 
followed by

$$
N_{2}+e_{p h} \rightarrow N_{2}\left(A^{3} \sum_{u}^{+}\right)(\text {Zhang et al. }, 2005)
$$

$$
\left.N_{2}\left(A^{3} \sum_{u}^{+}\right)+O \rightarrow O\left({ }^{1} S\right)+N_{2} \text { (Zhang et al. }, 2005\right)
$$

The production of $O\left({ }^{1} S\right)$ by this reaction has two peaks, one above $130 \mathrm{~km}$, and the other below 120 km [Witasse et al., 1999; Culot et al., 2004].

The three-body recombination of the Barth mechanism:

followed by

$$
O+O+M=O_{2}^{*}+M \text { (Zhang et al.,2005) }
$$

$$
\mathrm{O}_{2}^{*}+\mathrm{O} \rightarrow \mathrm{O}\left({ }^{1} \mathrm{~S}\right)+\mathrm{O}_{2} \quad \text { (Zhang et al.,2005) }
$$

(Zhang et al.,2005) The production of this process peaks in the E-region, at about $100 \mathrm{~km}$, and persists in both daytime and nighttime. It is regarded as an indirect process associated with the Sun because the atomic oxygen in the three-body reaction is first produced from photo dissociation by solar irradiance in the reaction of equation (3), and the process of equation (6)

occurs much later than that of equation (3).

Loss Processes:

The three main loss processes are

$$
O\left({ }^{1} S\right)+O_{2} \rightarrow O\left({ }^{3} P\right)+O_{2}(\text { Zhang et al. }, 2005)
$$

whose loss rate depends on the quenching rate $k_{O_{2}}$;

$$
O\left({ }^{1} S\right)+O \rightarrow O\left({ }^{3} P\right)+O(\text { Zhang et al. }, 2005)
$$

whose loss rate depends on the quenching rate $k_{O}$; and

$$
O\left({ }^{1} S\right) \rightarrow O+h v(557.7 \mathrm{~nm}, 297.2 \mathrm{~nm}) \text { (Zhang et al.,2005) }
$$

whose loss rate depends on the Einstein coefficients. There are uncertainties in the quenching rates and the Einstein coefficients (Zhang et al.,2005). The quenching is larger at lower altitude due to larger atmospheric density ( Zhang et al.,2005).

\section{Vertical Profile of the Daytime $O\left({ }^{1} S\right)$ Volume Emission Rate:}

(Zhang et al.,2005) The measured profile is the combination of various production and loss processes and measurement errors, as mentioned above. From (Zhang, et al.,2005) we know among the main sources of production listed in section 2.1.1, two of them depend heavily on the ion and electron density profile, and the third on the photo dissociation of $\mathrm{O}_{2}$ molecules, which depends on the absorption of solar irradiation. (Zhang et al.,2005) Since both F-layer and E-layer of the green line follow chapman function and they overlap then the actual vertical emission profile is the sum of them. We will use an empirical formula for our analysis from (Zhang et al.,2005).

Then all the required variables to fit function for the volume emission rate profile may be written as follows ( Zhang et al.,2005). 


$$
\begin{aligned}
V E R(z)=V_{f} \exp \exp \left[1-b_{f}-\exp \exp \left(b_{f}\right)\right] \\
+V_{e} \exp \left[1-b_{e}-\exp \exp \left(-b_{e}\right)\right](\text { Zhang et al. 2005) }
\end{aligned}
$$

where $b f=\left(z-H_{f}\right) / W_{f}, b e=\left(z-H_{e}\right) / W_{e}$, $\mathrm{z}$ is the altitude in $\mathrm{km}, V_{f}$ and $V_{e}$ are the peak VERs of the F-layer and the E-layer in photon $\mathrm{cm}^{-3} \mathrm{~s}^{-1}, H_{f}$ and $H_{e}$ are their heights, and $W_{f}$ and $W_{e}$ are the widths of the Chapman function, respectively (Zhang et al. ,2005).

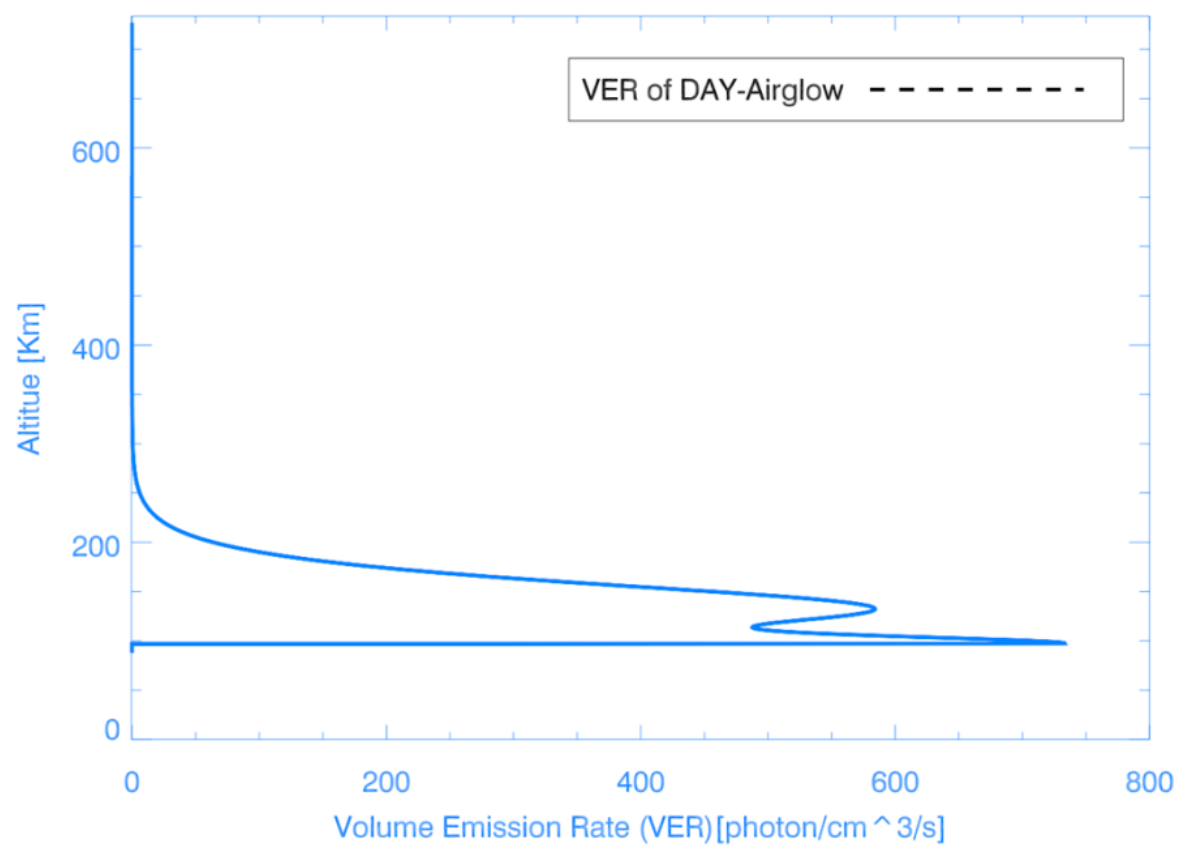

Figure 24 Volume Emission Rate (VER) of Day Airglow for Green line. 


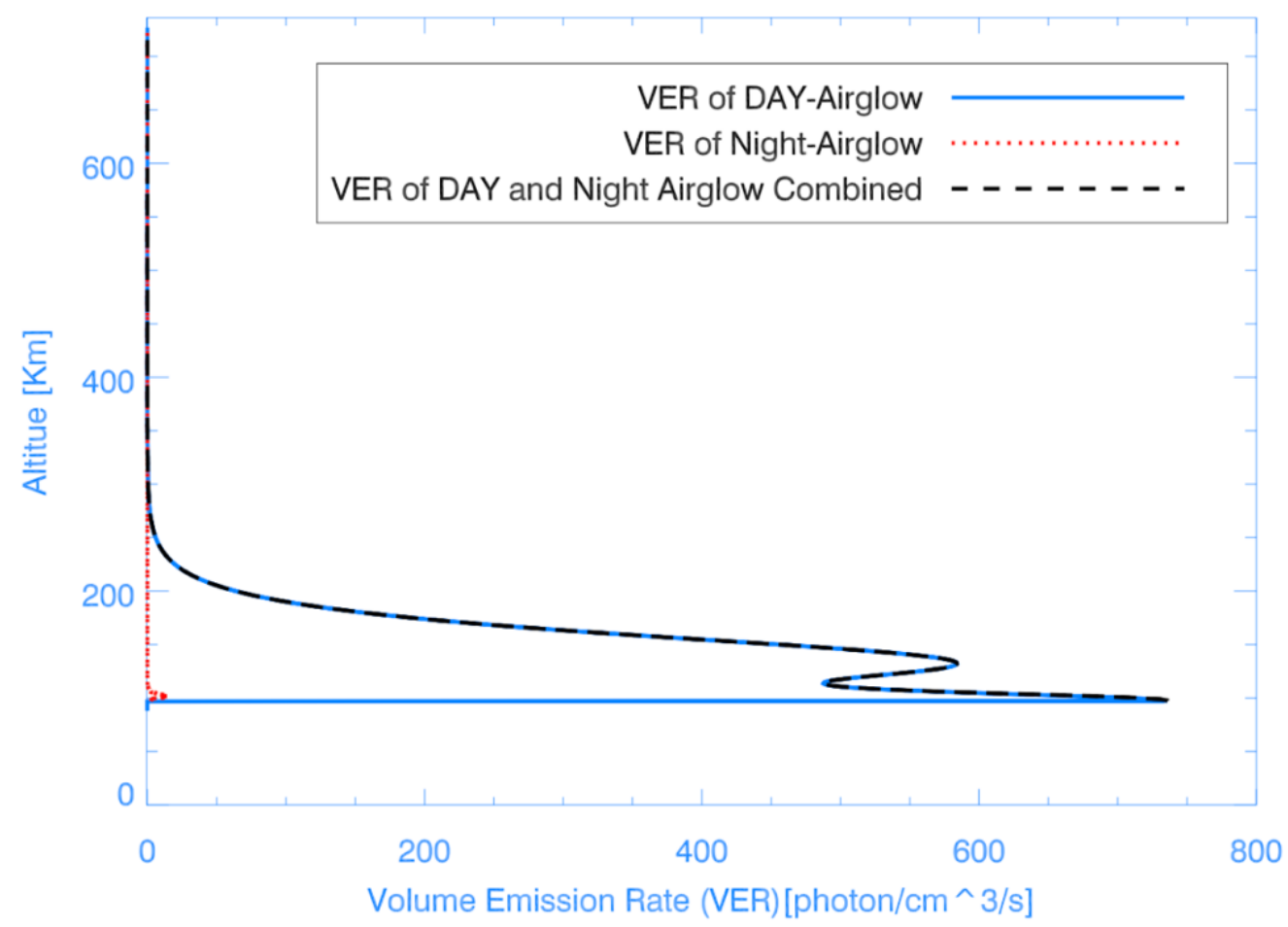

Figure 25 Volume Emission Rate (VER) of Day and Night Airglow Combined for Green line.

In the above two figures it shows the variation of volume emission rate (VER) of green line airglow along altitude. Figure 2 represents variation of (VER) at the Daytime where figure 3 compares variation of (VER) both Day and Nighttime combined. It is evident from the two figures above that all the green line airglow contribution is coming from the Daytime, because we are showing daytime case for this figure.

\subsubsection{Red Daytime Airglow:}

The red line emission at $630.0 \mathrm{~nm}$ from the $O\left({ }^{1} D\right)$ level of atomic oxygen is a prominent feature in the thermosphere between 100 and $400 \mathrm{~km}$, (Zhang et al.,2004) the production mechanisms of the $\mathrm{O}\left({ }_{1} \mathrm{D}\right)$ day-glow is complex, here only the three major mechanisms are summarized, which are (1) dissociative recombination (2) photoelectron excitation (3) photodissociation. 


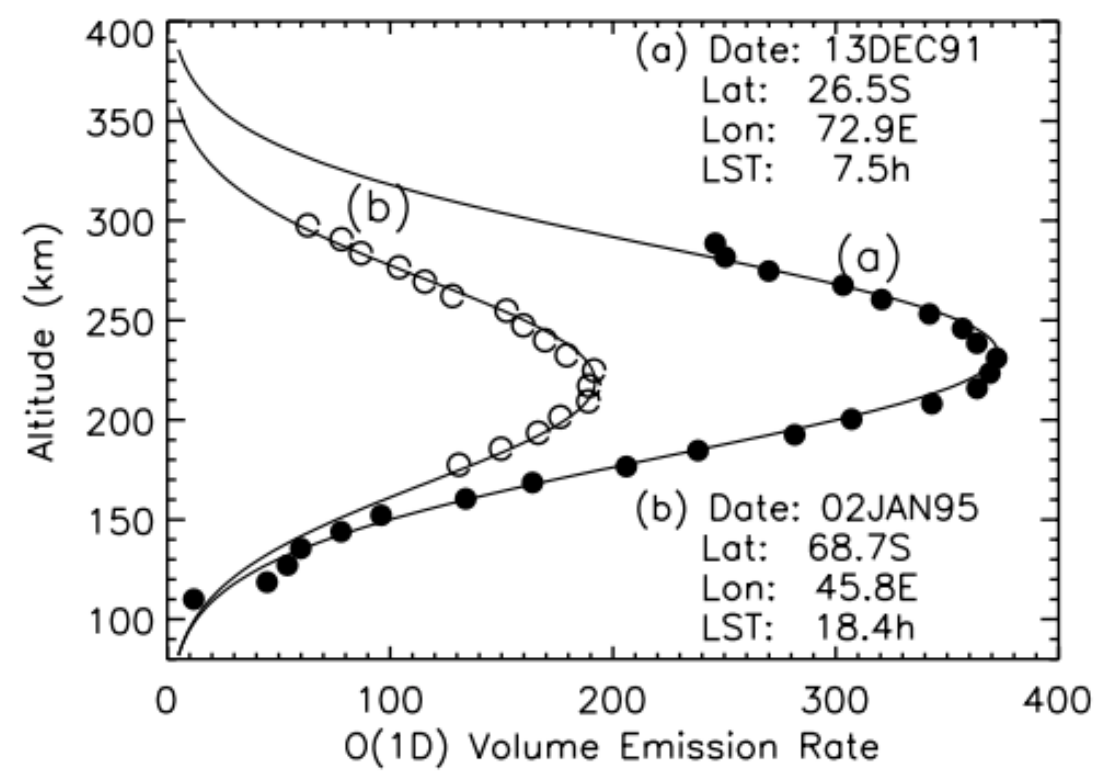

Figure 26 Two samples of the measured red line profile and Gaussian fitting curve from (Zhang et al.,2004).

The contributions of the three reactions are mainly in the F2, F1, and E regions, respectively.

(1) Dissociative recombination

$$
O_{2}^{+}+e \rightarrow O+O\left({ }^{1} D\right) \quad(\text { Zhang et al.,2004) }
$$

(2) Photoelectron excitation

$$
e^{*}+O \rightarrow e^{*}+O\left({ }^{1} D\right) \quad(\text { Zhang et al. }, 2004)
$$

where $\mathrm{e}^{*}$ is a photoelectron,

(3) Photodissociation

$$
O^{2}+h v \rightarrow O\left({ }^{3} P\right)+O\left({ }^{1} D\right) \quad(\text { Zhang et al. }, 2004)
$$

Vertical Profile of the $O\left({ }^{1} D\right)$ Volume Emission Rate:

(Zhang et al.,2004) Due to the Rayleigh dispersion in the atmosphere, the daytime airglow is extremely difficult to measure from the ground. Thus, it is difficult to calculate integrated $O\left({ }^{1} D\right)$ emission rates using ground-based observations.

(Zhang et al.,2004) In order to calculate the integrated emission rate (I) in Rayleigh (R, $10^{6}$ photons $\mathrm{cm}^{-3} \mathrm{~s}^{-1}$ ), we used the equation,

$$
V(z)=V_{p} \exp \exp \left[-\frac{\left(z-h_{p}\right)^{2}}{\left(2 W^{2}\right)}\right]
$$

where $\mathrm{z}$ is altitude in $\mathrm{km}, V$ is a function of $\mathrm{z}, V_{p}$ is the peak $V$,

$$
V_{p}=(1.791 * F 10.7+76.4) * \cos ^{\frac{1}{e}}(\chi)+35 \quad(\text { Zhang et al. }, 2004)
$$

$h_{p}$ is the height of $V_{p}$ in $\mathrm{km}$, and $\mathrm{W}$ is the profile width of the Gaussian function in $\mathrm{km}$. The unknown variables, $V_{p}, h_{p}$, and $W$, can be derived from (Zhang et al.,2004). 


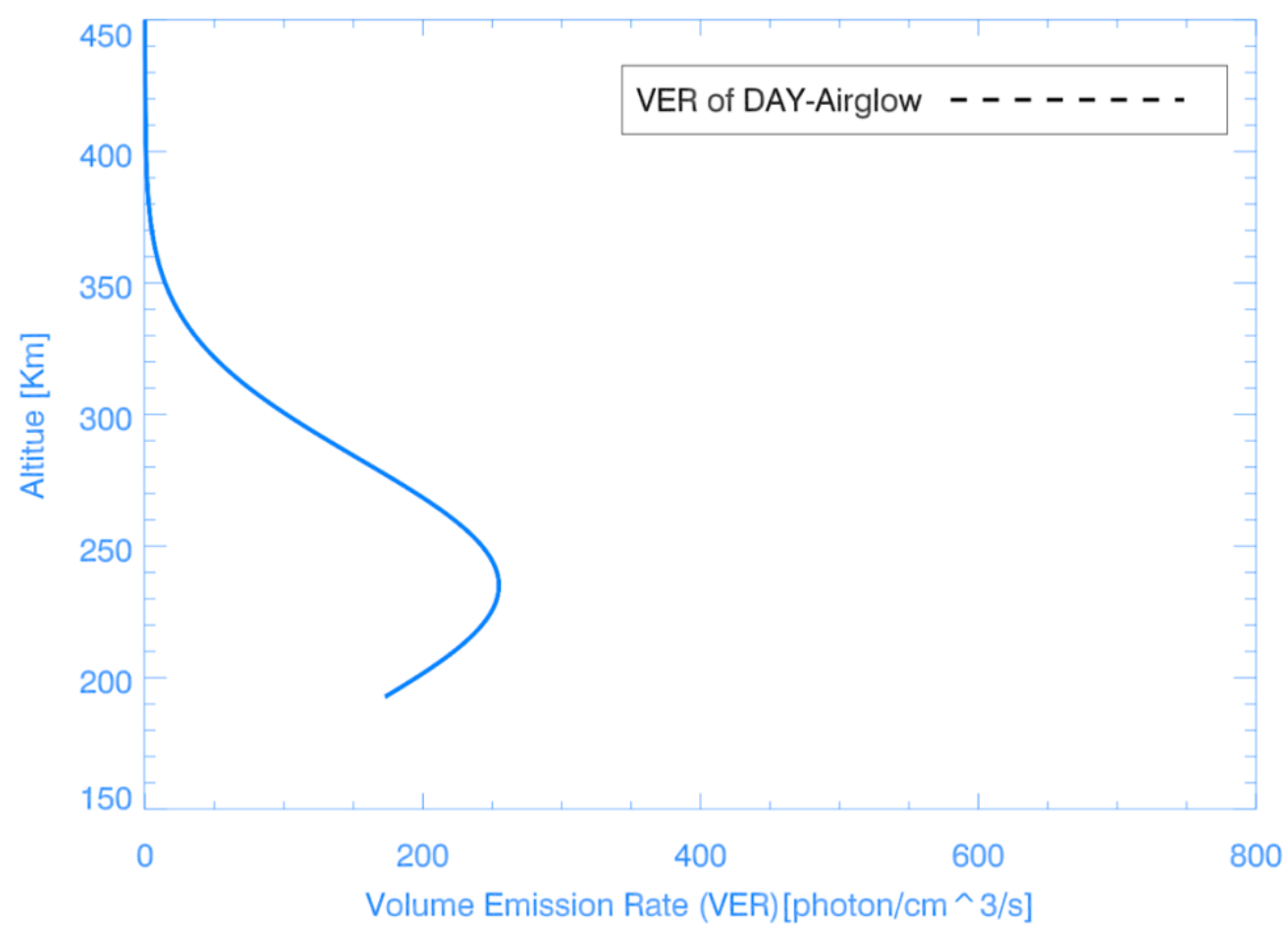

Figure 27 Volume Emission Rate (VER) of Day airglow for Red line.

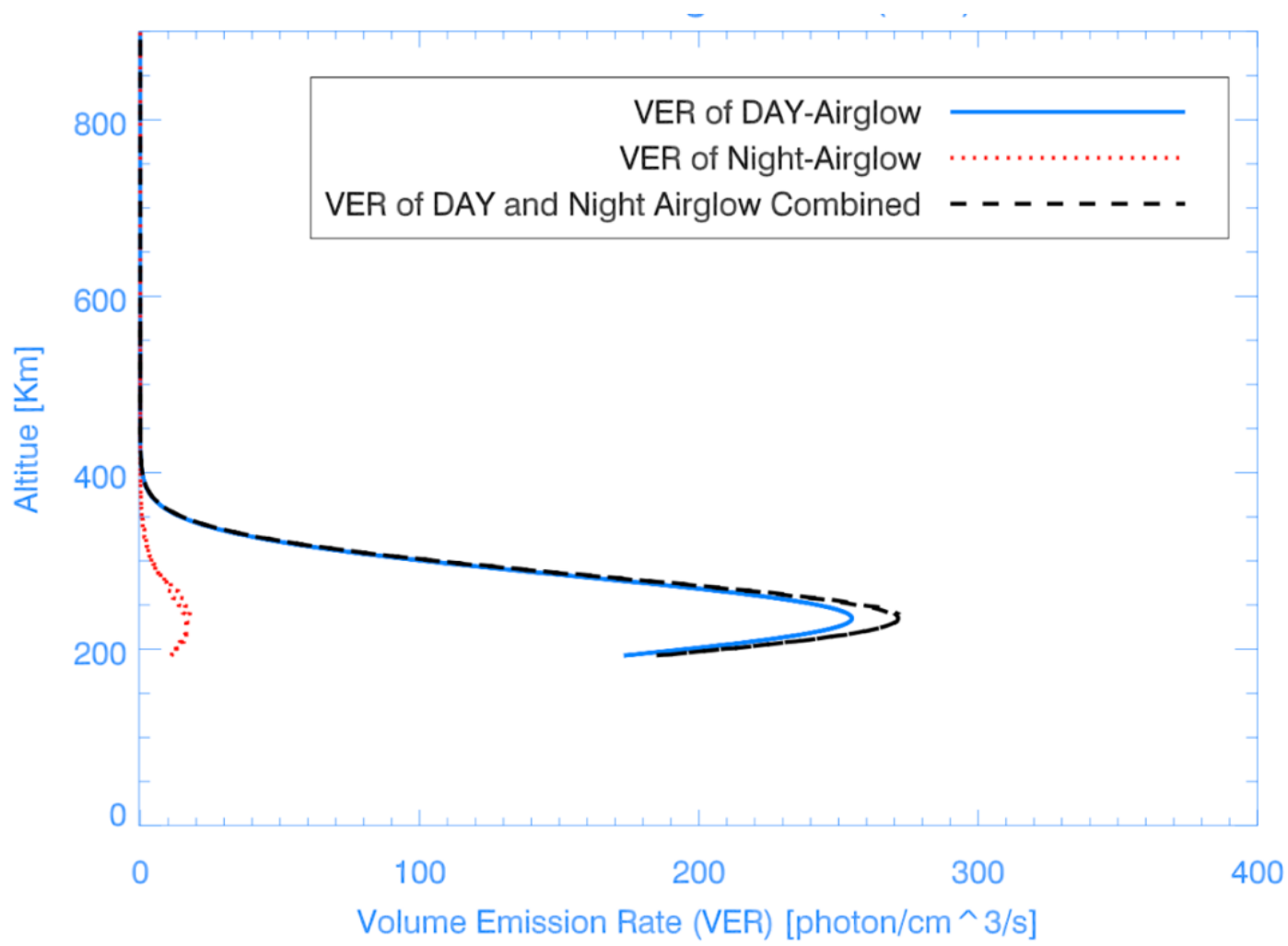

Figure 28 Volume Emission Rate (VER) of Day and Night Airglow Combined for Green line. 
In the above two figures it shows the variation of volume emission rate (VER) of red line airglow along altitude. Figure 5 represents variation of (VER) at the Daytime where figure 6 compares variation of (VER) both Day and Nighttime combined. It is evident from the two figures above that most of the red line airglow contribution is coming from the Daytime, because we are showing daytime case for this figure.

\subsection{MIGHTI Viewing Geometry}

\subsubsection{Instrument:}

The Michelson Interferometer for Global High-resolution imaging of the Thermosphere and Ionosphere (MIGHTI) instrument was built on the NASA Ionospheric Connection Explorer (ICON) mission for launch and operation (Immel et al, 2018). The instrument was designed to measure the green and red atomic oxygen emissions at $557.7 \mathrm{~nm}$ and $630.0 \mathrm{~nm}$, thermospheric wind speed profiles and thermospheric temperatures in altitude regions between $90 \mathrm{~km}$ and 300 $\mathrm{km}$ (Harding, et al. 2017). (Englert, et al., 2017) The wavelength shift is measured by field-wide, temperature-compensated Doppler Asymmetric Spatial Heterodyne (DASH) spectrometers with $e^{\prime}$ chelle gratings for the different atmospheric lines operating in two different orders. (Englert, et al., 2017) Temperature measurement is carried out by a photometric multi - channel measurement of the spectral shape of the A-band molecular oxygen around $762 \mathrm{~nm}$ wavelength.

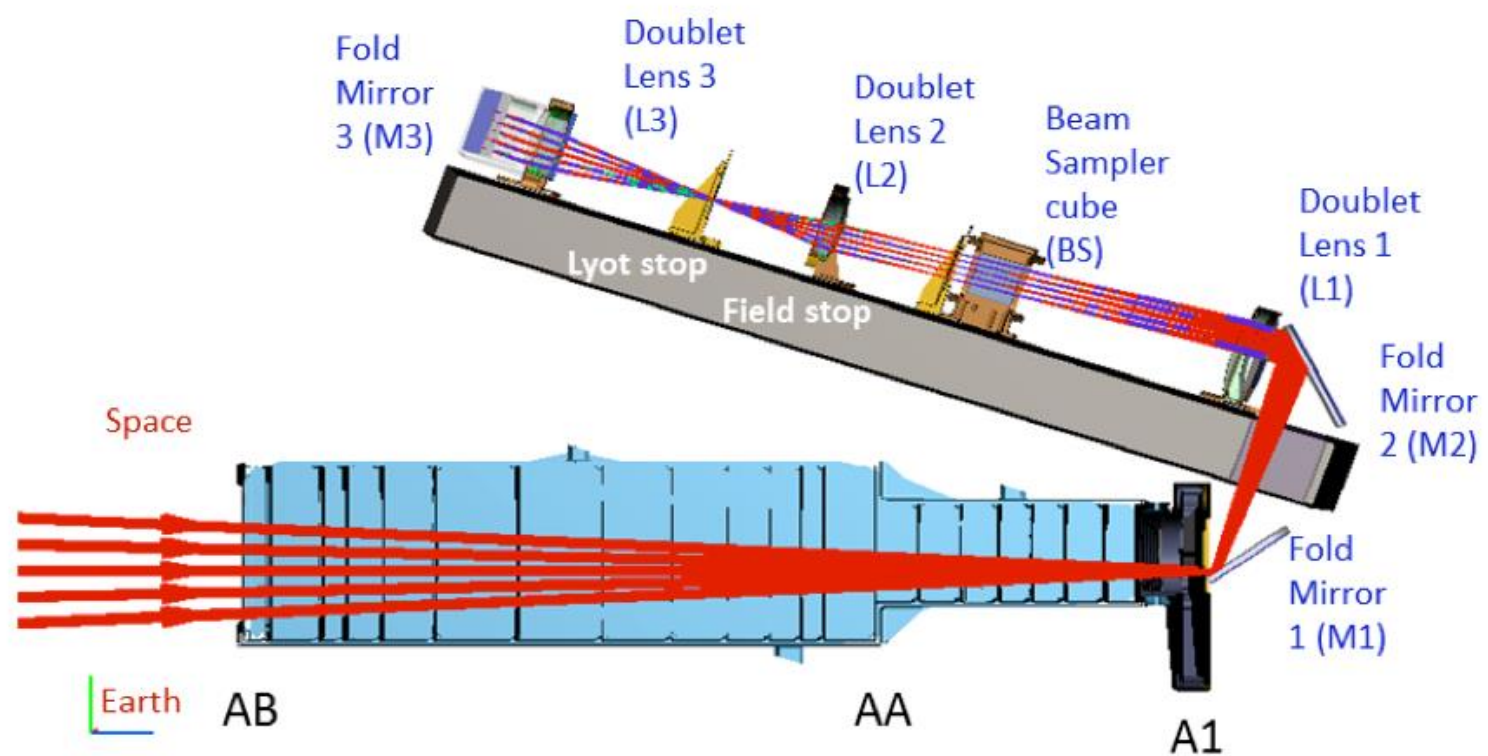

Figure 29 (MIGHTI) Instrument source (Harding, et al. 2017).

(Englert, et al., 2017) The wind velocity observation is based on the Doppler shift measurement of the Red and Green lines at the wavelengths of $630.0 \mathrm{~nm}\left(\mathrm{O}\left(1 \mathrm{D} \rightarrow{ }_{3} \mathrm{P}\right)\right)$ and $557.7 \mathrm{~nm}(\mathrm{O}(1 \mathrm{~S} \rightarrow$ 1D)) respectively, imaging the limb of the Earth between 90 and 300 kilometers tangent point 
altitude during day and night. Wind directions are determined by combining observations of two fields of view, each of which is directed at an azimuth angle of 45 degrees and 135 degrees from the direction of the spacecraft ram. MIGHTI uses the Doppler Asymmetric Spatial Heterodyne (DASH) technique to measure the Doppler shift. (Englert, et al., 2017) Radiometric measurement based temperature observation of three narrow band regions within the temperature dependent molecular oxygen Atmospheric band $\left(A-\right.$ band, $O_{2}\left(b^{1} \Sigma \rightarrow X^{3} \Sigma(0,0)\right)$ around the wavelength of $762 \mathrm{~nm}$. Two additional passbands are used on either side of the band to observe the background contribution while avoiding the signal from the $(1,1)$ vibration band. (Englert, et al., 2017) The A- band observations are made using the same optics and detector as the wind observations and cover an altitude range of approximately $90-150 \mathrm{~km}$.

\subsubsection{Algorithm:}

We will describe an algorithm to find thermospheric wind profiles, $\mathrm{O}, \mathrm{O}_{2}, \mathrm{O}_{+}, \mathrm{O}_{2}+$ densities, Volume emission rate (VER) of green and red line airglow from measurements of the (MIGHTI). We will calculate the asymmetry along the ray suggested by (Harding et al., 2017) using our algorithm. For each ray, we will calculate the summation of volume emission rate (VER) for each point before and after the tangent point (Figure 30). Then we will calculate the asymmetry by calculating the difference of the summation before and after the tangent point and then divide by the summation before the tangent point.

$$
\text { Assymetry }=\frac{\text { Sum Before the Tangent Point }- \text { Sum Before the Tangent Point }}{\text { Sum Before the Tangent Point }}
$$

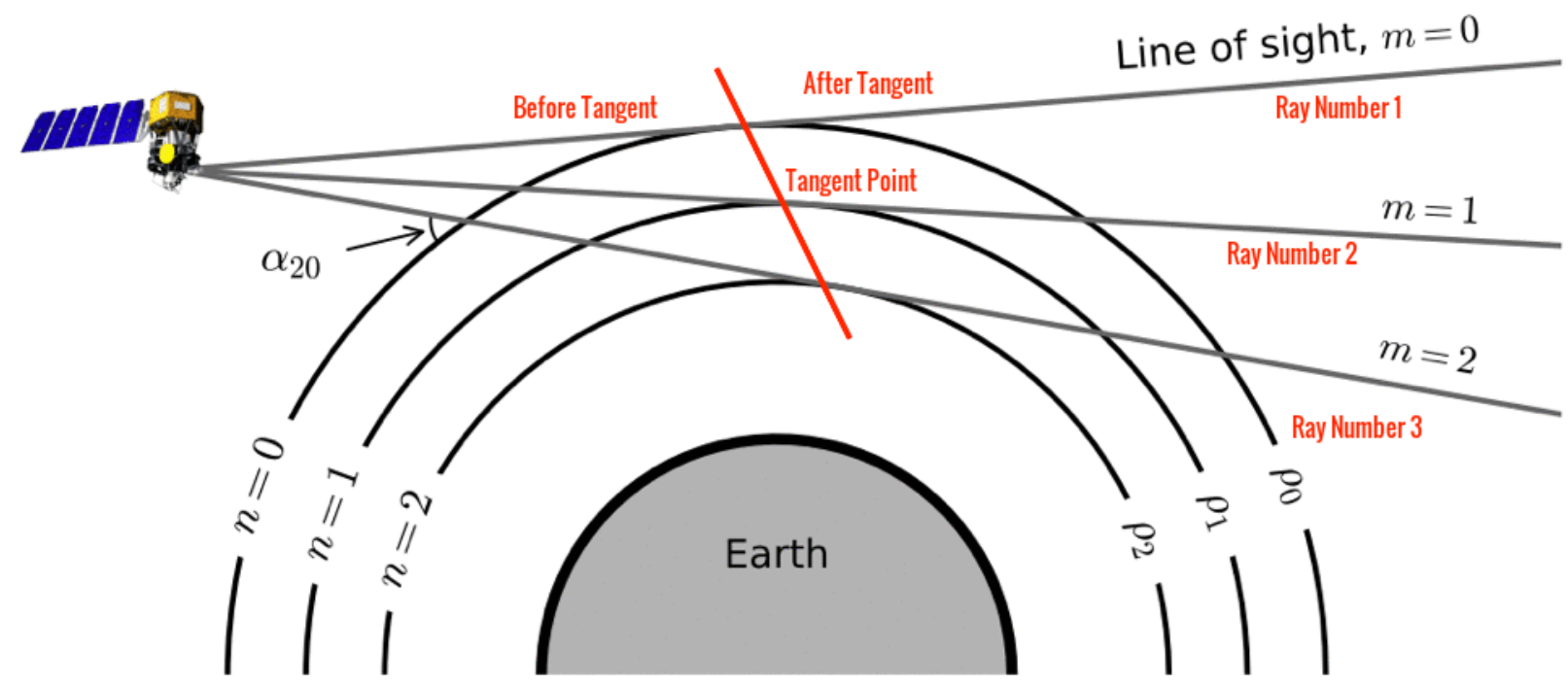

Figure 30 Observation geometry for a MIGHTI interferogram (Source: Harding, et al. 2017).

\section{Algorithm:}

$\Rightarrow$ Define constants: Numerous constants are used throughout the code, but both for debugging and future development, any one of these can be updated. Setting them here makes the most sense. 
$\Rightarrow$ Define inputs: This component sets up all the input files from which all the following computation will be done. Input files needed - MIGHTI ancillary file (24 hours / file), GPI file (1 file covers many years), TIEGCM file (24 hours / file).

$\Rightarrow$ Read MIGHTI ancillary input file: Open the MIGHTI ancillary file \& read relevant parameters (S/C position, instrument viewing unit vectors, time of each exposure.) All parameters needed are given at the time of each exposure. Select if we are doing MIGHTI_A or MIGHTI_B. And S/C velocity.

$\Rightarrow$ Set range of timesteps to run over: Define if we wish to calculate the winds \& brightness at each time step in the file, or just at one time step (e.g., the very first-time step). Using just one-time step is useful for debugging purposes.

$\Rightarrow$ Compute tangent point in the middle of the image: There are several parameters we will use in the model that we can just approximate to be the same across the whole image. These include the central latitude, longitude, and local time (computed from time and longitude).

$\Rightarrow$ Define output arrays: These will have dimensions of vertical $x$ number of exposures.

$\Rightarrow$ Begin loop in time: Having defined how many time steps will be run, the output arrays (wind, brightness etc) can be generated.

$\Rightarrow$ Calculate vertical profile of view directions (unit vectors): For each vertical pixel (from 90 to 300 $\mathrm{km}$ for green, 180 to $300 \mathrm{~km}$ for red), we need a unit vector for its view direction.

$\Rightarrow$ Compute LOS rays along each view direction: Compute all Line of Sight rays in ECEF for all lat-lonalt along each view direction.

$\Rightarrow$ Compute all other geometry parameters at each step along ray (SZA etc): At each point along each ray, we need the SZA.

$\Rightarrow$ Compute tangent point in the middle of the image: There are several parameters we will use in the model that we can just approximate to be the same across the whole image. These include the central latitude, longitude, and local time (computed from time and longitude).

$\Rightarrow$ Read TIEGCM model input file: Open the TIEGCM file.

$\Rightarrow$ Identify altitude array corresponding to location of the middle of the image: Using the latitude \& longitude and time from above, select the central location from the model.

$\Rightarrow$ Find the pixel index in the TIEGCM model closest to each point along each ray: We have the locations along each ray from step 8 above, we use these to find the nearest point in the model to these.

$\Rightarrow$ Read required model parameters: We will need things like $\mathrm{O}, \mathrm{O}_{2}, \mathrm{O}^{+}, \mathrm{O}_{2}{ }^{+}, \mathrm{T}$, wind. We will do this for every point along every ray. 
$\Rightarrow$ Read GPI input file: Open the GPI file. Find the index that corresponds to the day we are looking at. Read the F10.7 value.

$\Rightarrow$ Compute red and green VER at each point along each ray: Using the equations from Zhang \& Shepard, and also some parameters from GPI (Solar F10.7 index), SZA, and the model $\left(\mathrm{O}^{+}-\right.$ nighttime), we compute the VER for green \& red at each point along each ray.

$\Rightarrow$ Compute red and green brightness at each point along each ray: Sum up the VER along each ray. We need the step size (10 or $20 \mathrm{~km})$, and the VER.

$\Rightarrow$ Compute LOS (line of sight) wind at each point along each ray: Inputs we need: wind from the model, S/C velocity form the ancillary file, the Earth's rotation rate, the angle to horizontal for each ray.

$\Rightarrow$ Compute asymmetry in brightness along each ray - for example, for 1 ray, find total Greenline brightness before tangent point vs after, find difference as a \%.

$\Rightarrow$ Compare to MIGHTI: If we see asymmetry, look at both A\&B, especially things like temperature, brightness.

(Harding, et al., 2017) The field of view is $90-300 \mathrm{~km}$ in altitude for green and 150-300 $\mathrm{km}$ in altitude for red. The green emission is used during the day to determine the altitude profile of the winds below $170 \mathrm{~km}$ and the red is used over $170 \mathrm{~km}$ (Harding, et al., 2017). (Harding, et al., 2017) During the night, measurements are limited to $90-105 \mathrm{~km}$ (green) and 210-300 km (red) by narrowing the atmospheric emission profiles. The MIGHTI native altitude sampling is approximately $2.2 \mathrm{~km}$, although we expect to be $5 \mathrm{~km}$ in green and $30 \mathrm{~km}$ in red to improve statistics while meeting ICON's scientific needs (Harding, et al., 2017). (Harding, et al., 2017) As with all limb observations, the MIGHTI measurements are averages (weighted by airglow emission rate) along the horizontal region covered by the sight line (many hundreds of $\mathrm{km}$ ), the vertical sampling (native $2.2 \mathrm{~km}$ ) and the exposure time (30 or 60 seconds) that the spacecraft carries. 


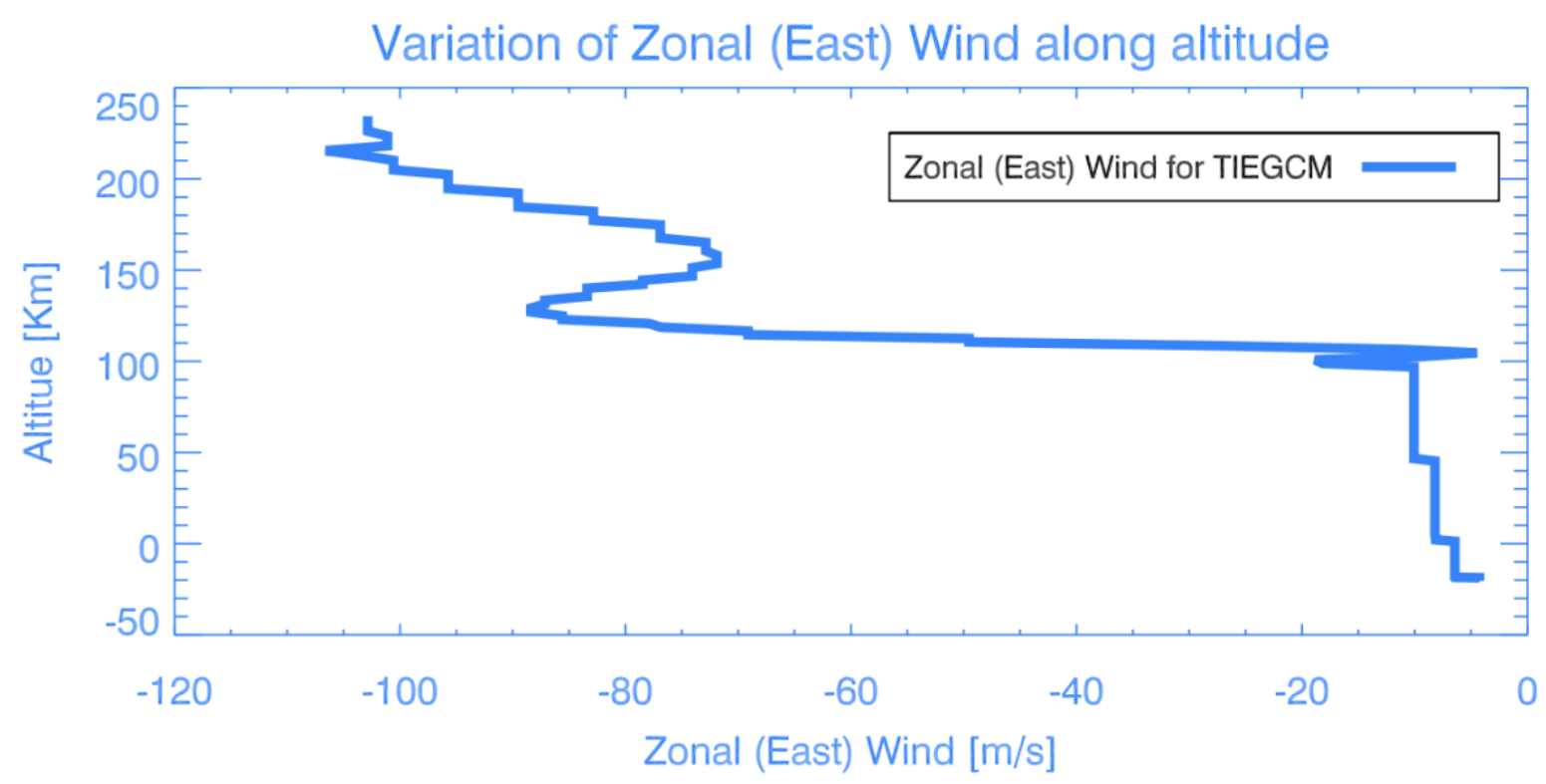

Figure 31 Variation of Zonal (East) Wind along altitude.

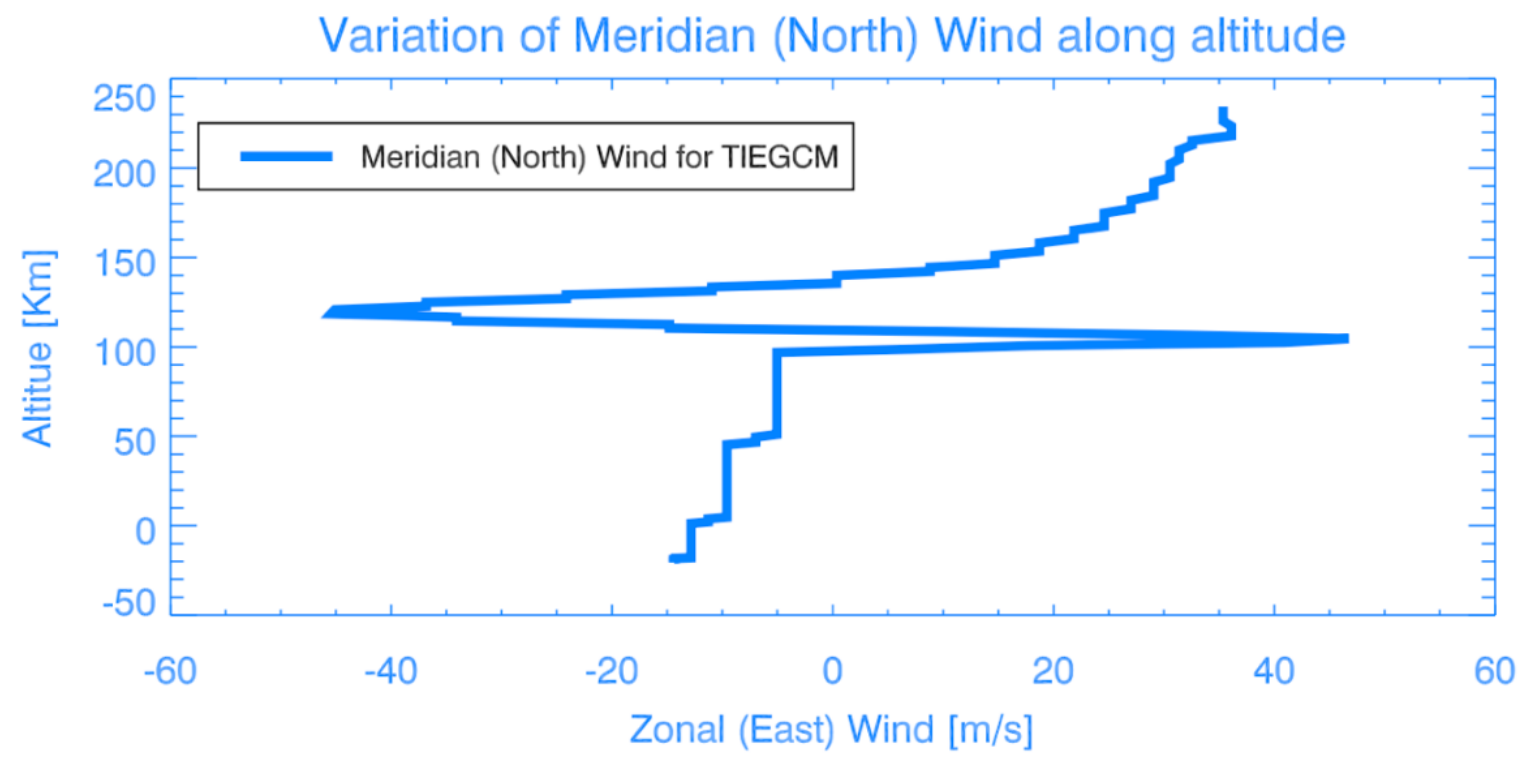

Figure 32 Variation of Meridian (North) Wind along altitude.

\subsection{Geometry of MIGHTI observation:}

In this section we will describe the geometry of the ICON mission which is aimed to find the extreme fluctuation of Earth's Ionosphere and identify its causes behind it. 


\subsubsection{Wind and Temperature Measurement:}

The MIGHTI instrument consists of two units with orthogonal fields of view, pointing to the port (northern) side of the spacecraft at $45^{\circ}$ and $135^{\circ}$ from the direction of the velocity S / C, this viewing geometry lets MIGHTI instrument to make two perpendicular line-of-sight wind measurements of the same air volume as the spacecraft passes by.

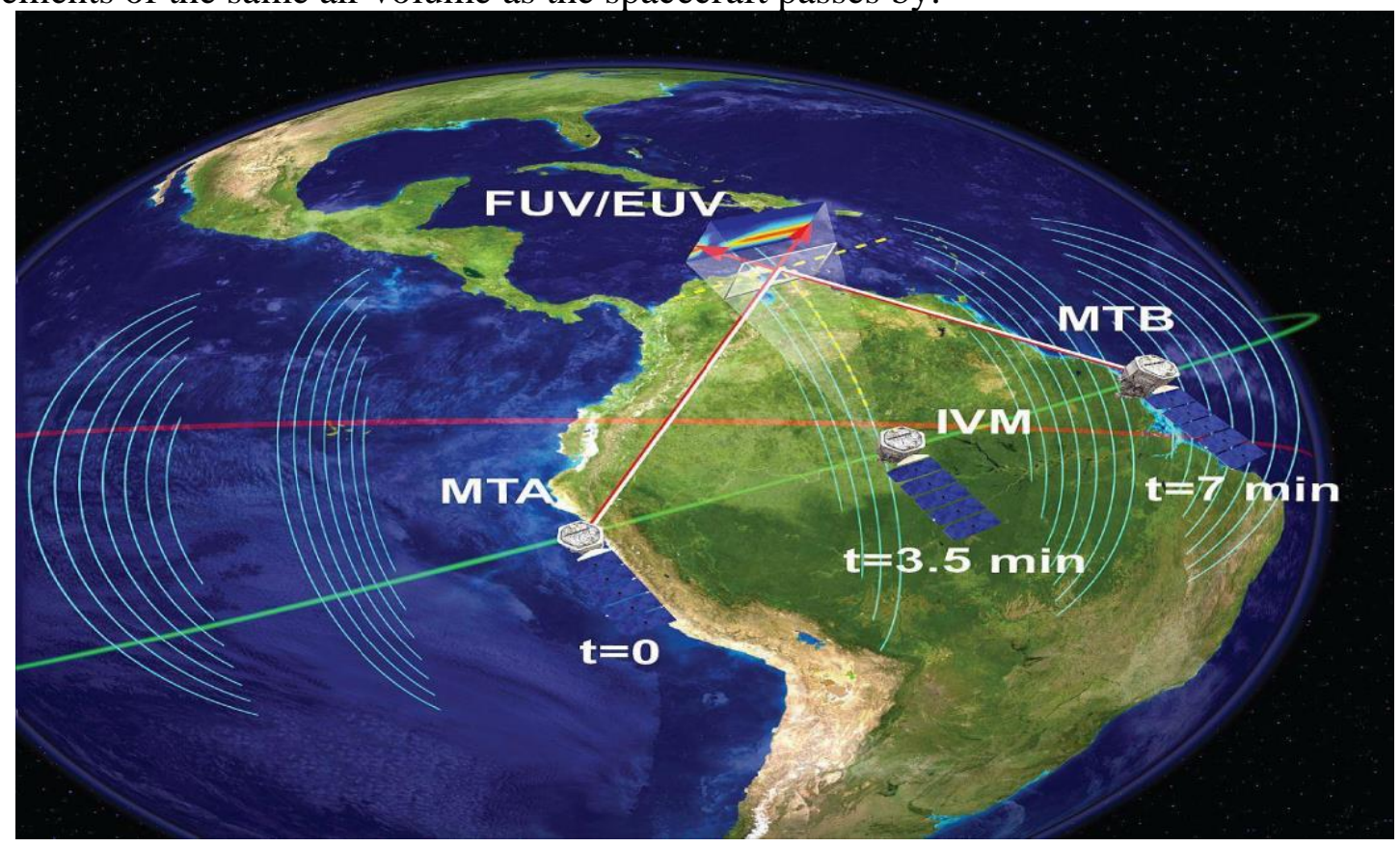

Figure 33 ICON's observational geometry allows simultaneous in situ and remote sensing of the ionosphere-thermosphere system [21].

When oxygen emission line (e.g green $(557.7 \mathrm{~nm})$ and one red $(630.0 \mathrm{~nm})$ approaches moving towards Line of sight (LOS) their wavelength shortens, and MIGHTI use this change in wavelength to calculate the wind measurements. 

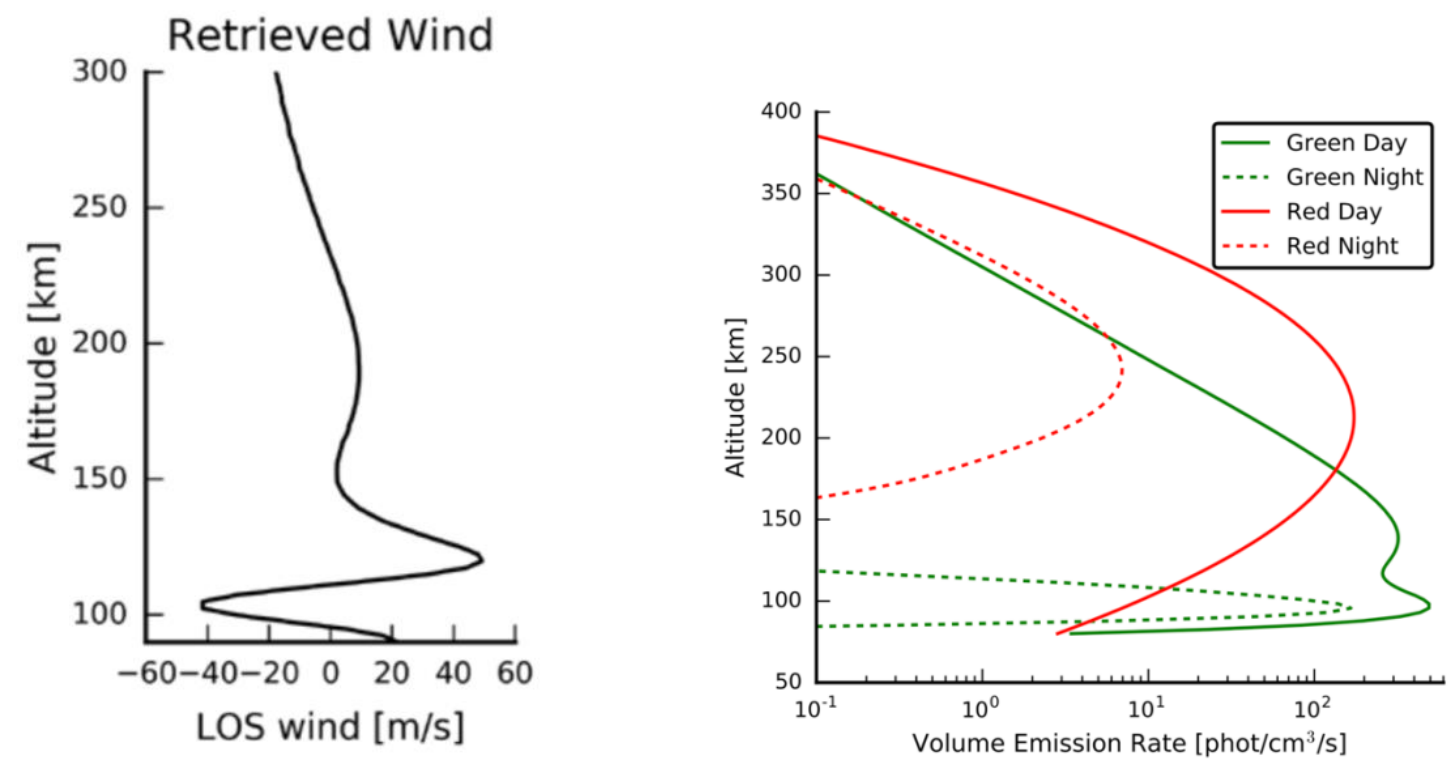

Figure 34 Example 1D 'image’ of the wind \& brightness (Source: Harding, et al. 2017).

Temperature and wind measurements are carried out in simultaneously, MIGHTI measures the $\mathrm{O}_{2}$ emission band of $762 \mathrm{~nm}$. By measuring the brightness in different parts of the $762 \mathrm{~nm}$ band, MIGHTI detects this shape change.

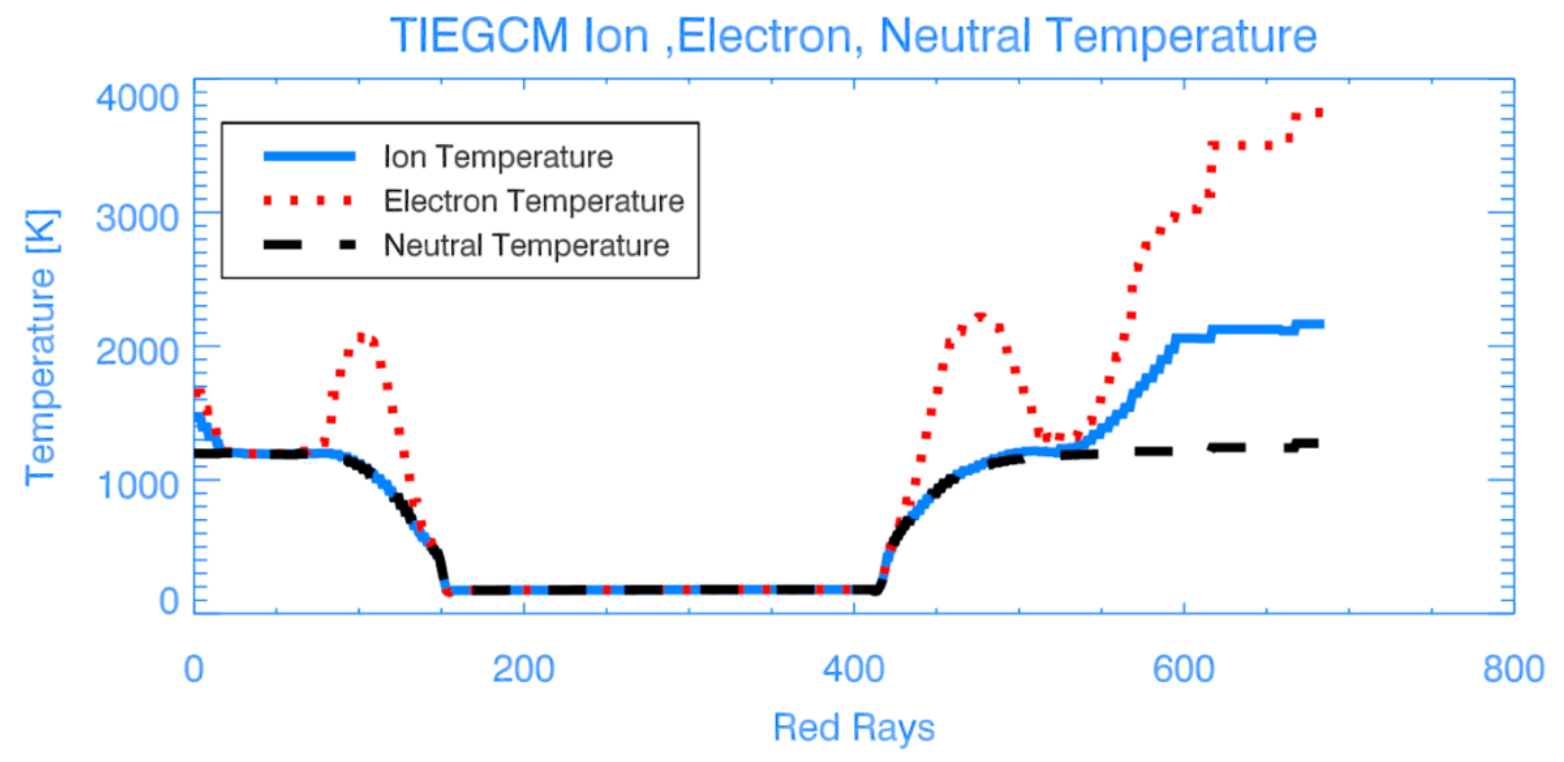

Figure 35 Variation of TIEGCM Ion, Electron, Neutral Temperature.

Solar Zenith Angle: We know that the Solar Zenith Angle (SZA) is the angle between the local zenith (i.e. directly above the point on the ground) and the line of sight from that point to the sun (Hu, et al. 2018). This indicates that with raising the Sun height, the SZA decreases or low solar zenith angle indicates daytime and high solar zenith angle indicates nighttime. 


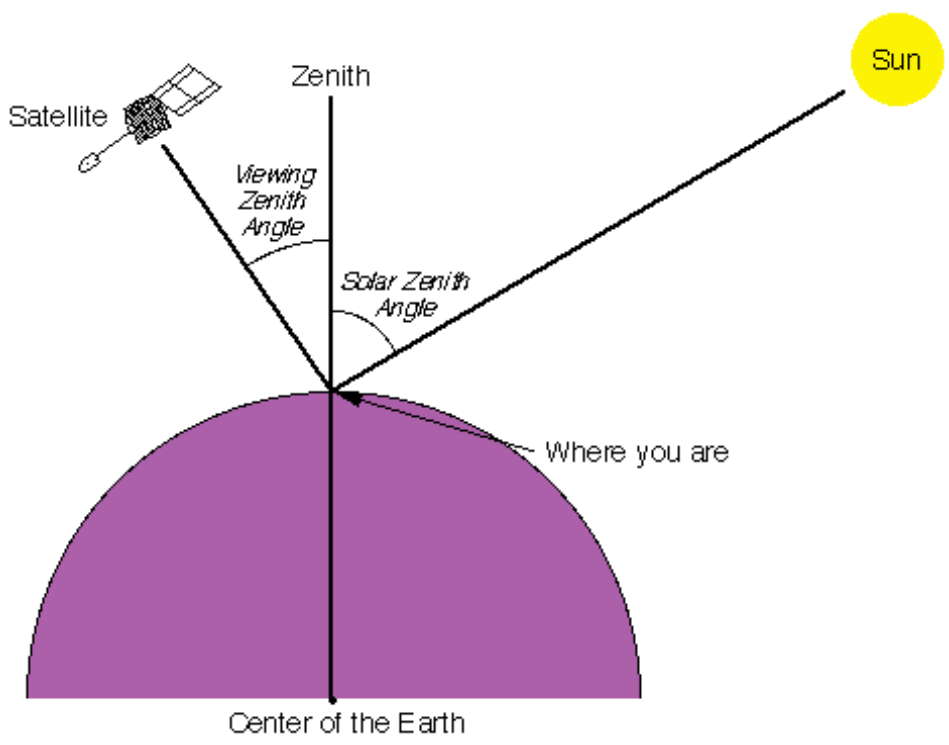

Figure 36 Schematic illustration of the Solar Zenith Angle (SZA) and Viewing Zenith Angle (VZA) for observations from satellite-based instrument. [image taken from a NASA page].

We need the solar zenith angle for calculating the Volume Emission Rate (VER), Brightness using different sets of empirical formula. We have the MIGHTI solar zenith angle in the plotted below. Where we see a high of 156.0921 degree, and a low of 23.786 degree.

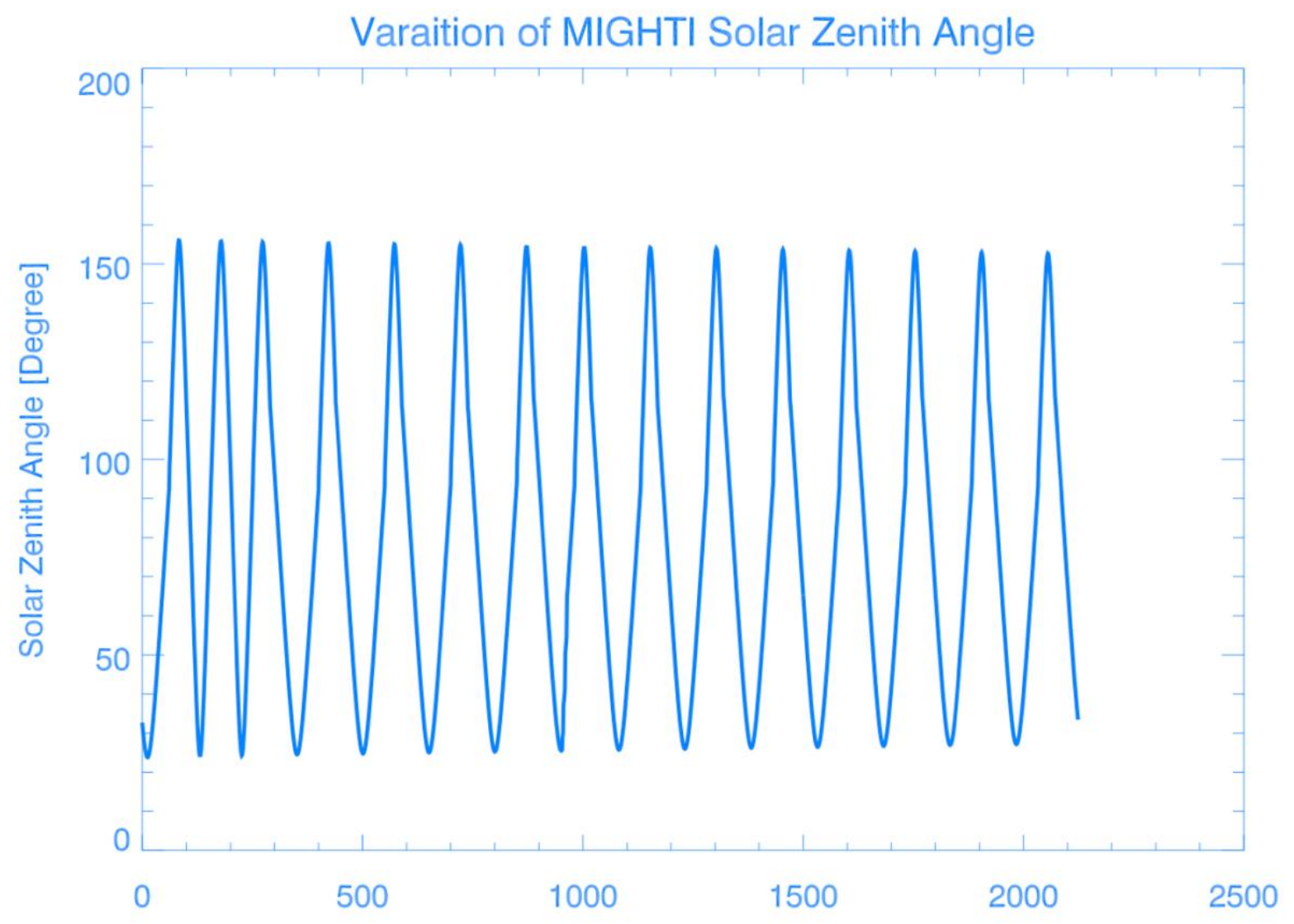


Figure 37 Variation of MIGHTI Solar Zenith Angle.

\subsection{Approach (Ray Tracing)}

One of the techniques we will use is called ray-tracing approach. Using this technique, we will read parameters like $\mathrm{O}, \mathrm{O}_{2}, \mathrm{O}_{+}, \mathrm{O}_{2+}$, wind, solar $\mathrm{F} 10.7$ index, for every point along every ray. These parameters then will be calculated from the model and brightness and Line of Sight (LOS) wind as a function of altitude and time. To implement the ray tracing approach, we need the knowledge of Spacecraft Position, and convert its position in correct coordinate system.

\subsubsection{Spacecraft position:}

We know that ICON will be analyzing the part of the atmosphere where earth and space weather meets. (Immel, et al., 2018) To perform the desired goal ICON will be placed into a circular orbit, with a height of $575 \mathrm{~km}$ and 27o inclination.

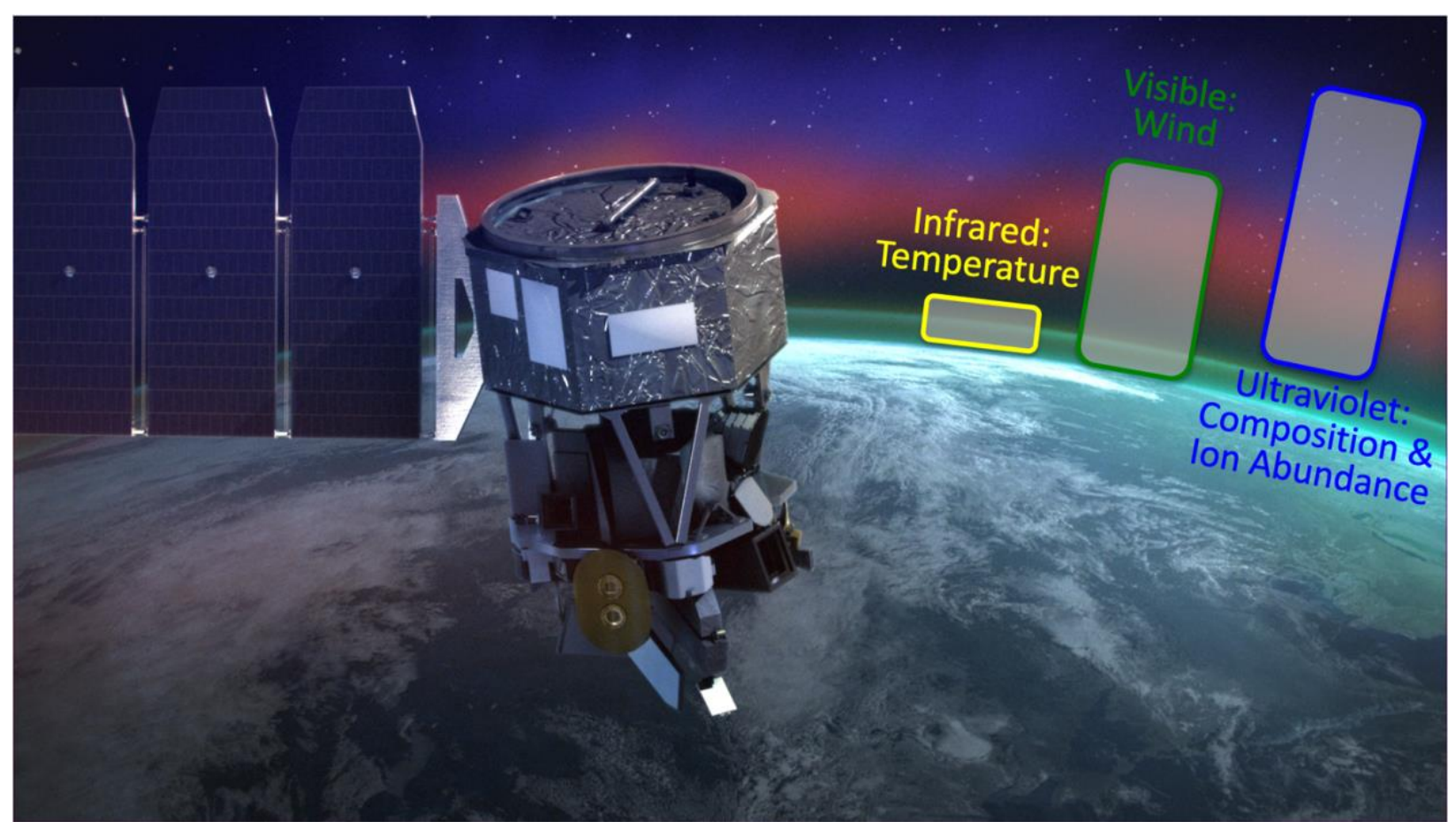

Figure 38 Artist imagination if ICON in space [22].

We know that earth has a complex shape, however we need a simple, yet accurate, method to approximate a particular position with respect to the earth's shape. During orbit the satellite will change its altitude, latitude, longitude, etc. We need to account for these changes and need tools to analyze the change. We will discuss the appropriate coordinate system and the conversion we need. 
There are two generic types of coordinates:

- Cartesian

- Angular or Curvilinear Coordinates

Cartesian: The Cartesian coordinates/Rectangular coordinates system is used to specify the location of a particular point in three-dimensional space. We know Cartesian coordinate system is based on three mutually perpendicular coordinate axes in a three-dimensional space.

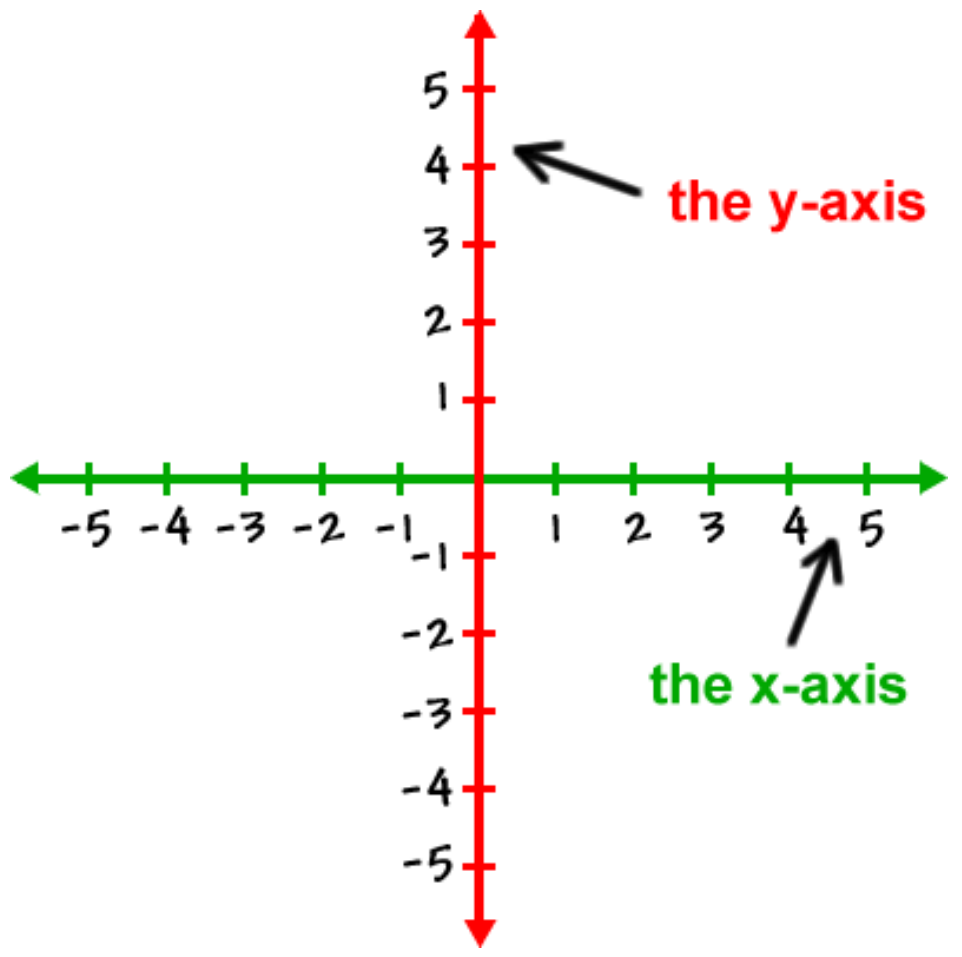

Figure 39 The Cartesian (Rectangular) Coordinate System Source: (http://www.coolmath.com/).

\section{ECEF Coordinate System:}

ECEF or Earth Centered, Earth Fixed (ECEF) Coordinates are Cartesian coordinate systems that we will use. These Earth Centered, Earth Fixed ECEF coordinates is the most popular system used to determine earth position.

ECEF Coordinate System has the following characteristics (from wrld3d.com/unity/latest/docs/examples/ecef-coordinate-system/):

- The origin $(0,0,0)$ is the center of mass of the earth.

- The positive $X$ axis passes through Latitude and Longitude respectively at $(0,-90)$.

- The positive Y axis passes through the South-North pole.

- The positive $\mathrm{Z}$ axis passes through the prime meridian (0 longitude) at Latitude and Longitude respectively $(0,0)$.

Conventionally, we use a left-handed coordinate system, where (from wrld3d.com/unity/latest/docs/examples/ecef-coordinate-system/): 
- The positive $X$ axis points right.

- The positive $\mathrm{Y}$ axis points up.

- The positive $\mathrm{Z}$ axis points forward.

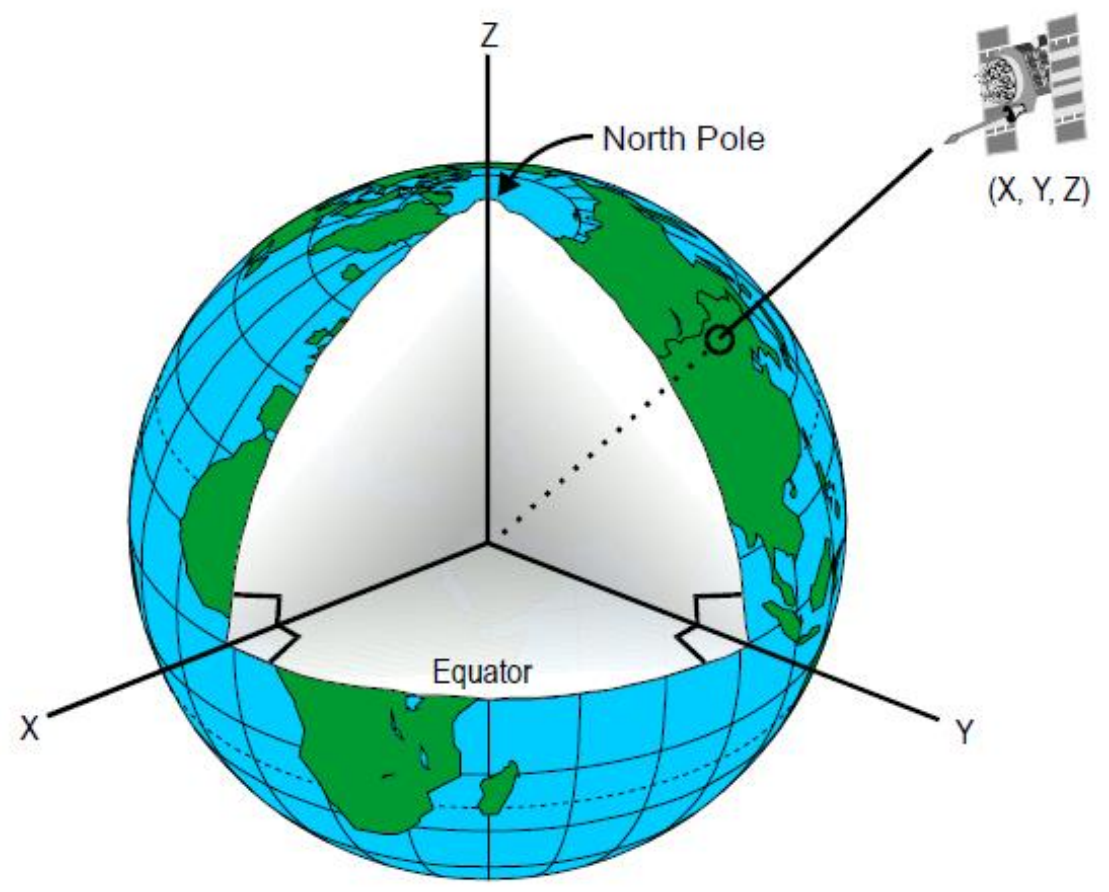

Figure 40 ECI (Earth Centered Inertial) system [4].

\section{Angular or Curvilinear Coordinates:}

Angular coordinate system is specified by three numbers (from courses.lumenlearning.com/boundless-calculus/chapter/vectors-and-the-geometry-of-space/) :

- The radial distance of that point from a fixed origin,

- Its polar angle measured from a fixed zenith direction, and

- The azimuth angle of its orthogonal projection on a reference plane.

Spherical/ Angular coordinates ( $\mathrm{r}, \theta, \varphi) /$ (latitude, longitude and height) as commonly used in physics.

Angular coordinate system these angles seen from the center of the earth (James R. Clynch, 2006):

- The angle up from the equator is latitude. In the southern hemisphere is it negative.

- The angle in the equatorial plane is the longitude. 


\subsubsection{Coordinate Conversion:}

We know that ECEF uses three-dimensional XYZ coordinates to describe the location of a GPS user or satellite. We will use a reference ellipsoid for the conversion of the ECEF coordinates to the more commonly used geodetic-mapping coordinates of Latitude, Longitude, and Altitude (LLA) (Mustafa, 2013).

A reference ellipsoid can be described by a series of parameters that define its shape and which include a semi-major axis (a), a semi-minor axis (b) and its first eccentricity (e) and its second eccentricity (e') as shown in Figure 41(from GPS-E1 Evaluation Kit for GPS-MS1 and GPS-PS1, 1999). Depending on the formulation used, ellipsoid flattening (f) may be required.

For global applications, we will use the World Geodetic System 1984 (WGS84). This geodetic reference (datum) ellipsoid has its origin coincident with the ECEF origin (from GPS-E1 Evaluation Kit for GPS-MS1 and GPS-PS1, 1999).

The WGS84 system has the following parameters according to (from GPS-E1 Evaluation Kit for GPS-MS1 and GPS-PS1, 1999):

Semi-major axis, $\mathrm{a}=6378137$

Semi-minor axis, $b=a(1-f)$

Ellipsoid flattening, $\mathrm{f}=1 / 298.257223563$

Eccentricity, $\mathrm{e}=\sqrt{\frac{a^{2}-b^{2}}{a^{2}}}$

Eccentricity, $\mathrm{e}^{`}=\sqrt{\frac{a^{2}-b^{2}}{b^{2}}}$

\section{Latitude, Longitude, and Altitude (LLA) to Earth Centered, Earth Fixed (ECEF) conversion:}

The conversion from LLA to ECEF (in meters) is shown below, following the method described in (from GPS-E1 Evaluation Kit for GPS-MS1 and GPS-PS1, 1999).

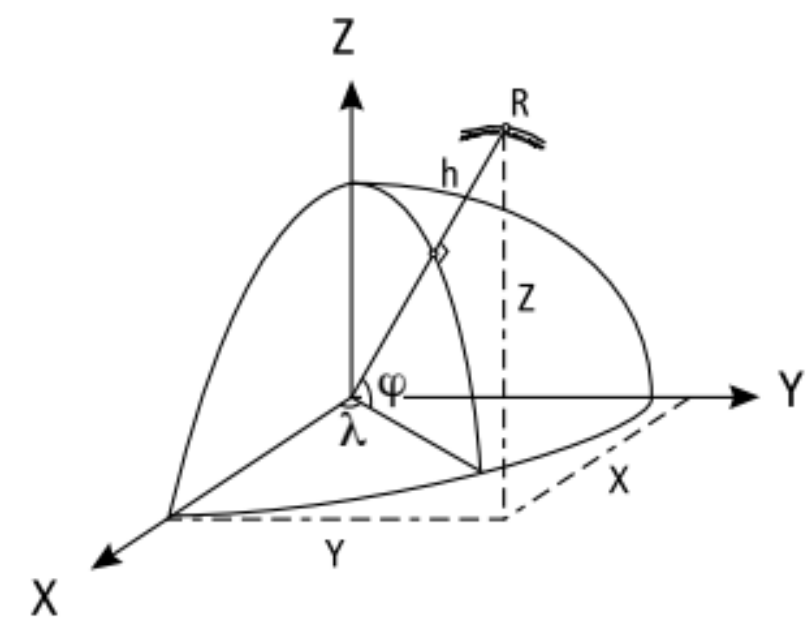

Figure 41 Coordinate Conversion photo taken from (colorado.edu). 


$$
\begin{aligned}
& X=(N+h) \cos \varphi \cos \lambda \\
& Y=(N+h) \cos \varphi \sin \lambda \\
& Z=\left(\frac{b^{2}}{a^{2}} N+h\right) \sin \varphi
\end{aligned}
$$

Where

$\lambda=$ Longitude

$$
\varphi=\text { Latitude }
$$

$h=$ Height above ellipsoid (meters)

$N=$ Radius of Curvature (meters), defined as: $\frac{a}{\sqrt{1-e^{2} \sin ^{2} \varphi}}$

\section{Earth Centered, Earth Fixed (ECEF) to Latitude, Longitude, and Altitude (LLA) conversion:}

The conversion between XYZ and LLA is slightly more involved but can be achieved using one of the following methods:

$$
\begin{gathered}
\lambda=\arctan \frac{Y}{X} \\
\varphi=\arctan \frac{Z+e^{-2} b \sin ^{3} \theta}{p\left(1-e^{2} \cos ^{3} \theta\right)} \\
h=\frac{p}{\cos \varphi}-N
\end{gathered}
$$

Where auxiliary values are:

$$
\begin{aligned}
& p=\sqrt{X^{2}+Y^{2}} \\
& \theta=\arctan \frac{Z a}{p b}
\end{aligned}
$$

\section{Vertical Profile:}

We will calculate the winds \& brightness at each time step in the file, or just at one time step (e.g., the very first-time step). Using just one-time step is useful for debugging purposes.

\section{Green Airglow, Red Airglow and LOS (Line of Sight) wind:}

We will calculate vertical profile of view directions (unit vectors) for each vertical pixel (from 90 to $300 \mathrm{~km}$ for green, 180 to $300 \mathrm{~km}$ for red), we need a unit vector for its view direction. We also need the East, North and Up unit vectors for calculating the Zonal wind (East), Meridian Wind (North), brightness etc.

Defining First Input

Defining Second Input

$$
\operatorname{llh} 0=[\varphi, \lambda, h]
$$

$$
l l h=[[\varphi+0.5, \lambda, h],[\varphi, \lambda+.5, h],[\varphi, \lambda, h+60 .]]
$$


Location of reference point in radians

$$
\begin{gathered}
\text { phi }=\operatorname{llh} 0(0) * ! p i / 180 . \\
\operatorname{lam}=\operatorname{llh} 0(1) * ! p i / 180 . \\
h=\operatorname{llh} 0(2)
\end{gathered}
$$

Where altitude (h) is in meters

Location of data points in radians

$$
\begin{gathered}
d p h i=[\varphi+0.5, \varphi, \varphi] * ! p i / 180 .-p h i \\
\text { dlam }=[\lambda, \lambda+.5, \lambda] * ! \frac{p i}{180} .- \text { lam } \\
d h=[h, h, h+60 .]-h
\end{gathered}
$$

Some useful definitions

$$
\begin{gathered}
\operatorname{tmp} 1=\operatorname{sqrt}\left(1-e 2 * \sin (p h i)^{\wedge} 2\right) \\
c l=\cos (\operatorname{lam}) \\
s l=\sin (\text { lam }) \\
c p=\cos (p h i) \\
s p=\sin (p h i)
\end{gathered}
$$

Transformations to North vectors, $d n$

$$
d n=\left(\frac{a}{t m p 1}+h\right) * c p * d \operatorname{lam}-\left(a * \frac{1-e 2}{t m p^{3}}+h\right) * s p * d p h i * \text { dlam }+c p * \text { dlam } * d h
$$

Transformations to East vectors, de

$$
\begin{gathered}
d e=\left(a * \frac{1-e 2}{t m p 1^{3}}+h\right) * d p h i+1.5 * c p * s p * a * e 2 * d p h i^{2}+s p^{2} * d h * d p h i+0.5 * \\
s p * c p *(a / t m p 1+h) * d l a m^{\wedge} 2
\end{gathered}
$$

Transformations to Up vectors, $d u$

$$
\begin{gathered}
d u=d h-0.5 *\left(a-1.5 * a * e 2 * c p^{2}+0.5 * a * e 2+h\right) * d p h i^{2}-0.5 * c p^{2} \\
*(a / t m p 1-h) * d l a m^{\wedge} 2
\end{gathered}
$$

Calculating magnitude of East vectors,

$$
\text { vector_mag_de }=\sqrt{d e 1^{2}+d e 2^{2}+d e 3^{2}}
$$

Calculating magnitude of Up vectors,

$$
\text { vector_mag_du }=\sqrt{d u 1^{2}+d u 2^{2}+d u 3^{2}}
$$

Calculating magnitude of North vectors,

$$
\text { vector_mag_ } d n=\sqrt{d n 1^{2}+d n 2^{2}+d n 3^{2}}
$$

To calculate the unit vector, we will divide the East, North and Up vectors with their magnitude.

Calculating Unit East vector,

Calculating Unit Up vector,

$$
d n \_u n i t \_v e c t o r=d e / v e c t o r \_m a g \_d e
$$

Calculating Unit North vector,

$$
d u \_u n i t \_v e c t o r=d u / v e c t o r \_m a g \_d u
$$

$$
d e \_u n i t \_v e c t o r=d n / v e c t o r \_m a g \_d n
$$


At the current time step, we can read the unit vectors given for MIGHTI are given - one in the center of the FOV, 4 at the edges (corners) and 4 in the middle of each side). We only need the central ones, and really only the upper and bottom-most. Then define the view directions to the 90 and $300 \mathrm{~km}$ points. Generate a profile of view directions (do one for green, and this will work for red as well), by using these 2 view directions. We should have 84 sub-divisions between these two, in even angular steps.

Then we will compute LOS rays along each view direction at all steps out to $6860 \mathrm{~km}$ along each ray (all 84), in ECEF and lat-lon-alt. This should be an array of about 84 x 3 x 686 (where 3 is $\times$, $\mathrm{y}, \mathrm{z}$ or latitude ,longitude ,altitude, and 686 is the steps along the ray). Find \& save the minimum alt along each ray - your green array should be roughly from 90 to 300, and red from 180 to 300 if they are not, then we have to take another step.

After that we will compute all other geometry parameters at each step along ray like SZA (Solar Zenith Angle]. At each point along each ray, we need the SZA. We can easily calculate SZA at each point along each ray if we know the time, day, and location. There are several parameters we will use in the model that we can just approximate to be the same across the whole image. These include the central latitude, longitude, and local time (computed from time and longitude).

\subsection{TIEGCM Model}

Here we need a model for the coupled Thermosphere/Ionosphere system and extends from lower to upper thermosphere, including the physical and chemical processes suitable for the mesosphere and the upper stratosphere, the thermosphere so that we can find thermospheric wind profiles, $\mathrm{O}$, $\mathrm{O}_{2}, \mathrm{O}_{+}, \mathrm{O}_{2+}$ densities, Volume emission rate (VER) of green and red line airglow along the altitude. (Maute, 2017) The Thermosphere-Ionosphere-Electrodynamics General Circulation Model (TIEGCM) is a comprehensive, first-principle, three - dimensional, non - linear representation of the combined thermosphere and ionosphere system that includes a self - consistent low-latitude electric field solution. The model solves the three - dimensional momentum, energy and continuity equations of neutral and ion species with a semi-implicit, fourth-order, centered finite difference scheme on each pressure surface at each stage. This model assumes Hydrostatic equilibrium, constant gravity, incompressibility on constant pressure surfaces, and steady-state ion/electron energetics further potential field and $E \times B$ drifts specify ion speeds. The (TIEGCM),

The standard low-resolution grid parameters are (from hao.ucar.edu/modeling/tgcm/tie.php):

Spherical geographic coordinates.

Latitude: $-87.5^{\circ}$ to $87.5^{\circ}$ in $5^{\circ}$ increments.

Longitude: $-180^{\circ}$ to $180^{\circ}$ in $5^{\circ}$ increments.

Altitude: Pressure levels from -7 to +7 in increments of $H / 2$.

Lower boundary: $\sim 97 \mathrm{~km}$.

Upper boundary: 500 to $700 \mathrm{~km}$ depending on solar activity.

Strengths of TIEGCM model (from hao.ucar.edu/modeling/tgcm/tie.php): 
- Provides, self-consistent and accurate calculation of thermosphere and ionosphere coupled system.

- Provides estimation for all important aeronomic parameters and minor species.

- Calculates solar forcing proxy models or measurements.

- Determines auroral forcing by empirical relationships, by the output of the AMIE process or by a magnetosphere model such as the LFM.

Inputs of TIEGCM model (from hao.ucar.edu/modeling/tgcm/tie.php)::

- Takes 81-day centered mean of the F10.7 daily index as input.

- Takes $K_{\mathrm{p}}$ index/IMF and Solar Wind/ specified cross-cap potential and hemispheric power as input.

Outputs of TIEGCM model (from hao.ucar.edu/modeling/tgcm/tie.php):: Output fields specified in 3 spatial dimensions plus time:

- Temperature Neutral, ion, electron (K)

- Neutral Winds zonal, meridional, vertical $(\mathrm{m} / \mathrm{s})$

- Composition: $\mathrm{O}_{2} \mathrm{O}_{2}, \mathrm{O}_{+}, \mathrm{O}_{2+}, \mathrm{N}_{2+}, \mathrm{N}_{+}$

\subsection{MSIS Model}

Due to limitation of TIEGCM model below $90 \mathrm{~km}$ we need the MSIS model to run for the Green airglow below $90 \mathrm{Km}$, where the TIEGCM model does not give accurate calculation. The MSISE model describes the neutral temperature and densities in the atmosphere from ground to thermosphere and that's why is suitable for besides TIEGCM model. MSISE is also not a preferential model for specialized troposphere work. It is rather for studies that reach different atmospheric limits.

\subsubsection{Inputs of MSIS Model (from en.wikipedia.org/wiki/NRLMSISE-00):}

The inputs for the model are,

- Year and day

- Time of day

- Geodetic altitude from 0 to $1.000 \mathrm{~km}$

- Geodetic latitude

- Longitude

- Local apparent solar time

- 81-day average of F10.7 solar flux

- Daily F10.7 solar flux for previous day

- Daily magnetic index 


\subsubsection{Outputs of MSIS Model (from en.wikipedia.org/wiki/NRLMSISE-00):}

Output of the model is,

- Atomic Oxygen $(\mathrm{O})$ number density

- Oxygen $\left(\mathrm{O}_{2}\right)$ number density

- Atomic Nitrogen (N) number density

- Nitrogen (N2) number density

- $\operatorname{Argon}(\mathrm{Ar})$ number density

- Hydrogen $(\mathrm{H})$ number density

- Ionized Atomic Oxygen $\left(\mathrm{O}_{+}\right)$number density

- Ionized Oxygen $\left(\mathrm{O}_{2+}\right)$ number density

- Ionized Atomic Nitrogen $\left(\mathrm{N}_{+}\right)$number density

- Ionized Nitrogen ( $\left.\mathrm{N}_{2+}\right)$ number density

- Temperature at altitude

\subsection{Chapter 3 WINDII Data}

In Chapter 2 we have explained the detail description of the ICON and the MIGHTI instrument, geometry of MIGHTI observation, MIGHTI data structure etc. However, ICON is yet to launch so we need a set of real observational data set from a similar instrument like MIGHTI to validate our methods and approach. Here, in this section we will discuss a different instrument which is similar to MIGHTI called Wind Imaging Interferometer (WINDII), from a different mission called Upper Atmosphere Research Satellite (UARS). We will use the data from WINDII to test as much of the code we developed for MIGHTI as is possible, but we note that as WINDII is not identical, and the orbits are different between the two spacecraft, a complete test will not be possible.

\subsubsection{Upper Atmosphere Research Satellite (UARS):}

The Upper Atmosphere Research Satellite (UARS) was an Earth Observing System (EOS) NASA mission launched in September 12, 1991 from Cape Canaveral from (https://uars.gsfc.nasa.gov), 
Florida. The main purpose of the mission was to study the earth atmospheric from $50 \mathrm{mi}$ and 180 mi which the same altitude ranges of the earth upper atmosphere as ICON. UARS was launched into a $585 \mathrm{~km}, 57$-degree inclination orbit with an orbital period of 96 minutes from (https://uars.gsfc.nasa.gov). UARS was active until September 24, 2011, orbiting the Earth more than 78,000 times over an entire 11-year solar cycle.

UARS was equipped with 10 onboard instruments from (https://uars.gsfc.nasa.gov),

1. ACRIM (Active Cavity Radiometer Irradiance Monitoring)

2. CLAES (Cryogenic Limb Array Etalon Spectrometer)

3. HALOE (Halogen Occultation Experiment)

4. HRDI (High Resolution Doppler Imager)

5. ISAMS (Improved Stratospheric and Mesospheric Sounder)

6. MLS (Microwave Limb Sounder)

7. PEM (Particle Environment Monitor)

8. SOLSTICE (Solar Stellar Irradiance Comparison Experiment)

9. SUSIM (Solar Ultraviolet Spectral Irradiance Monitor)

10. WINDII (Wind Imaging Interferometer)

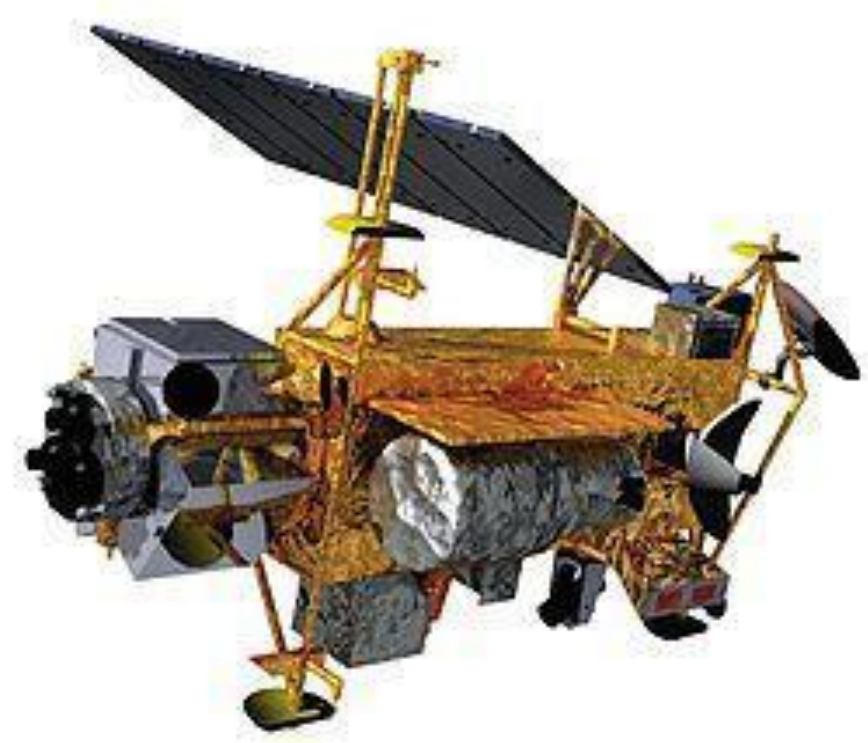

Figure 42 Upper Atmosphere Research Satellite (UARS) from (https://uars.gsfc.nasa.gov).

\subsubsection{WINDII Instrument:}

WINDII (Wind Imaging Interferometer) is one of 10 instruments aboard the (UARS) Satellite. Like MIGHTI it also measures Doppler shifts from visible region airglow. The instrument employed was a Doppler Michelson Interferometer that takes measurements during daylight and night conditions in the upper atmosphere mostly from 80 to $300 \mathrm{~km}$ (from https://uars.gsfc.nasa.gov) which covers the altitude range of what ICON is observing .WINDII helped in determining a number of atmospheric aspects among which, influence of dynamics on the transport of atmospheric species, non-migrating tides in the thermosphere both in equatorial and high latitudes, solar and geomagnetic influences, temperatures from atmospheric-scale heights 
, nitric oxide concentrations, and the occurrence of polar mesospheric clouds (Shepherd et al, 2012 provides a complete review). WINDII measures zonal and meridian winds, temperature, and VER in the upper mesosphere and lower thermosphere $(80$ to $300 \mathrm{~km})$ from observations of the Earth's airglow, for our research we are mostly interested in the change of the wavelength and the brightness of atomic oxygen $\mathrm{O}(1 \mathrm{D})$ redline $(630.0 \mathrm{~nm})$.
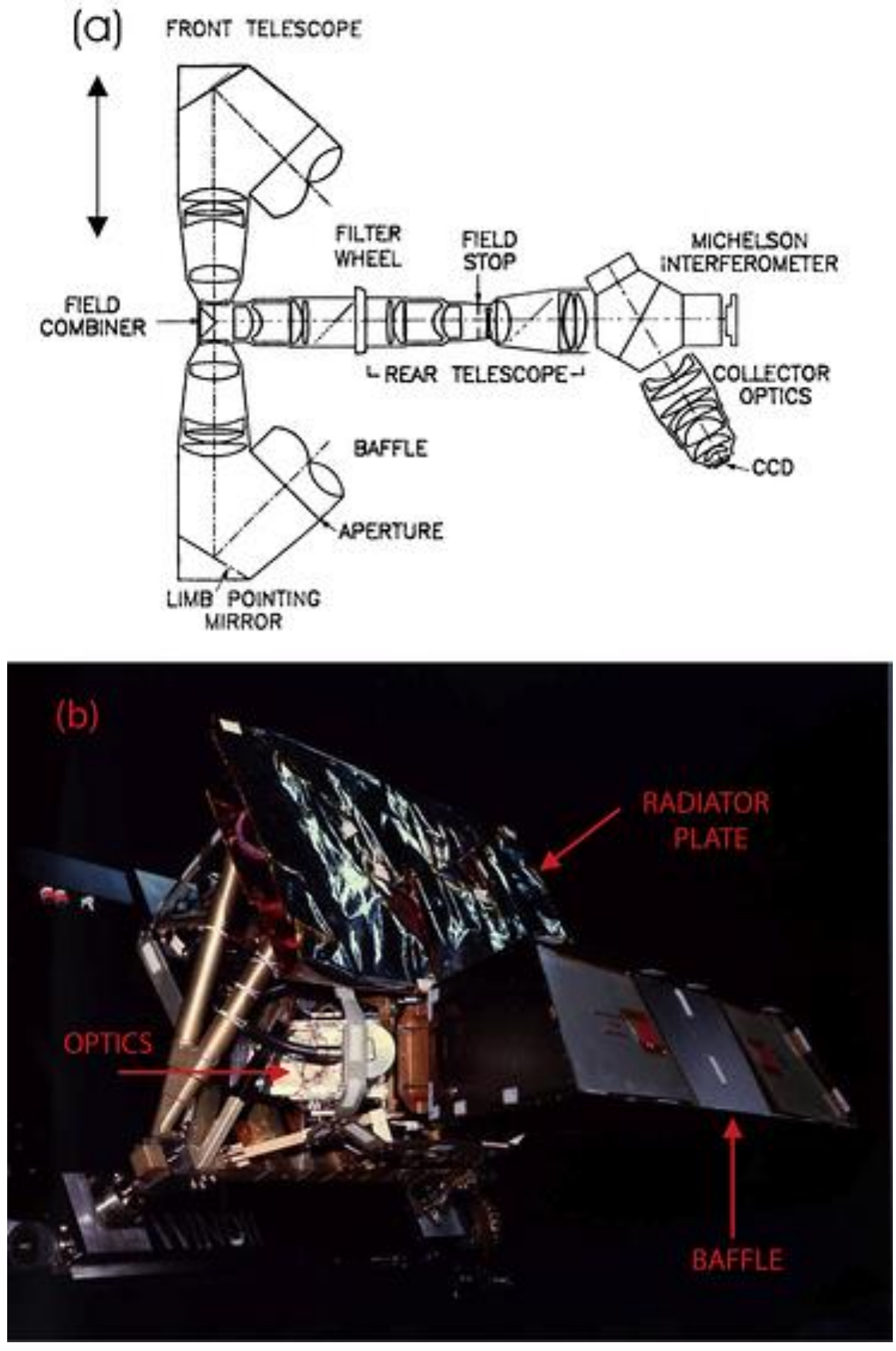

Figure 43 From (Shepherd et al., 2012) (a) WINDII optical schematic layout; the arrows show the two directions of WINDII motion corresponding to forward and backward UARS flight. (b) WINDII photo showing the baffle, the radiator plate, and the optics which are deep inside the structure.

We will use a similar approach to calculate vertical profile of both Red- airglow, Wind velocity, emission rate and compare them with TIEGCM results. 


\subsubsection{WINDII data set:}

For the purpose of this work we need time, latitude longitude, local solar time, solar zenith angles from the WINDII data set. We have taken a particular Day of the Year (1992 Year 015 Day) for our work, because it has both Zonal and Meridian wind from the redline, with good data availability. We have got data for Red line airglow for this day and our analysis for WINDII data set will only confined to Red line. For this particular day all the variables like time, latitude longitude, local solar time, solar zenith angles are stored in an array size of $[89,686]$ (from https://sscweb.gsfc.nasa.gov). This array represents the 89 vertical points 686 times.

\section{Missing data set:}

In this section we will discuss the variables we are missing from the WINDII data sets

- Volume Emission Rate (VER)

- Spacecraft individual tangent locations

- Line of Sight (LOS) Velocities

- Most importantly for WINDII there is no data available at sunset and sunrise.

WINDII only gives us data at some local times - actually none near sunrise or sunset (from Figures 47 and Figures 48) where we expect asymmetry to be a big problem - this is the reason we have no data. We expect MIGHTI to work better for Green than Red line airglow except day/night boundaries. (Harding et al., 2017) suggests there is a lot of asymmetry at night rather than during the day.

\section{Altitude:}

The 89 vertical points or altitude coverage for all the vertical coverage is from approximately from 0 to $400 \mathrm{~km}$ and the index of the data array defines the altitude as given by (from https://acdisc.gesdisc.eosdis.nasa.gov )

$$
\begin{array}{ll}
Z(i)=5 * i, & i<=12 \\
Z(i)=60+(i-12) * 3, & 13<=i<=32 \\
Z(i)=120+(i-32) * 5, & 33<=i<=88 .
\end{array}
$$

Altitude levels are in kilometers. For the convenience of our calculation we will only take 48 vertical points which covers altitude from 80 to $300 \mathrm{~km}$. 


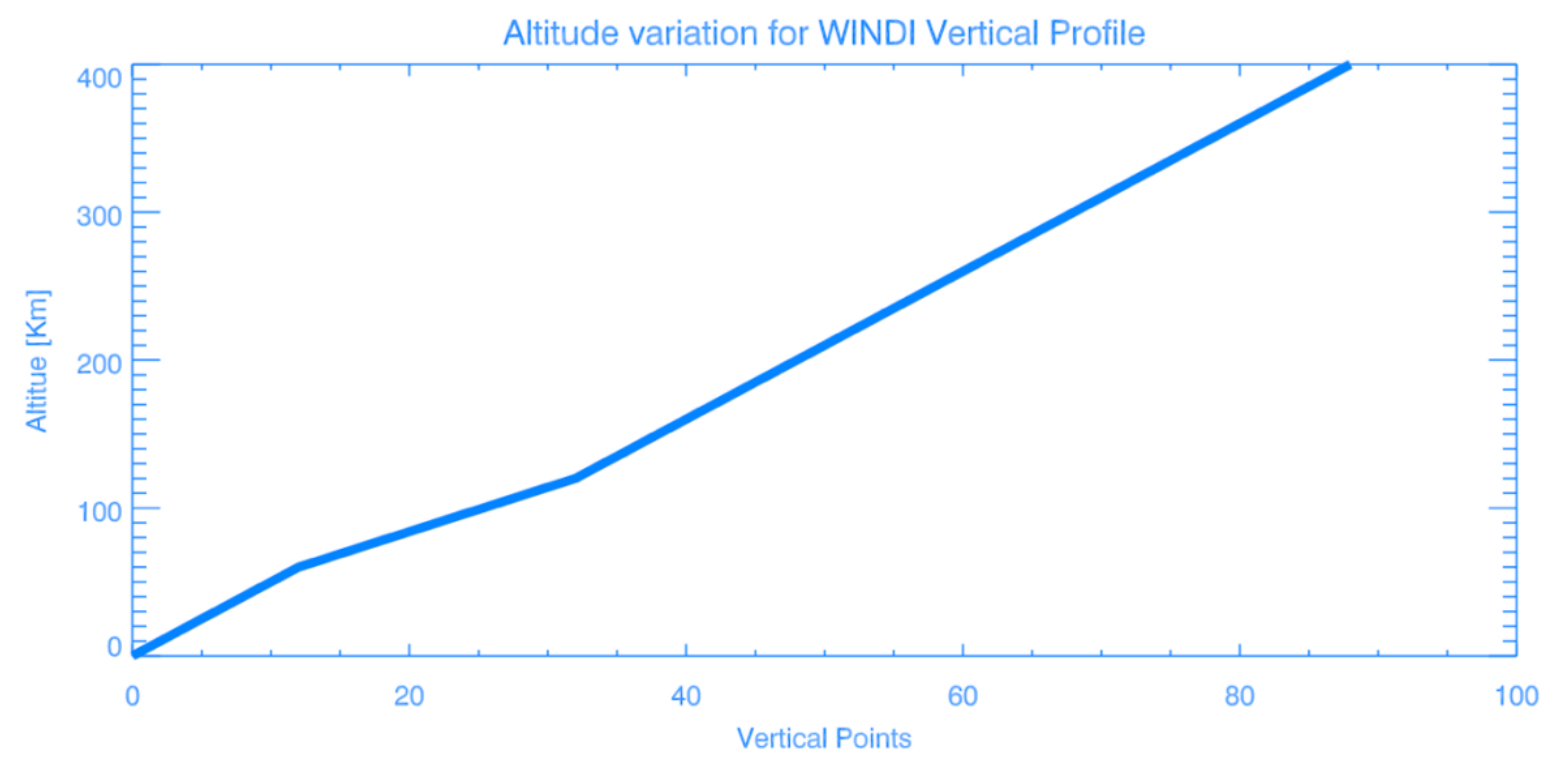

Figure 44 Altitude variation for WINDII Vertical Profile.

This altitude is for Red line airglow. The red line emission at $630 \mathrm{~nm}$ from the $\mathrm{O}(\mathrm{1D})$ level of atomic oxygen in the thermosphere varies in altitude between 100 and $400 \mathrm{~km}$.

Latitude and Longitude:

WINDII data files do not contain the spacecraft location. To get this information we use data from https://acdisc.gesdisc.eosdis.nasa.gov, which provides the spacecraft location at time intervals of 65.536 seconds, or about $495 \mathrm{~km}$ intervals along the LOS tangent track. We then interpolate these onto the times of the WINDII data to give us a good estimate of where the spacecraft was when the data were taken.

WINDII data in Latitude and Local Time

The figures below show the locations where the WINDII data exist for 1992 day 015. 
Latitude variation with Local time

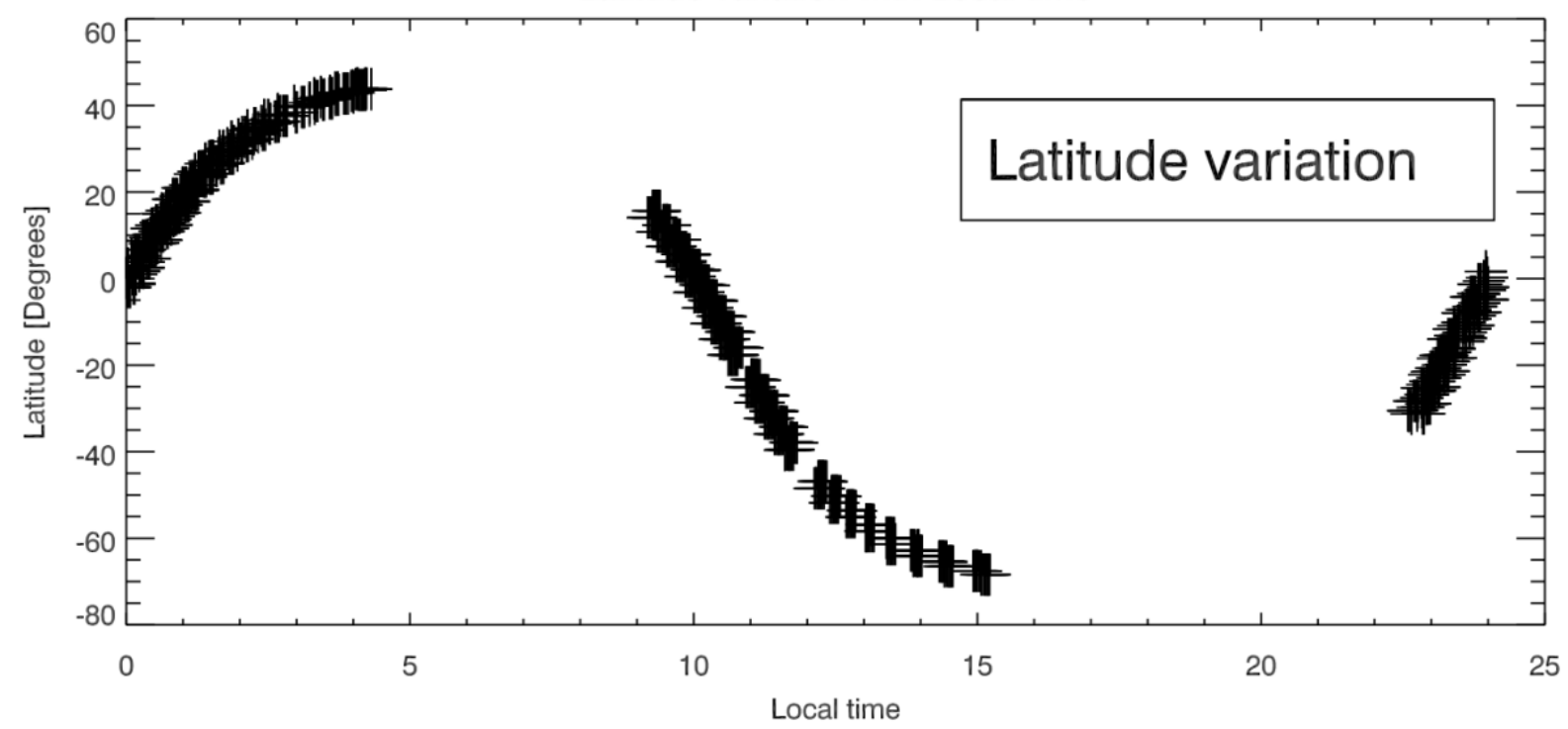

Figure 45 WINDII Latitude variation with Local time - for Year 1992 Day 015.

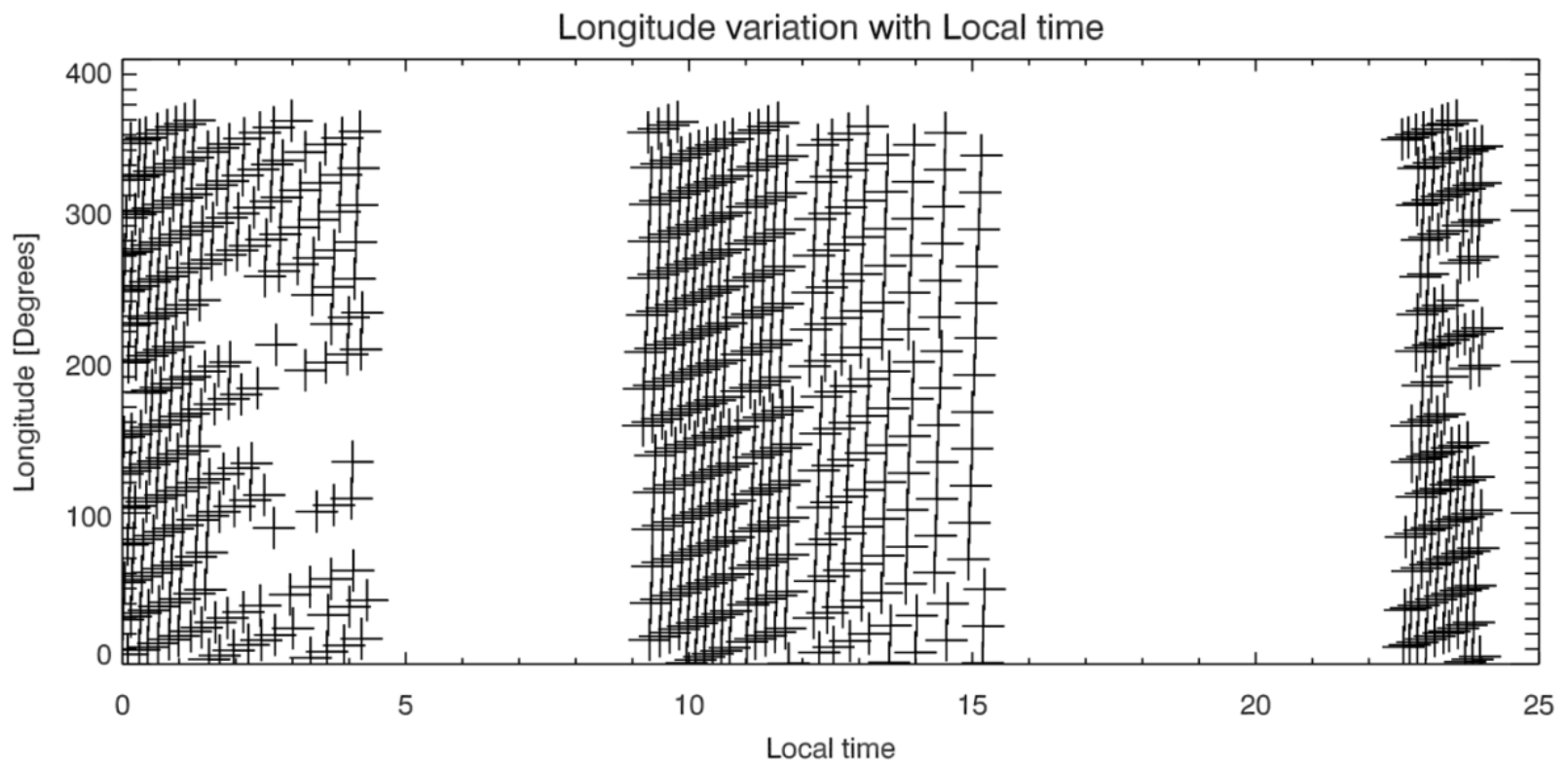

Figure 46 WINDII Longitude variation with Local time- for Year 1992 Day 015.

For both the plots the empty spaces mean the time interval of the instrument taking the data or the times there is no data. Please note, we can see we don't have any data near sunrise or sunset, which is where Harding et al expected the largest asymmetry. We do, however, have plenty of data at low to mid latitudes in both day and nighttime. 


\section{Zonal and Meridian Wind:}

For the day in 1992, day 015,from WINDII we have vertical profiles of wind (meridional and zonal components) are also saved in an array size of $[89,686]$ ( https://sscweb.gsfc.nasa.gov). This array represents the 89 vertical points 686 times.

\begin{tabular}{|l|l|l|l|}
\hline Subtype & DAAC Parameter Name & Units & Range \\
\hline MERWIN_A & MERIDIONAL WIND, ALTITUDE GRID & $\mathrm{m} / \mathrm{s}$ & -200 to +200 \\
\hline ZONWIN_A & ZONAL WIND, ALTITUDE GRID & $\mathrm{m} / \mathrm{s}$ & -200 to +200 \\
\hline
\end{tabular}

\section{Spacecraft Location:}

We will need the Spacecraft positions (X, Y, Z) in ECEF coordinate system to calculate vertical profile of view directions (unit vectors) for each vertical pixel (from 180 to $300 \mathrm{~km}$ for red). We have collected the locations of the spacecraft for the particular Day of the Year (1992 Year 015 Day) in (X, Y,Z ) in ECEF coordinate system from (https://spdf.gsfc.nasa.gov/) for UARS (Upper Atmosphere Research Satellite (UARS)).

From that particular day data we have 1440 points (Time, X, Y, Z, Latitude, Longitude,Altitude).

\section{Ray Geometry:}

Using spacecraft location and our altitude for Redline, the wind locations we get the ray geometry. Once we have the view directions, we will compute LOS rays along each view direction at all steps out to $6860 \mathrm{~km}$ along each ray (all 48), in ECEF and lat-lon-alt. This should be an array of about $48 \times 3 \times 686$ (where 3 is x, y, z or latitude, longitude, altitude, and 686 is the steps along the ray). This is exactly the same process as for MIGHTI discussed in Chapter 2. One example is shown below.

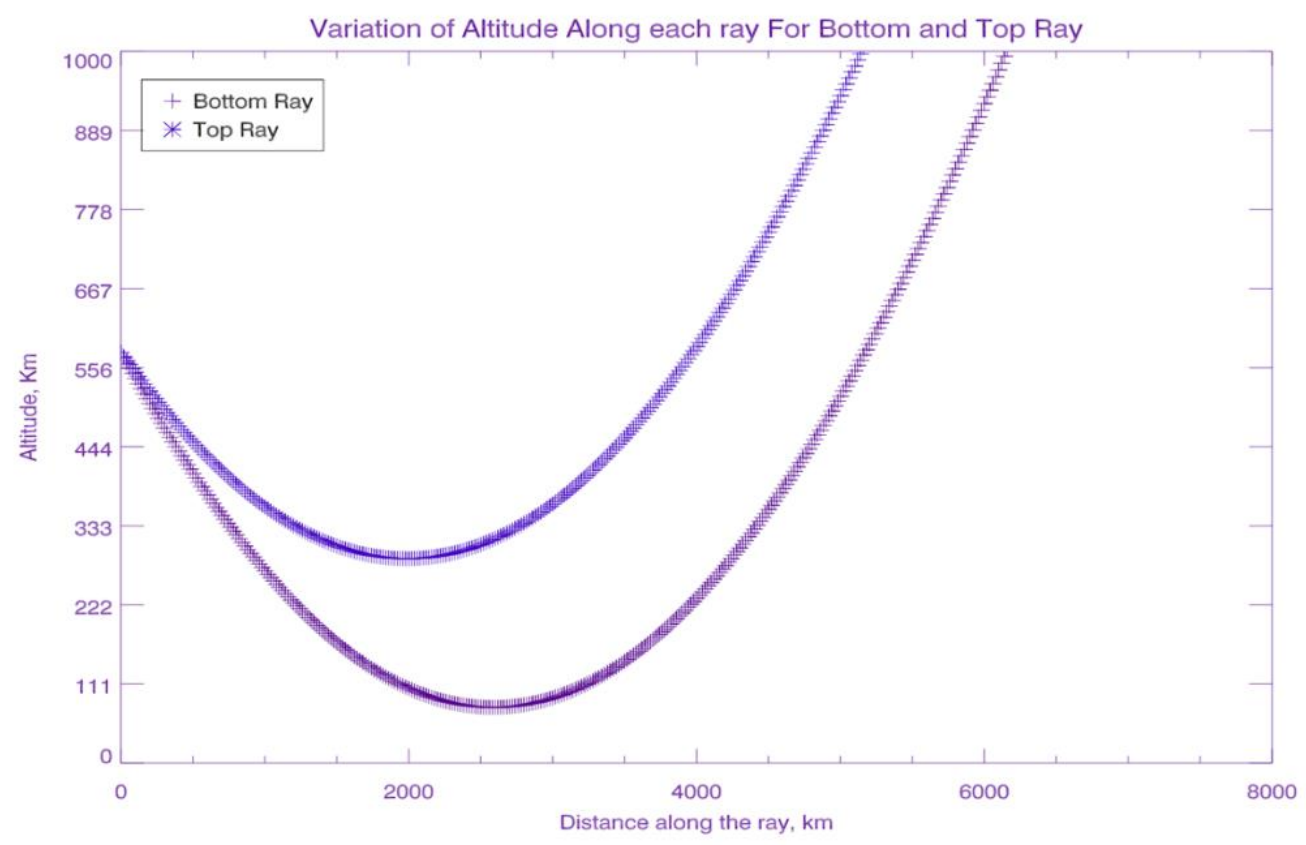

Figure 47 Altitude variation for Top and Bottom Rays - from Year 1992 Day 015. 


\section{TIEGCM data Interpolation:}

We have run the TIEGCM for 1992, Day 015, using the conditions present on that day (solar F10.7 etc.). We know that WINDII [89 (Altitude),686 (Times)] and TIEGCM [144 (Longitude), 72(Latitude), 57(Altitude), 24(Hour)] data set are different, to be able to use the same approach and methods they must have the dimension. We will interpolate the TIEGCM data set to fit into the WINDII grid to allow a 1:1 comparison.

\section{Results}

We will begin this section by comparing the WINDII data sets with TIEGCM model and textbook (from "Physics of the Earth's Space Environment”- Prölss 2004).

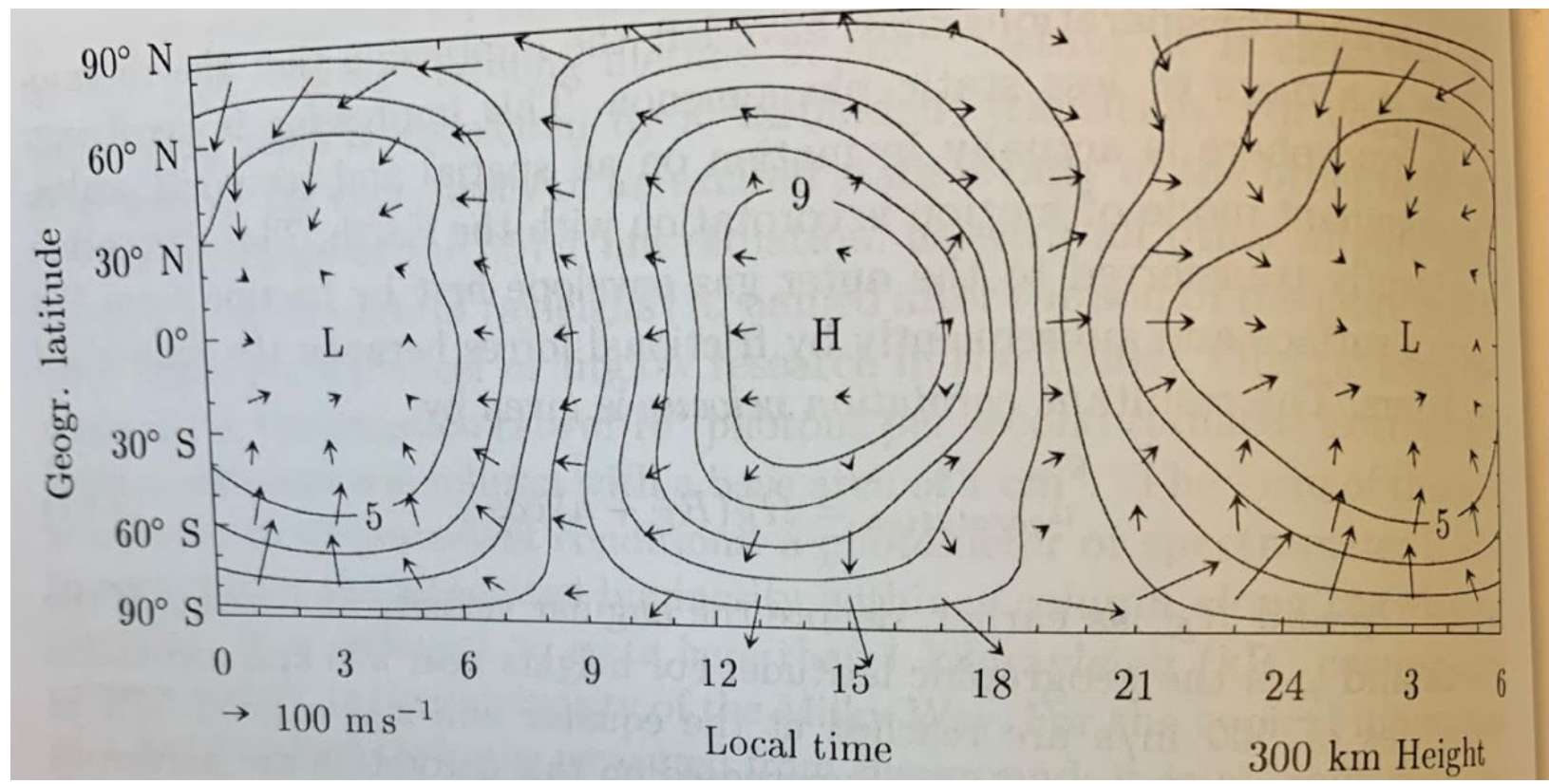


Figure 48 Global pressure and wind distribution for an altitude of $300 \mathrm{~km}$ during the spring equinox (21 march). The distribution was computed for the time12 UT, moderate solar activity ( $\mathrm{CI}=100)$ and week geomagnetic activity $(\mathrm{Kp}=2)$. The contours are lines of const ant pressure (isobar). The highest plotted pressure of the high-pressure region $(\mathrm{H})$ corresponds to a value of $9 \mu \mathrm{Pa}$; the lowest level of the lowpressure region (L) to a value of $5 \mu \mathrm{Pa}$. The difference between isobars drawn away from the point in question. The wind speed scale is shown below the models MSIS 86 (Hedin, 1987) and HWM 93 (Hedin 1996). Figure taken from "Physics of the Earth’s Space Environment"- Prölss 2004.

Figure 50 taken from "Physics of the Earth's Space Environment"- Prölss 2004 shows the global pressure and East and North wind distribution for an altitude of $300 \mathrm{~km}$ during the spring equinox with Local Time.

\subsection{Eastward wind comparison:}

Here we will compare WINDII eastward winds with TIEGCM model eastward winds at the equator. From TIEGCM wind color contour plot we can see at midnight the wind speed is eastward and around [ +10 , to $+15 \mathrm{~ms}-1]$. However, at noon, the wind is northward and ranges from $[-50$, to $-65 \mathrm{~ms}-1]$.

Again, at the before midnight the wind is eastward and varies from around [+12, to $+23 \mathrm{~ms}-1]$.

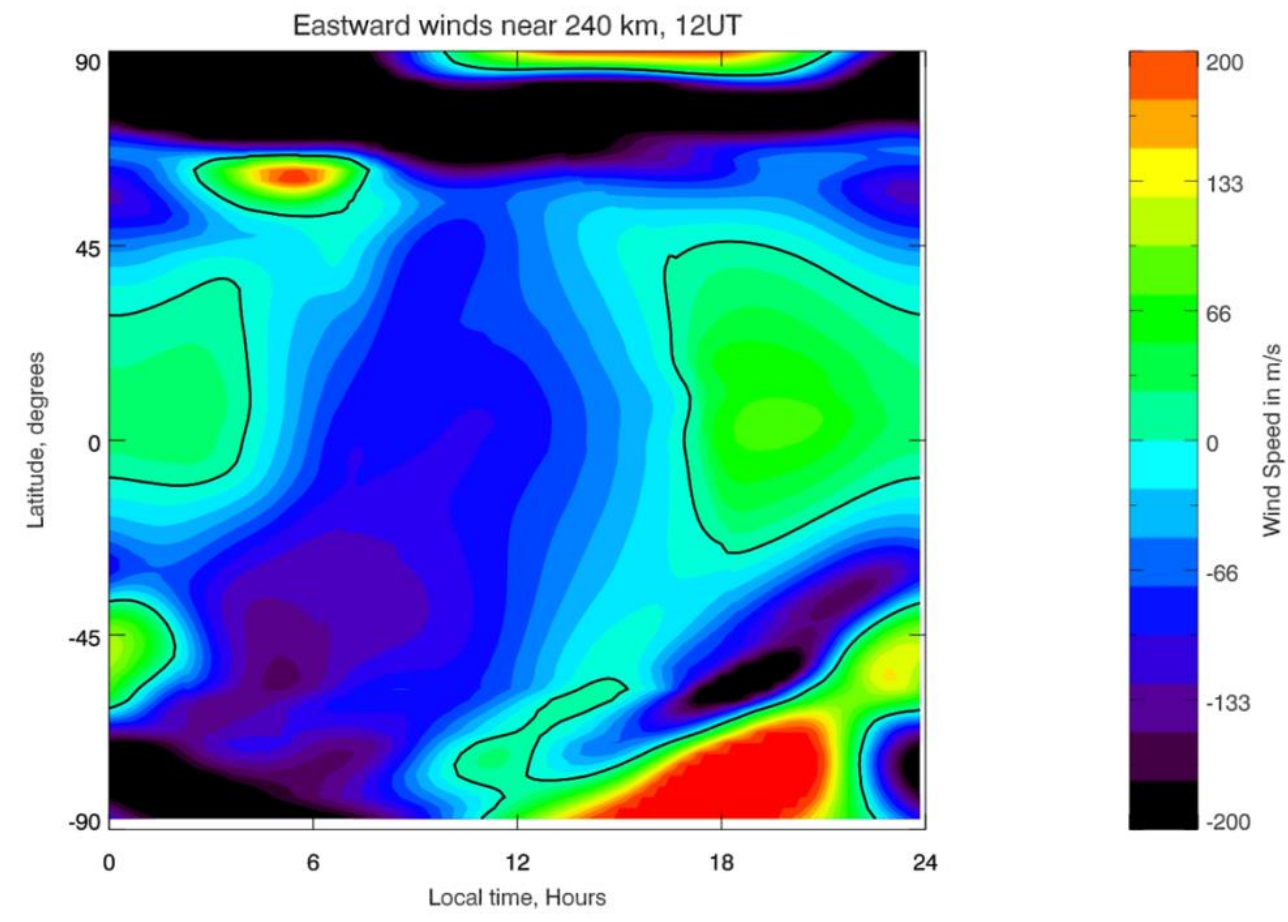



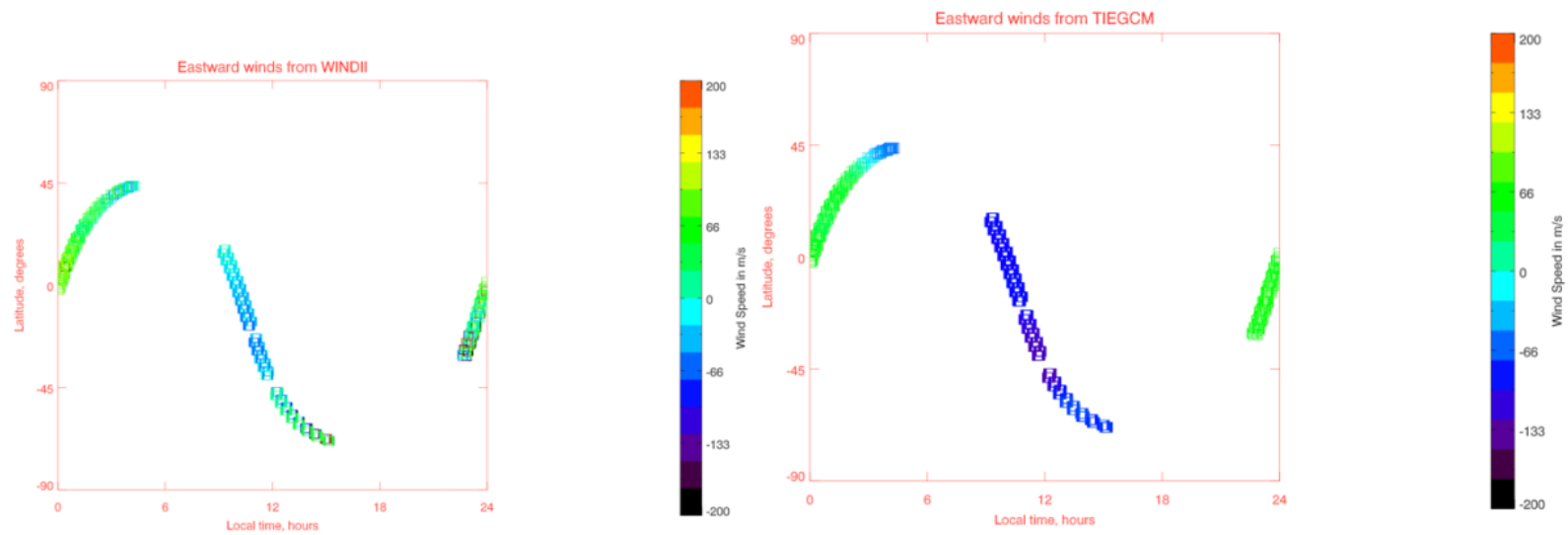

Figure 49 Comparison of Eastward wind between TIEGCM model and WINDII for an altitude of near $240 \mathrm{~km}$ at 12 Universal time.

Similarly, for the eastward winds from WINDII shows at midnight the wind speed is eastward and around [ +10 , to $+15 \mathrm{~ms}-1]$. At noon the wind is westward and ranges from [ -35 to $-45 \mathrm{~ms}-1]$.

At the before midnight the wind is eastward and around [+12, to $+23 \mathrm{~ms}-1]$. So, we can conclude that the WINDII eastward wind patterns matches both the TIEGCM model and textbook eastward wind patterns.

\subsection{Northward wind comparison:}

Here we will compare WINDII northward winds with TIEGCM model northward winds at the equator. From TIEGCM wind color contour plot we can see at midnight the wind speed is northward and around [ +10 , to $+15 \mathrm{~ms}-1]$. However, at noon the wind is going northward to eastward and ranges from ranges from [+10, to $-15 \mathrm{~ms}-1]$. Again, at the before midnight the wind is northward and varies from around [+12, to $+23 \mathrm{~ms}-1]$. 

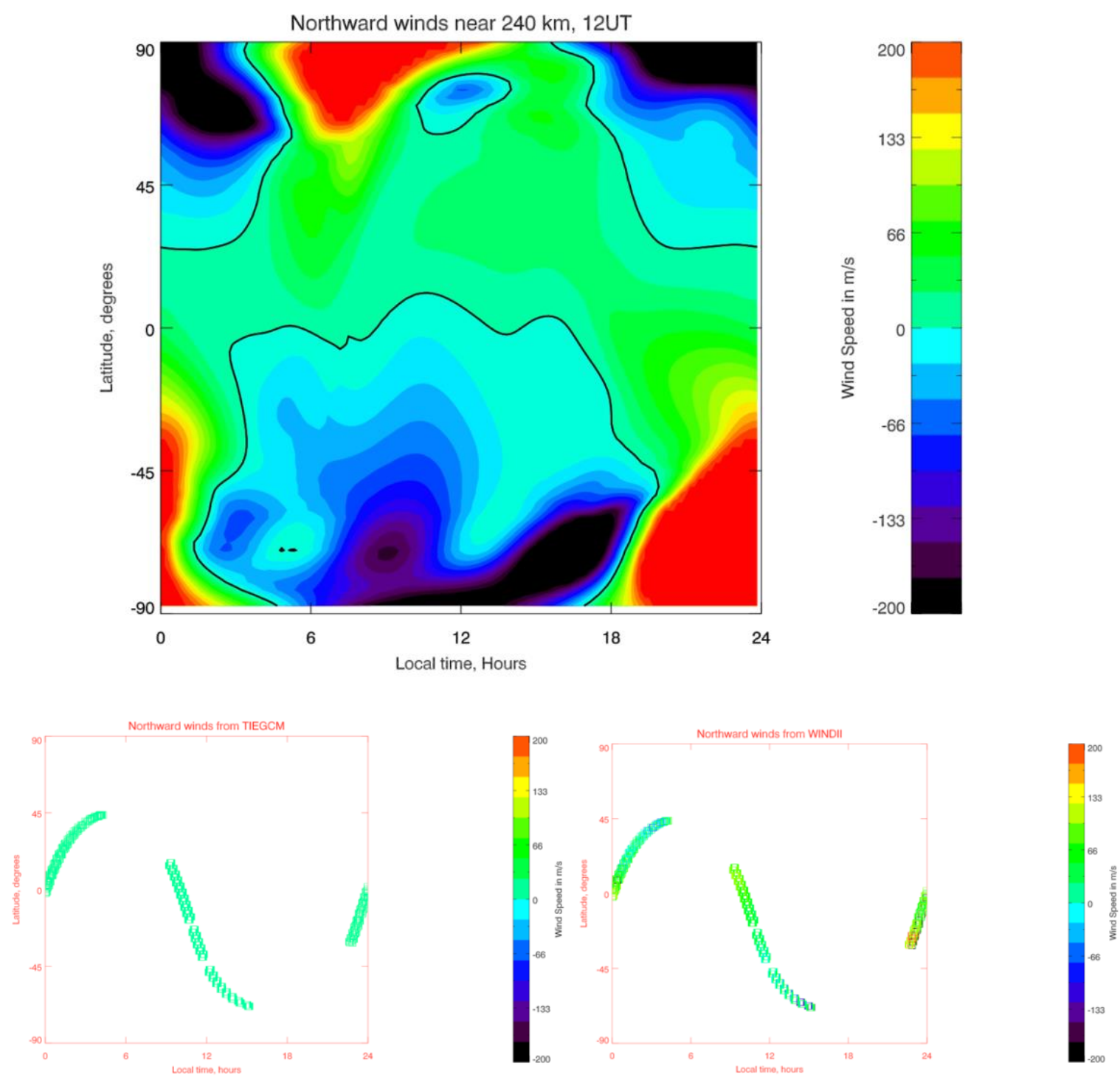

Figure 50 Comparison of Eastward wind between TIEGCM model and WINDII for an altitude of near $240 \mathrm{~km}$ at 12 Universal time.

Similarly, for the northward winds from WINDII shows at midnight the wind speed is northward and around [ +10 , to $+15 \mathrm{~ms}-1]$. At noon the wind is going from northward to eastward and ranges from $[+10$, to $-15 \mathrm{~ms}-1]$. Again, at the before midnight the wind is northward and ranges from around [+12 to $+23 \mathrm{~ms}-1]$. So, we can conclude that the WINDII northward wind patterns matches both the TIEGCM model and textbook northward wind patterns.

\subsection{Mean of WINDII and TIEGCM east and north winds:}




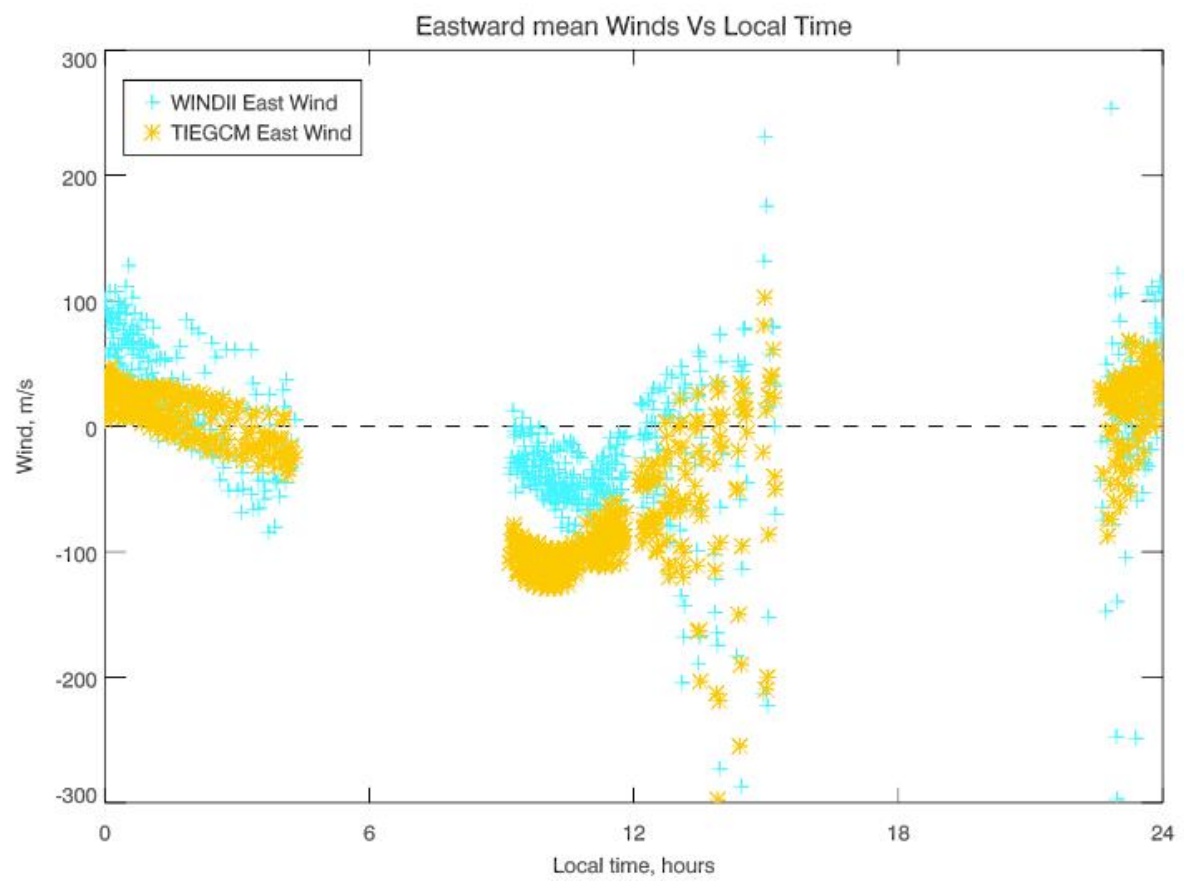

Figure 51 Eastward Mean Winds Vs Local Time.

Figure 53 shows the eastward mean winds vs local time where the blue points represent WINDII east mean winds and the yellow points TIEGCM east mean winds, we can see that there is visible similarity. The best match of the TIEGCM model east mean winds is seen, at night-time with the WINDII east mean winds. However, at nighttime the WINDII east winds are more spread compared to TIEGCM east winds, otherwise we can say the standard deviation of the WINDII east winds are higher than the TIEGCM east winds. There is a visible pattern in the night-time east winds, after midnight we see the east winds varies from positive to negative, for the WINDII east mean winds move from positive to negative (i.e. $+110 \mathrm{~ms}-1$ to $-90 \mathrm{~ms}-1$ ), for the TIEGCM east mean winds move from positive to negative (i.e. $+60 \mathrm{~ms}-1$ to $-40 \mathrm{~ms}-1$ ).

In the Day-time both WINDII and TIEGCM east mean winds are mostly negative with WINDII east mean winds vary from around [ $-90 \mathrm{~ms}-1$ to $+100 \mathrm{~ms}-1]$ and TIEGCM east mean winds vary from around [-120 ms-1 to $+80 \mathrm{~ms}-1]$, again there is a clear similarity in the winds pattern between them. However, winds in the afternoon are more spread than the winds in the noon, otherwise we can say the standard deviation of the east winds are higher in the afternoon than the east winds at noon. 


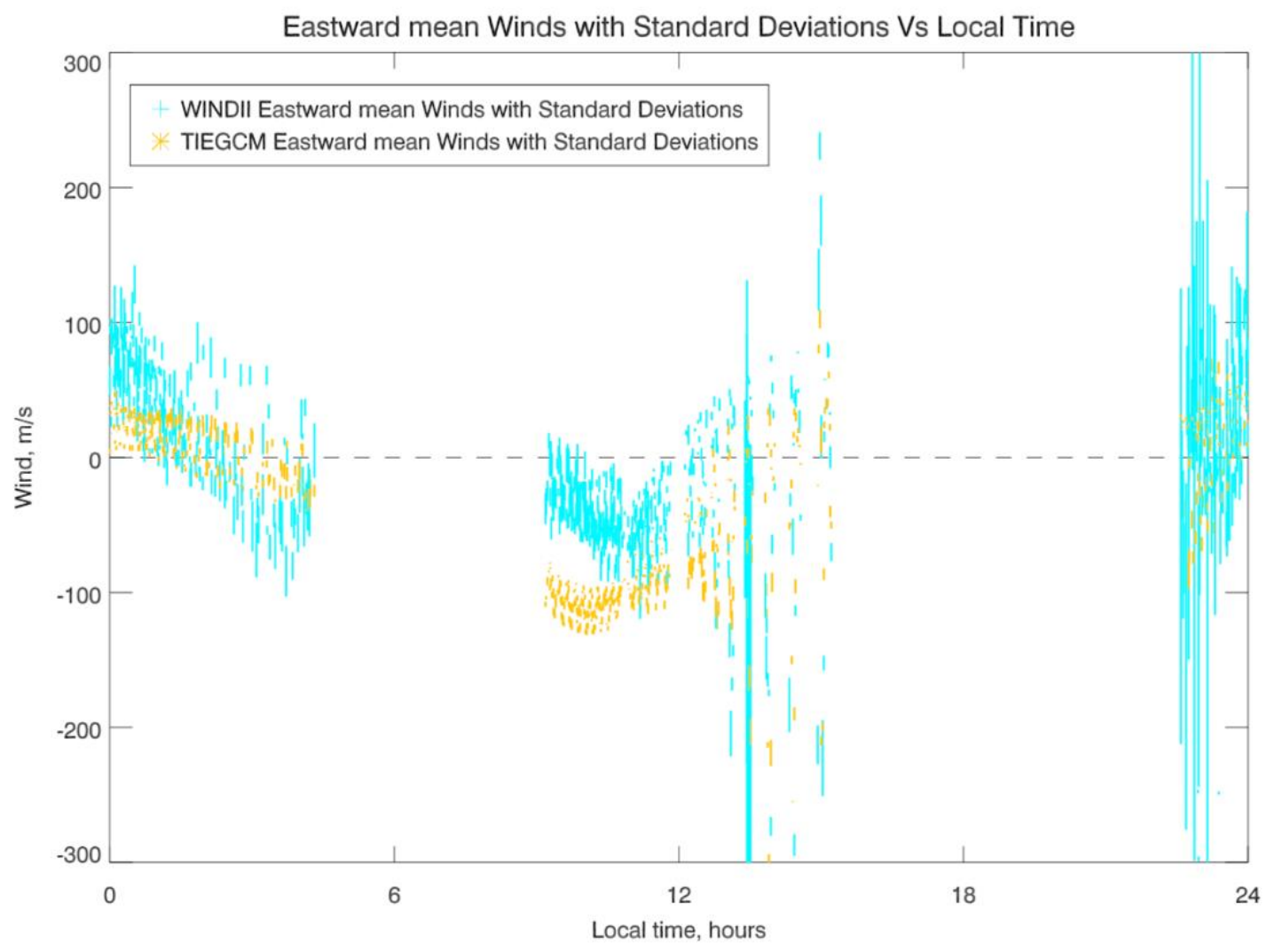

Figure 52 Eastward mean winds with Standard Deviation Vs Local Time.

Figure 54 shows the eastward mean winds with standard deviation vs local time where the blue points represent WINDII east mean winds with standard deviation and the yellow points TIEGCM east mean winds with standard deviation, we can see that there is no visible similarity and further the standard deviation of the WINDII eastward mean winds are bigger compared to the TIEGCM eastward mean winds both in Daytime and Nighttime. 


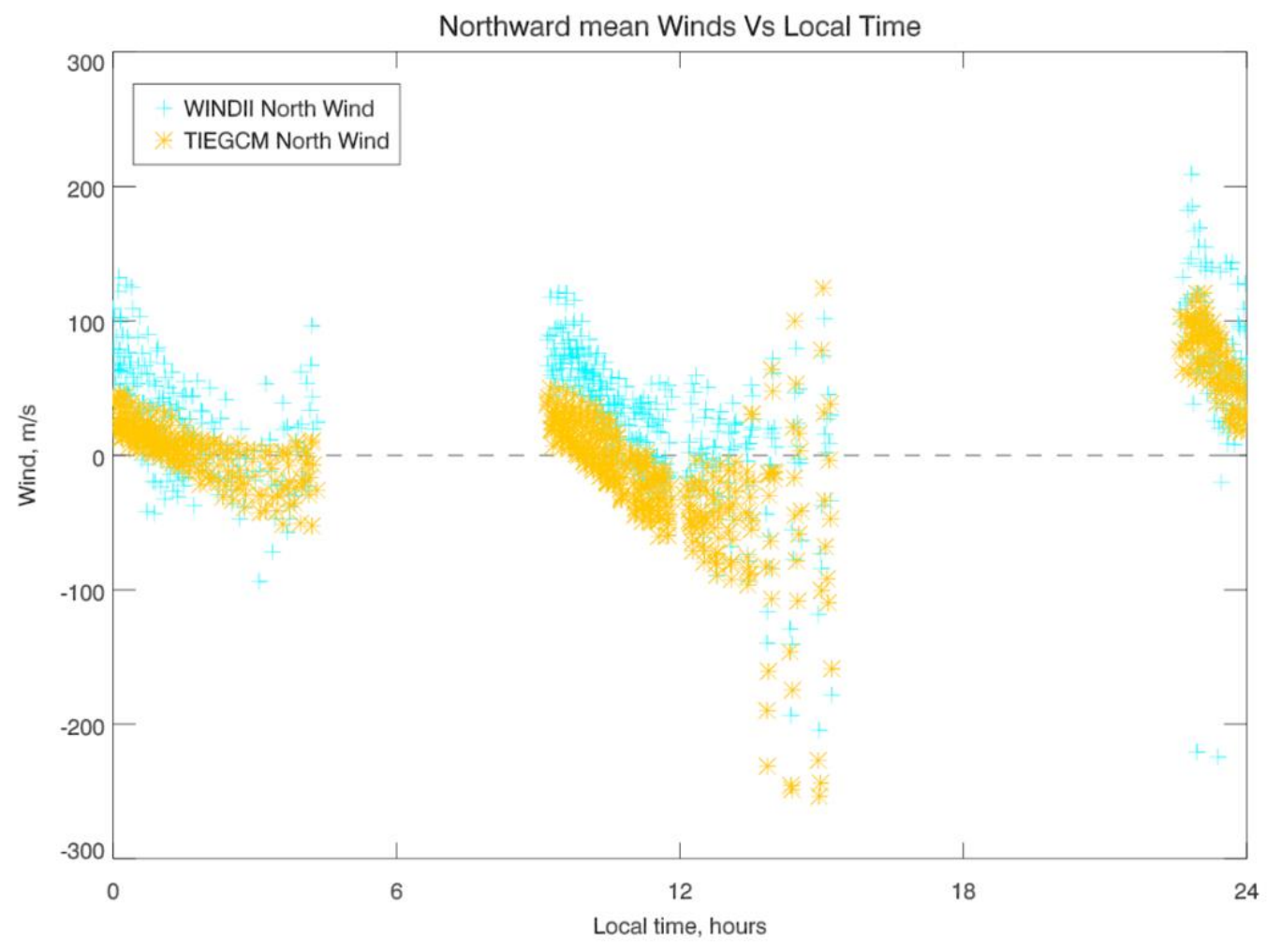

Figure 53 Northward Mean Winds Vs Local Time.

Figure 55 shows the Northward mean winds vs local time where the blue points represent WINDII north mean winds and the yellow points TIEGCM north mean winds, we can see that there is visible similarity. The best match of the TIEGCM model north mean winds is seen, at night-time with the WINDII north mean winds. However, at nighttime the WINDII north winds are more spread compared to TIEGCM north winds, otherwise we can say the standard deviation of the WINDII north winds are higher than the TIEGCM north winds. There is a visible pattern in the night-time north winds, after midnight we see the north winds varies from positive to negative, for the WINDII north mean winds move from positive to negative (i.e. $+120 \mathrm{~ms}-1$ to $-80 \mathrm{~ms}-1$ ), for the TIEGCM north mean winds move from positive to negative (i.e. $+40 \mathrm{~ms}-1$ to $-50 \mathrm{~ms}-1$ ).

In the Daytime both winds vary from positive to negative, for the WINDII north mean winds move from positive to negative (i.e. $+130 \mathrm{~ms}-1$ to $-110 \mathrm{~ms}-1$ ), for the TIEGCM north mean winds move from positive to negative (i.e. $+50 \mathrm{~ms}-1$ to $-90 \mathrm{~ms}-1$ ). However, winds in the afternoon are more spread than the winds in the noon, otherwise we can say the standard deviation of the north winds are higher at the afternoon than the north winds at the noon. 


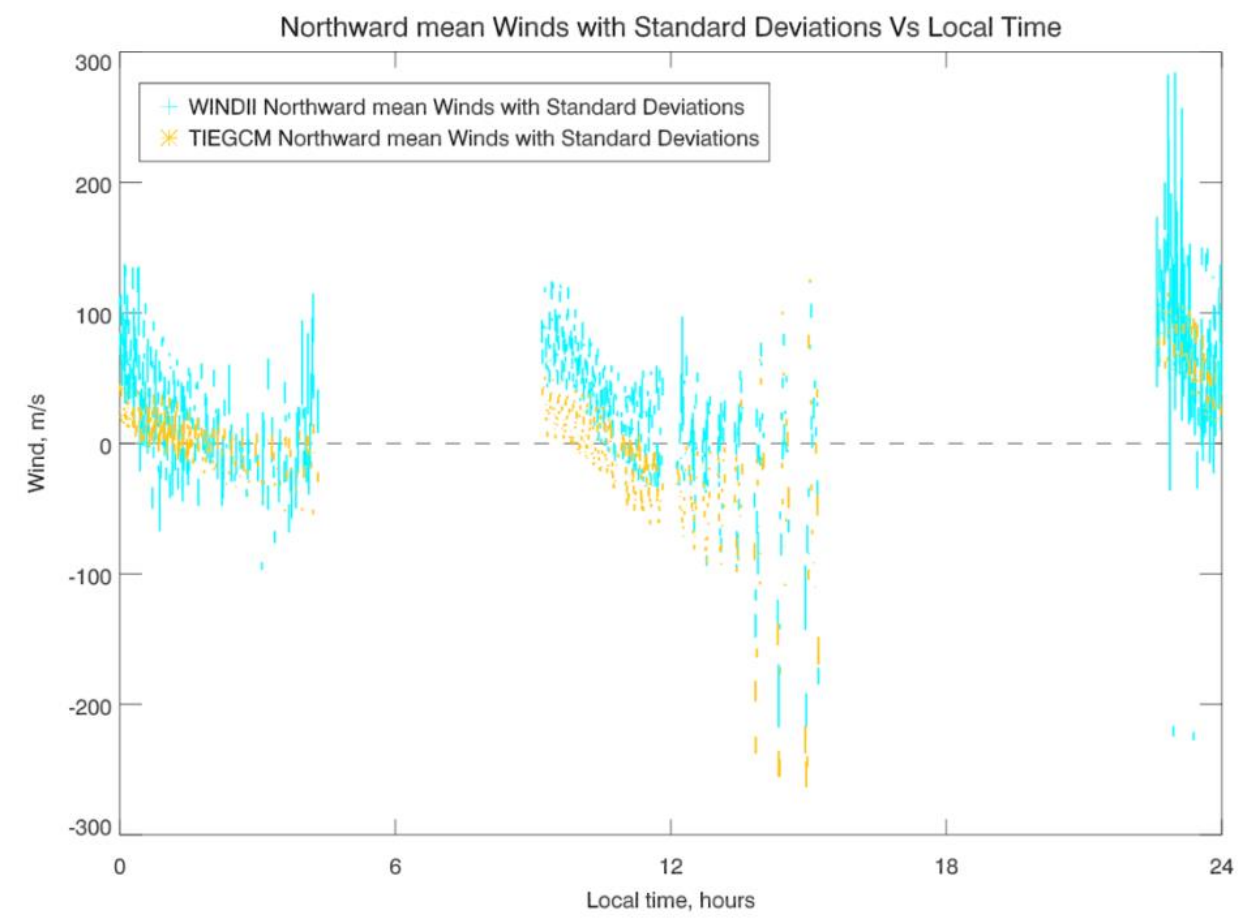

Figure 54 Northward mean winds with standard deviations Vs Local Time.

Figure 56 shows the northward mean winds with standard deviation vs local time where the blue points represent WINDII east mean winds with standard deviation and the yellow points TIEGCM east mean winds with standard deviation. We can see from the figure that there is no visible similarity. However, compared to eastward mean winds WINDII northward mean winds standard deviation is less and shows better agreement to the TIEGCM northward mean winds both in Day and Nighttime. 


\subsection{Mean East and North wind comparison with Latitude:}

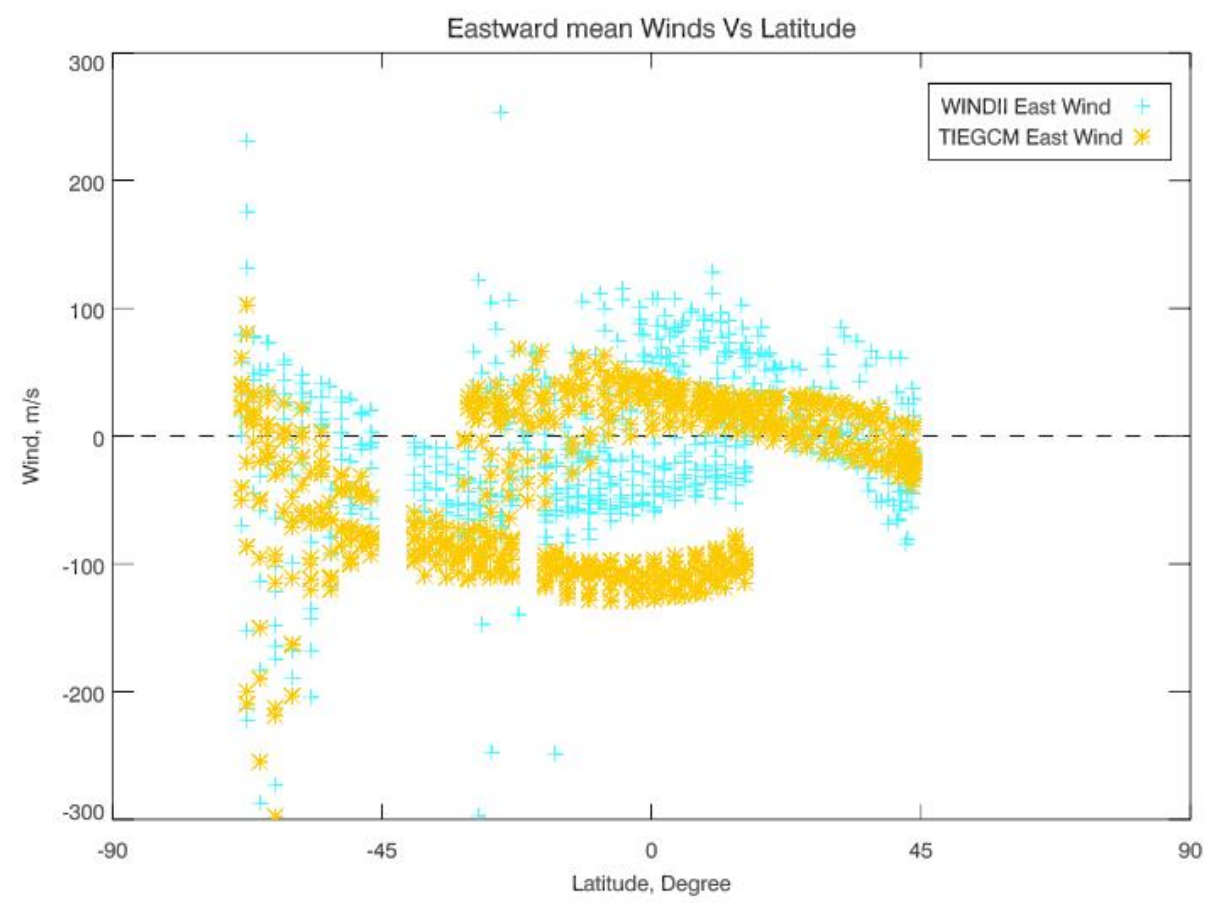

Figure 55 Eastward Mean Winds Vs Latitude.

Figure 57 shows the eastward mean winds vs Latitude where the blue points represent WINDII east mean winds and the yellow points TIEGCM east mean winds, we can see that there is no visible similarity, where most of the TIEGCM model east mean winds have negative values that vary from around [-210 ms-1 to $40 \mathrm{~ms}-1]$, in contrast to the WINDII east mean winds have both negative and positive values that vary from around [+110 ms-1 to $-50 \mathrm{~ms}-1]$. At low-mid-high latitudes WINDII mean winds have both positive and negative values where TIEGCM model east mean winds have negative values and again there is no similarity between them. 


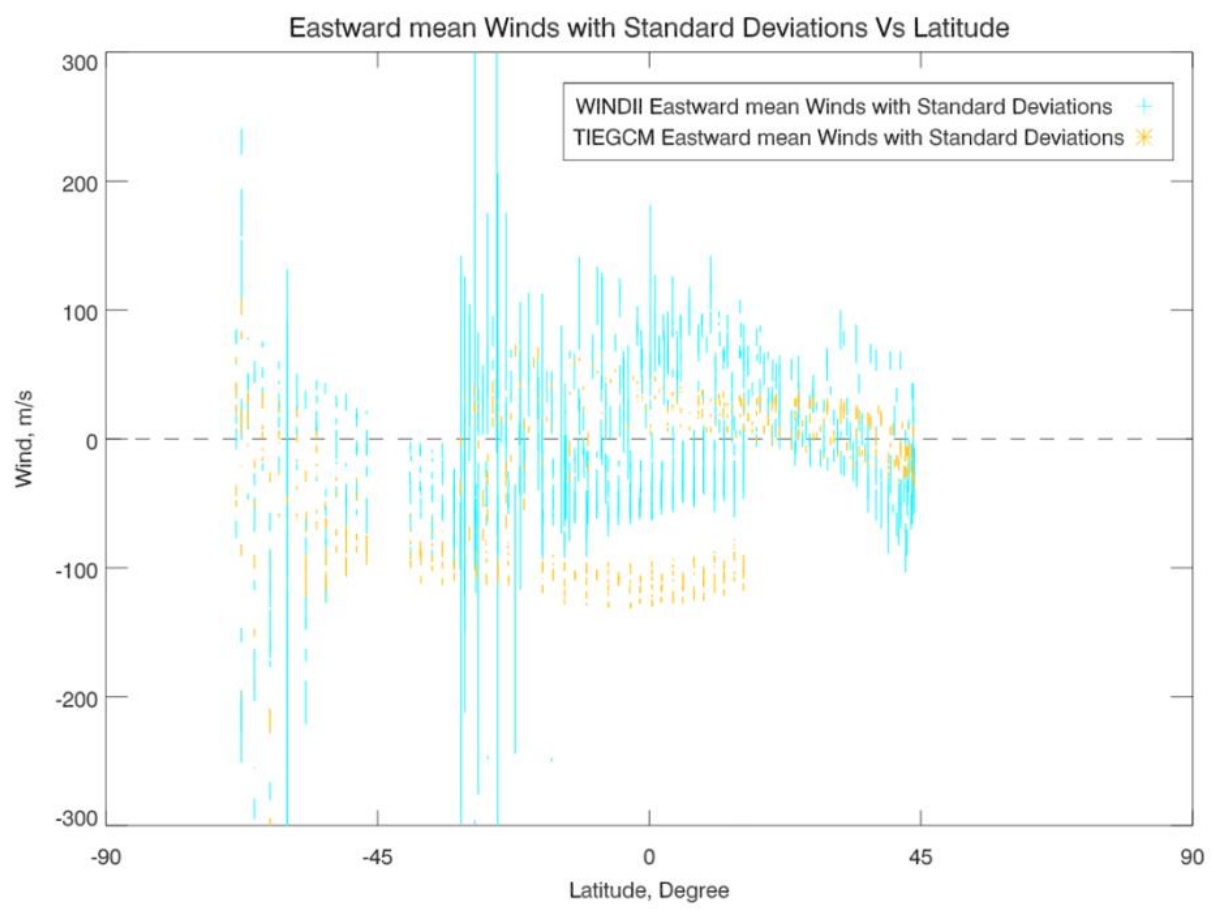

Figure 56 Eastward mean winds with standard deviations Vs Latitude.

Figure 58 shows the eastward mean winds with standard deviation vs Latitude where the blue points represent WINDII east mean winds with standard deviation and the yellow points TIEGCM east mean winds with standard deviation. We can see that there is no visible similarity and further the standard deviation of the WINDII eastward mean winds is bigger compared to the TIEGCM eastward mean winds at all (low-mid-high) latitudes. 


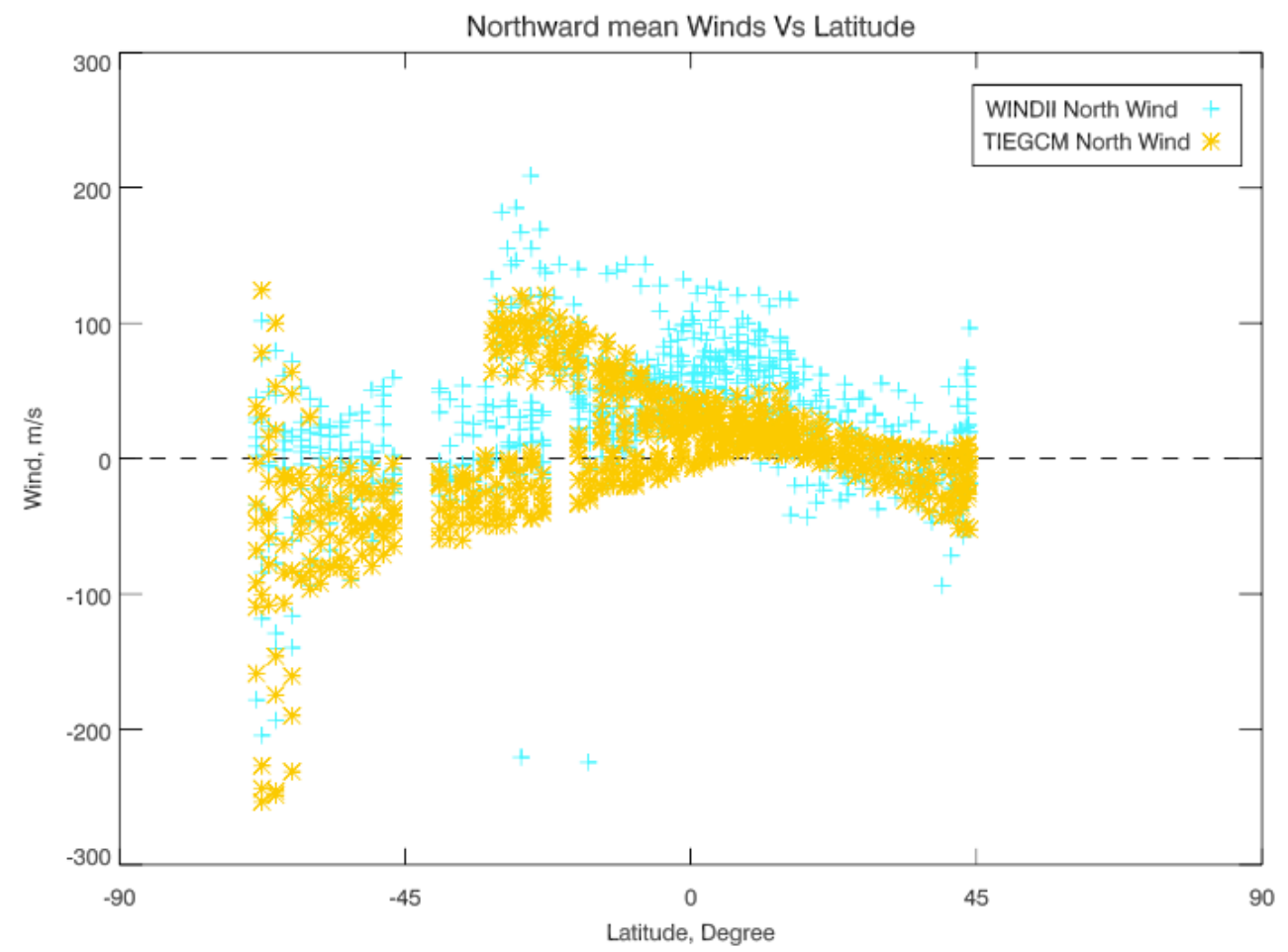

Figure 57 Northward mean winds Vs Latitude.

Figure 59 shows the northward mean winds vs Latitude where the blue points represent WINDII north mean winds and the yellow points TIEGCM north mean winds. From the figure it is clear that at low latitude WINDII north mean winds have a visible similarity though direction of the WINDII and TIEGCM north mean winds are different. WINDII north mean winds move from positive to negative where the TIEGCM north mean winds move from negative to positive. At high latitude WINDII and TIEGCM north mean winds show a similar pattern both move from positive from negative. Overall, we can state that WINDII northward mean winds agree more with TIEGCM northward mean winds compared to eastward mean winds. 




Figure 58 Northward mean Winds with Standard Deviations Vs Latitude.

Figure 60 shows the northward mean winds with standard deviation vs Latitude where the blue points represent WINDII north mean winds with standard deviation and the yellow points TIEGCM north mean winds with standard deviation. We can see from the figure that there is no visible similarity. However, compared to eastward mean winds WINDII northward mean winds standard deviation is less and shows better agreement to the TIEGCM northward mean winds at all (low-mid-high) latitudes. 


\subsection{Distribution of Asymmetry:}

In this section we will calculate the asymmetry along each ray as discussed in chapter 2 . Though we know from (Harding et al., 2017) there is a lot of asymmetry at night rather than at day and the greatest asymmetry at sunset and sunrise, due to no data at sunset and sunrise we will only calculate asymmetry at some other local times. We will also have a detailed look at one ray, and the variation of the altitude, latitude, longitude along the ray. This will help us understand how we calculated asymmetry along each ray.

\section{Variation Along the Ray:}

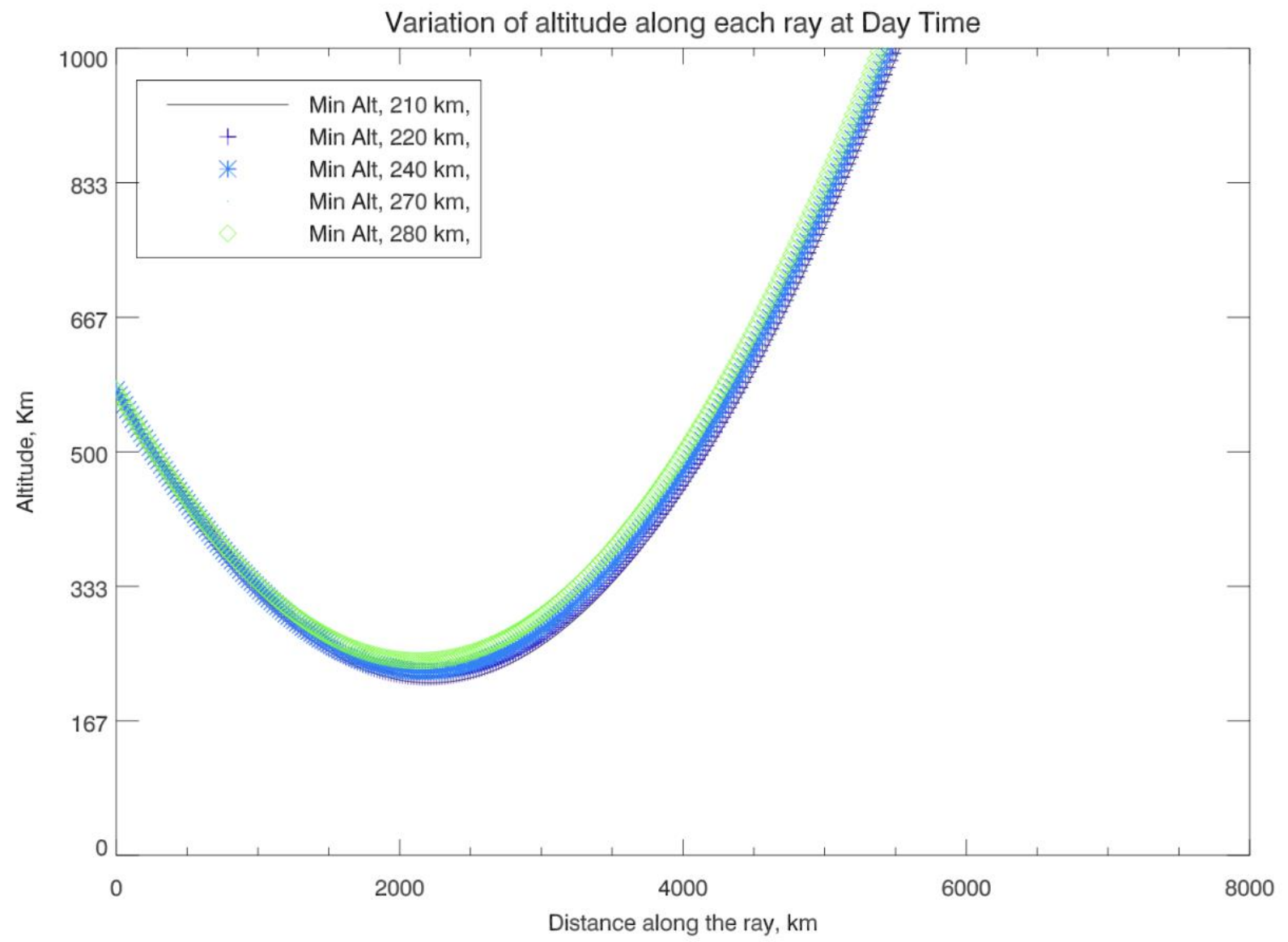

Figure 59 Variation of altitude along each ray at Day Time.

Figure 61 shows the variation of altitude along each ray. We have shown only the 5 rays along the rays for the simplification of our understanding, and their minimum altitude or tangent point are $210,220,240,270,280$ respectively. Each ray covers a distance of $7000 \mathrm{~km}(20 \mathrm{X} 350=7000 \mathrm{~km}$, $20 \mathrm{~km}$ each step and we ran for 350 steps). 


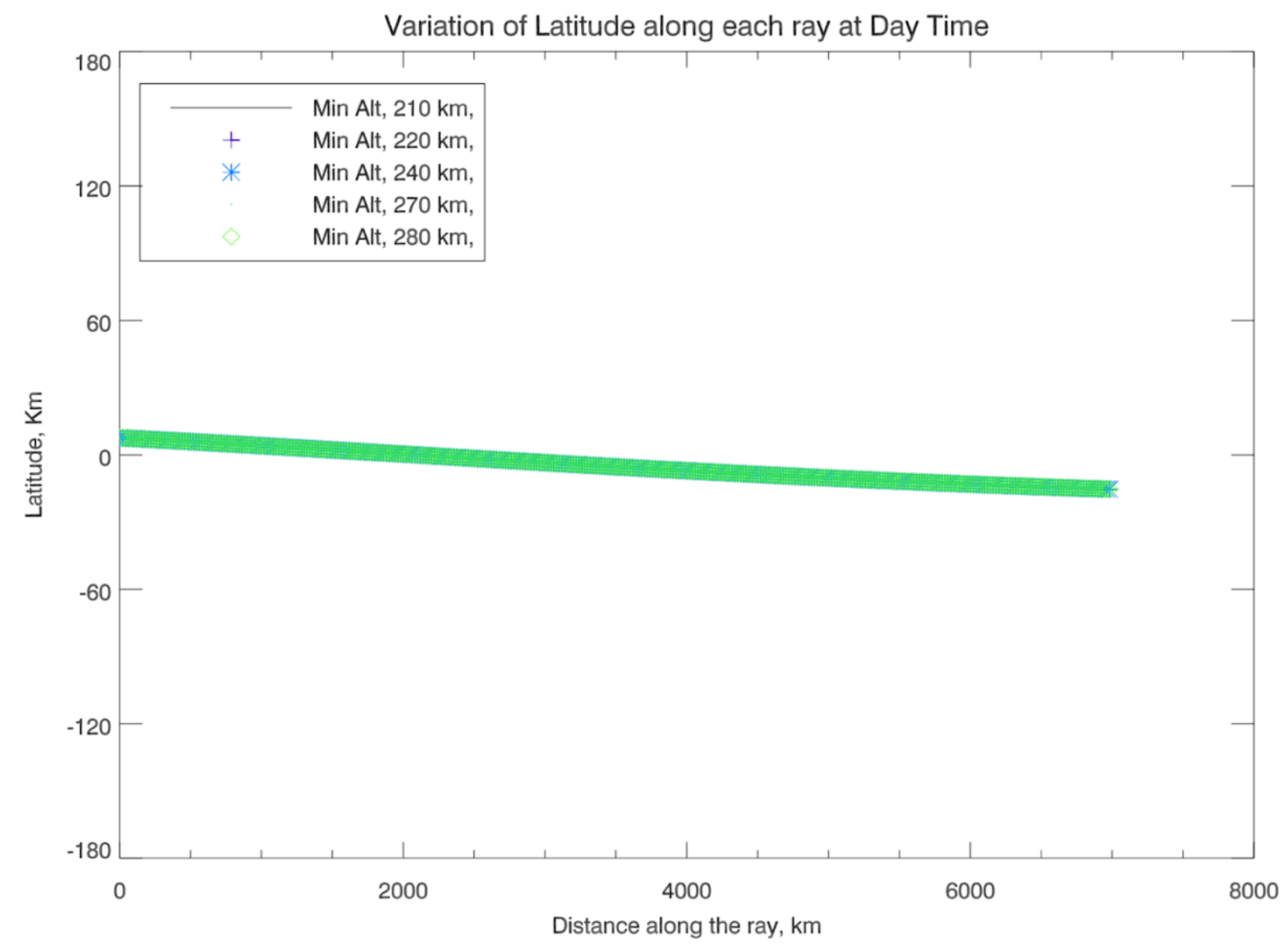

Figure 60 Variation of latitude along each ray at Day Time.

Figure 62 shows the variation of latitude along each ray. We have shown only the 5 rays along the rays for the simplification of our understanding, and their minimum altitude or tangent point are $210,220,240,270,280$ respectively. However, the change in latitude is hard to see in the figure and varies from [ $10 \mathrm{o}$ to $-20 \mathrm{o}$. 


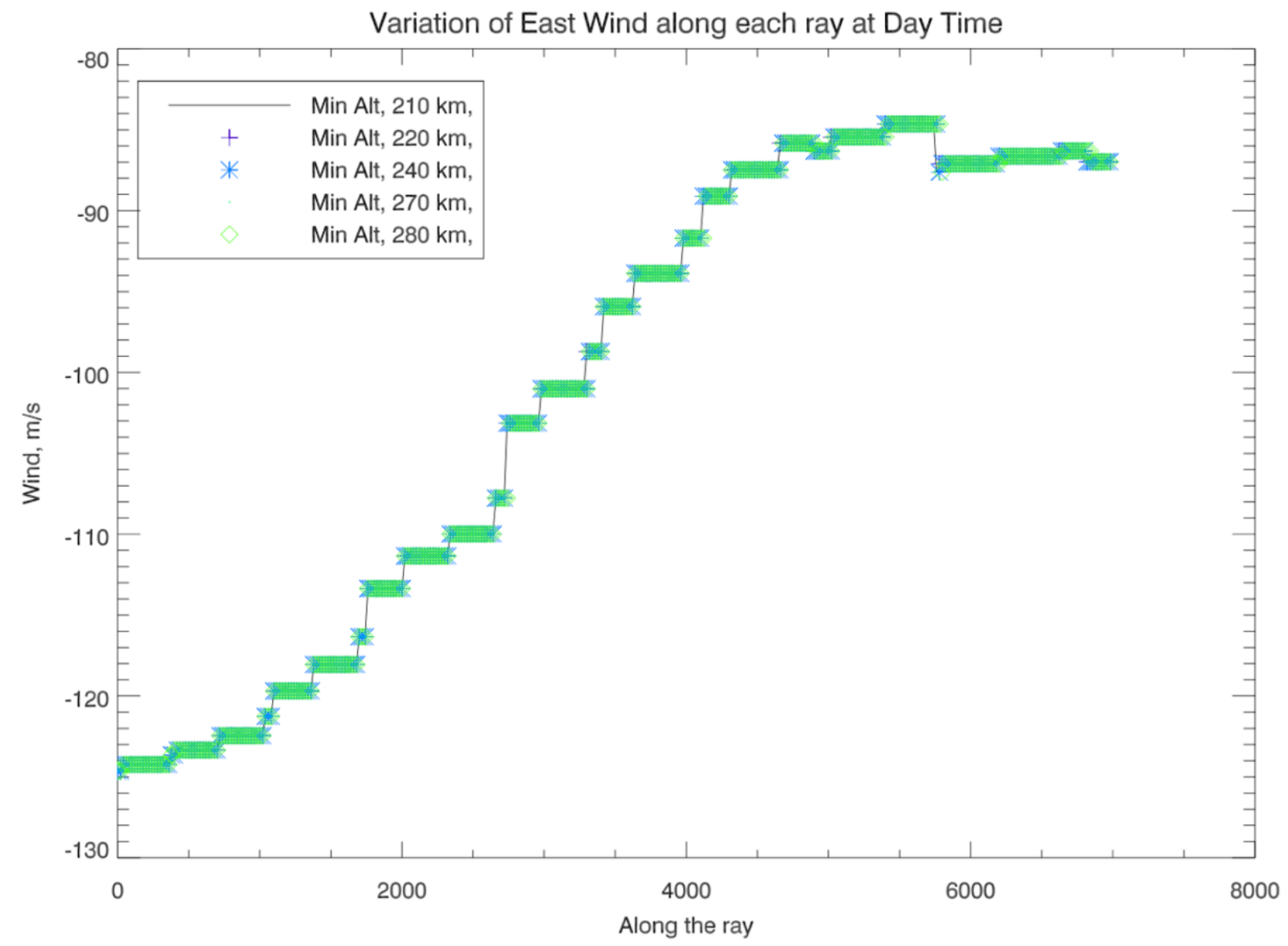

Figure 61 Variation of East Wind along each ray at Day Time.

Figure 63 shows the variation of east wind along each ray. We have shown only the 5 rays along the rays for the simplification of our understanding, and their minimum altitude or tangent point are $210,220,240,270,280$ respectively. However, the change in east wind is hard to see in the figure and varies from $[-124 \mathrm{o}$ to $-85 \mathrm{o}]$. 


\section{Distribution of Asymmetry After Midnight:}
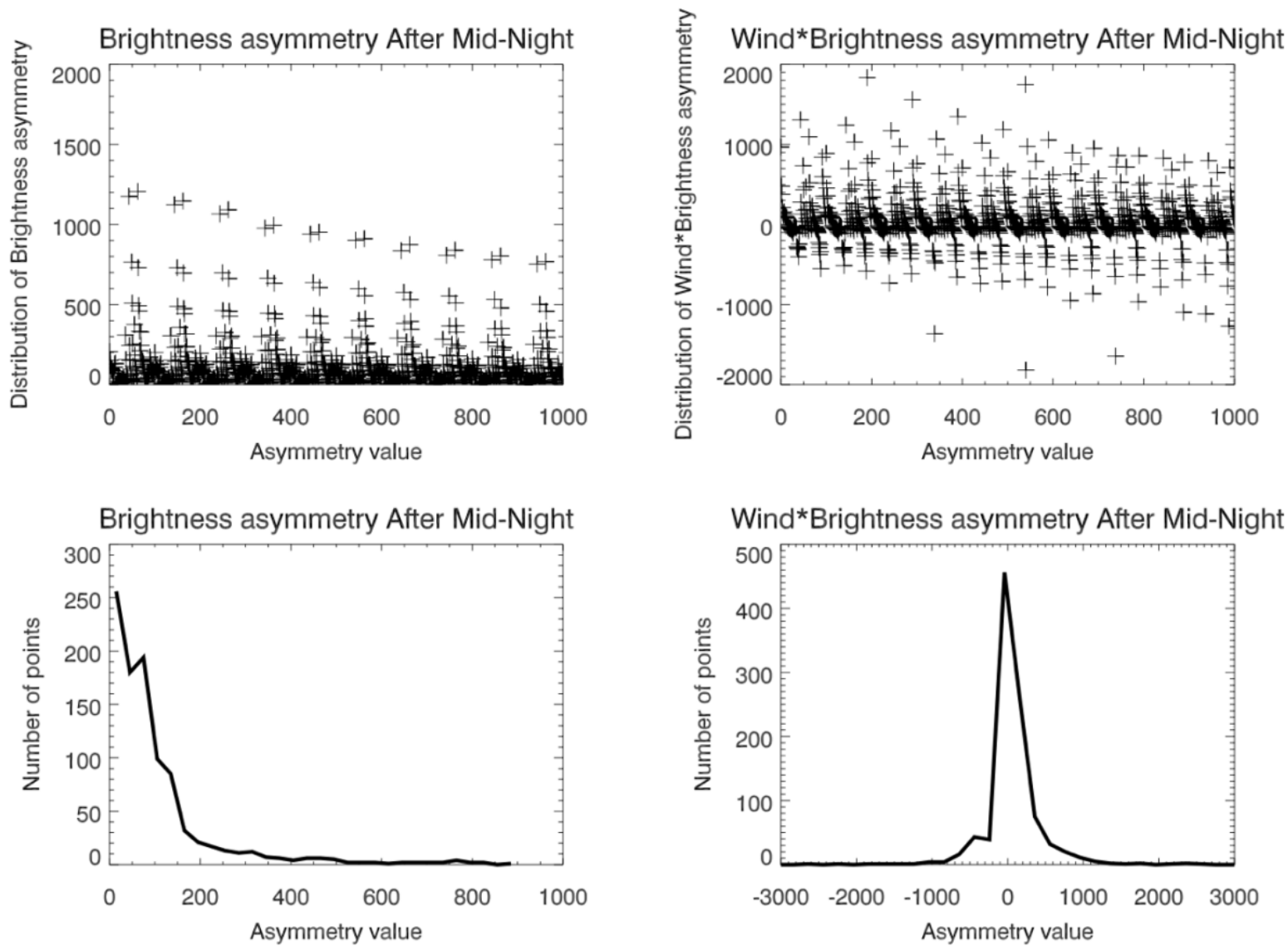

Figure 62 Distribution of Asymmetry after Midnight.

Figure 64 (Top Left) shows the distribution of brightness asymmetry after midnight. We can see that the brightness asymmetry is mostly positive and concentrated towards Zero. However, we also

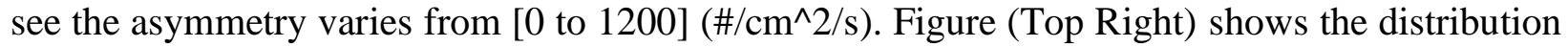
of wind*brightness asymmetry after midnight. We can see that the brightness asymmetry has distribution of both positive and negative, and concentrated towards Zero. However, we also see the asymmetry varies from [-1200 to 1800]. Figure (Bottom Left) shows the number of points in the brightness asymmetry distribution after midnight. We can see the distribution follows a Gaussian Distribution (only see the half here) with peak with 260 points and Full width at half maximum to be [110.0]. Figure (Bottom Right) shows the number of points in the wind*brightness 
asymmetry distribution after midnight. We can see the distribution follows a Gaussian Distribution with peak with 456 points and Full width at half maximum to be [555.0].

\section{Distribution of Asymmetry Before Midnight:}
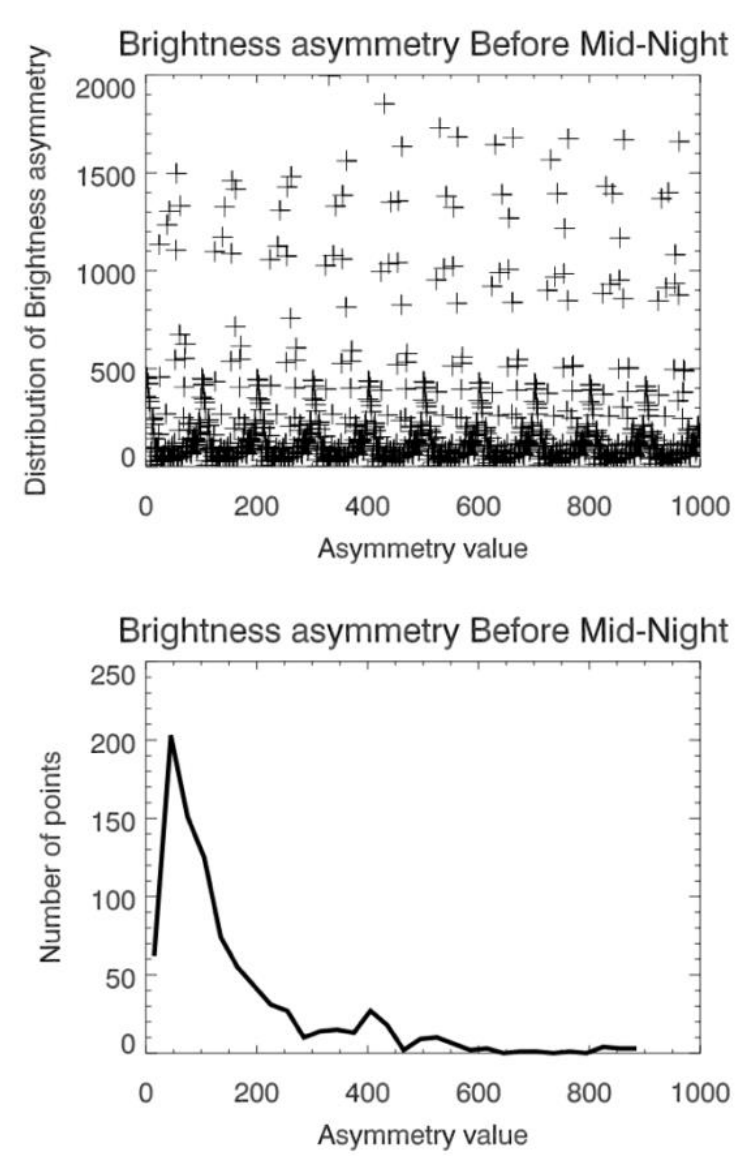

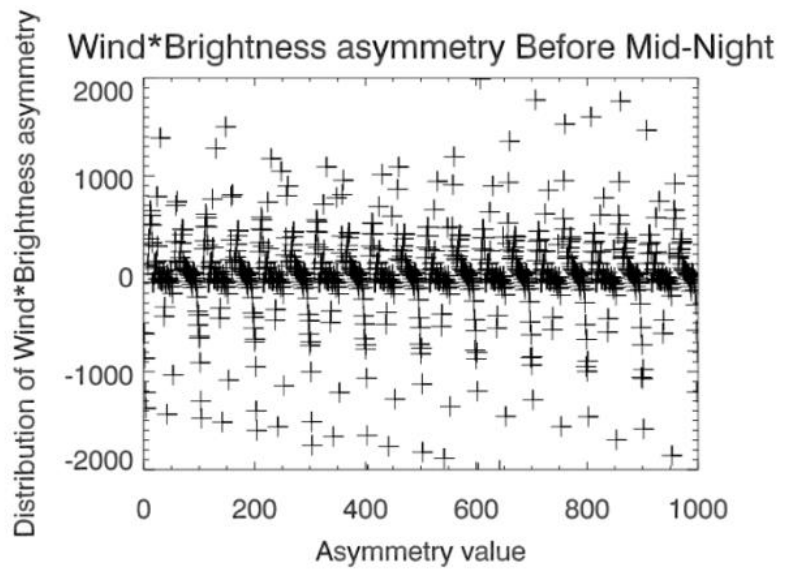

Wind*Brightness asymmetry Before Mid-Night

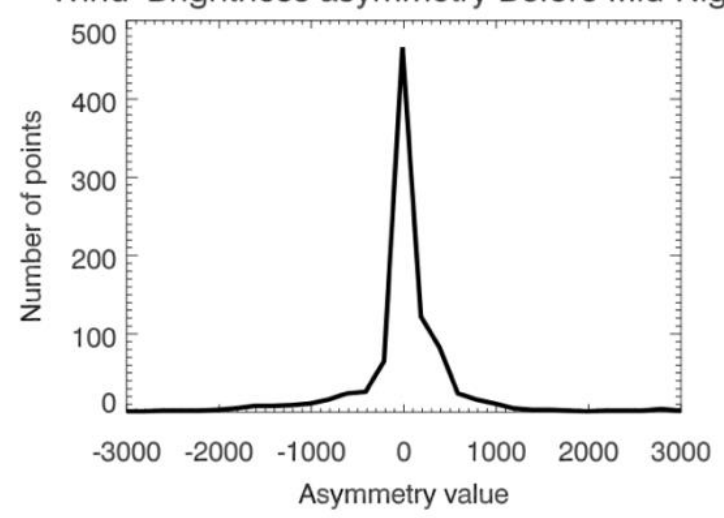

Figure 63 Distribution of Asymmetry before Midnight.

Figure 65 (Top Left) shows the distribution of brightness asymmetry before midnight. We can see that the brightness asymmetry is mostly positive and concentrated towards Zero. However, we also see the asymmetry varies from [0 to 1800$]\left(\# / \mathrm{cm}^{\wedge} 2 / \mathrm{s}\right)$. Figure (Top Right) shows the distribution of wind*brightness asymmetry before midnight. We can see that the brightness asymmetry has distribution of both positive and negative, and concentrated towards Zero. However, we also see the asymmetry varies from [-2200 to 1900] (\#/cm^2/s). Figure (Bottom Left) shows the number of points in the brightness asymmetry distribution before midnight. We can see the distribution follows a Gaussian Distribution (only see the half here) with peak with 63 points and Full width at half maximum to be [105.0]. Figure (Bottom Right) shows the number of points in the wind*brightness asymmetry distribution before midnight. We can see the distribution follows a Gaussian Distribution with peak with 466 points and Full width at half maximum to be [360.0]. 


\section{Distribution of Asymmetry After Noon:}
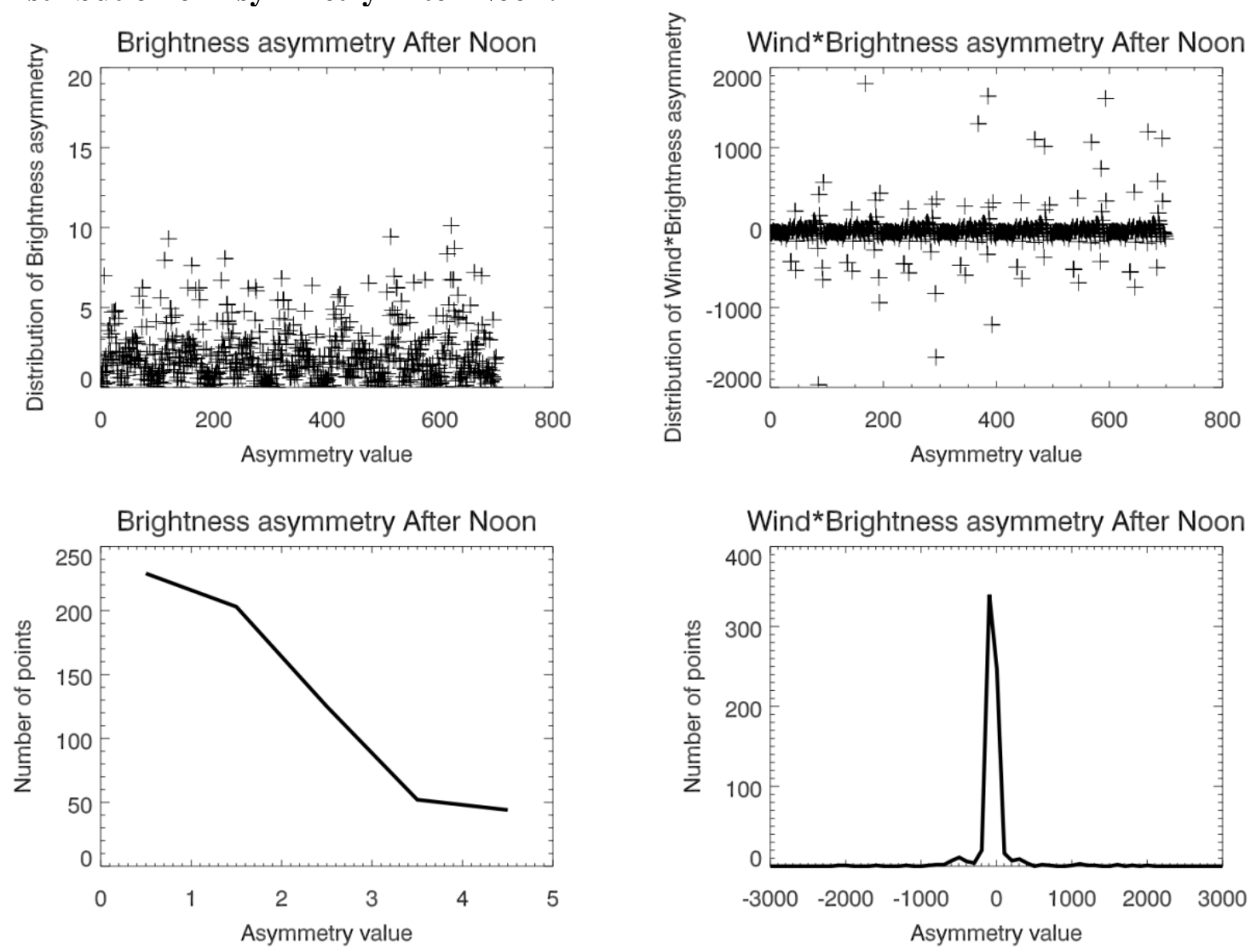

Figure 64 Distribution of Asymmetry after Noon.

Figure 66 (Top Left) shows the distribution of brightness asymmetry after noon. We can see that the brightness asymmetry is mostly positive and concentrated towards Zero. However, we also see the asymmetry varies from [0 to 10$]\left(\# / \mathrm{cm}^{\wedge} 2 / \mathrm{s}\right)$. Figure (Top Right) shows the distribution of wind*brightness asymmetry after noon. We can see that the brightness asymmetry has distribution of both positive and negative, and concentrated towards Zero. However, we also see the asymmetry varies from [-1100 to 1500] $\left(\# / \mathrm{cm}^{\wedge} 2 / \mathrm{s}\right)$. Figure (Bottom Left) shows the number of points in the brightness asymmetry distribution after noon. We can see the distribution follows a Gaussian Distribution (only see the half here) with peak with 229 points and Full width at half maximum to be [3.0]. Figure (Bottom Right) shows the number of points in the wind*brightness asymmetry distribution after noon. We can see the distribution follows a Gaussian Distribution with peak with 340 points and Full width at half maximum to be [270.0]. 


\section{Distribution of Asymmetry Before Noon:}
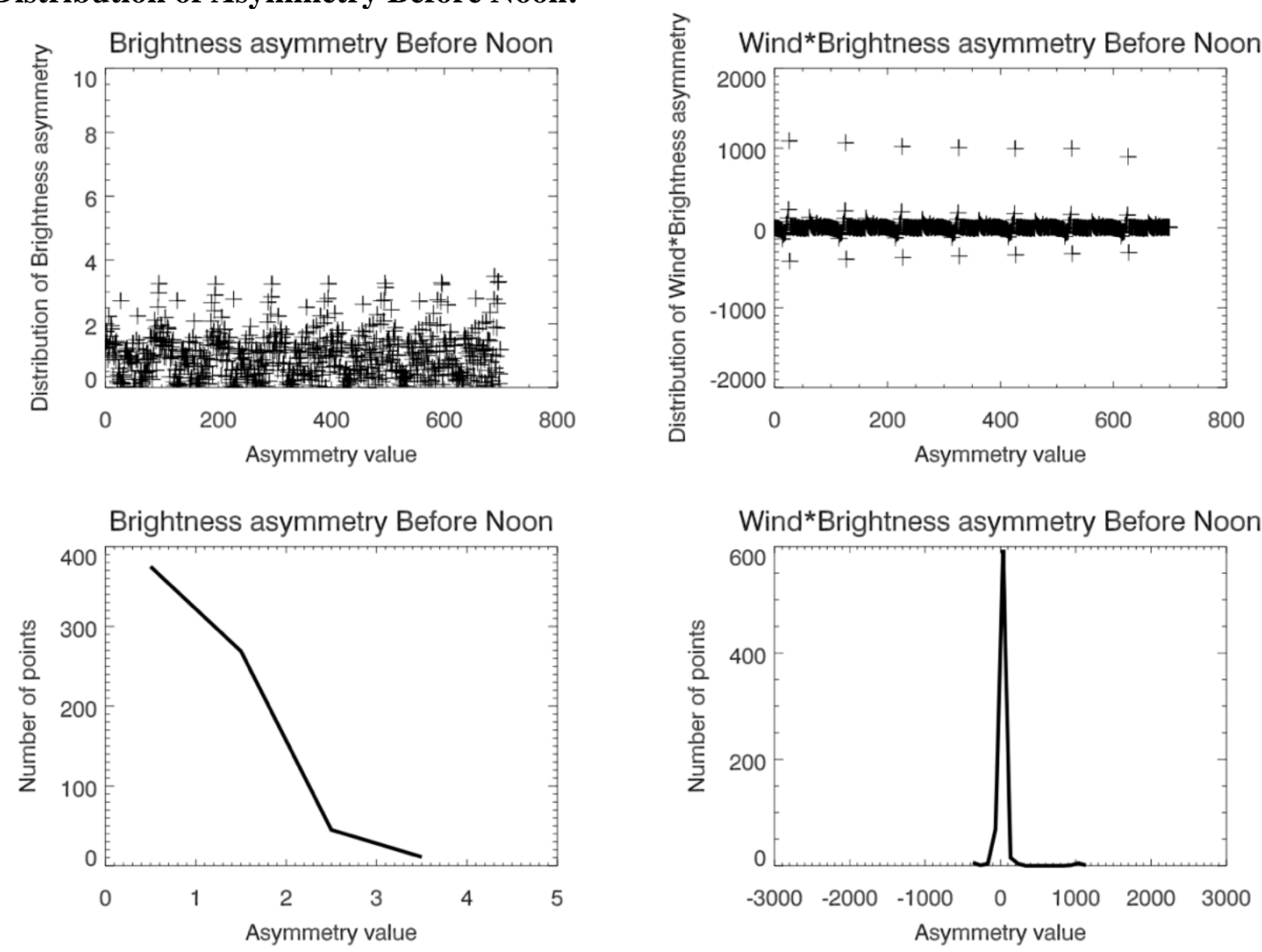

Figure 65 Distribution of Asymmetry before Noon.

Figure 67 (Top Left) shows the distribution of brightness asymmetry before noon. We can see that the brightness asymmetry is mostly positive and concentrated towards Zero. However, we also see the asymmetry varies from [0 to 4.0$]\left(\# / \mathrm{cm}^{\wedge} 2 / \mathrm{s}\right)$. Figure (Top Right) shows the distribution of wind*brightness asymmetry before noon. We can see that the brightness asymmetry has distribution of both positive and negative, and concentrated towards Zero. However, we also see the asymmetry varies from [-200 to 1100] $\left(\# / \mathrm{cm}^{\wedge} 2 / \mathrm{s}\right)$. Figure (Bottom Left) shows the number of points in the brightness asymmetry distribution before noon. We can see the distribution follows a Gaussian Distribution (only see the half here) with peak with 375 points and Full width at half maximum to be [2.5]. Figure (Bottom Right) shows the number of points in the wind*brightness asymmetry distribution before noon. We can see the distribution follows a Gaussian Distribution with peak with 594 points and Full width at half maximum to be [210.0].

Table 1 Brightness Asymmetry calculation.

\begin{tabular}{|l|l|l|l|l|}
\hline & After Midnight & Before Midnight & After Noon & Before Noon \\
\hline Highest Number of Points & 260 & 63 & 229 & 375 \\
\hline Full width at half maximum & 110.0 & 105.0 & 3.0 & 2.5 \\
\hline
\end{tabular}


Table 2 Wind*Brightness Asymmetry calculation.

\begin{tabular}{|l|l|l|l|l|}
\hline & After Midnight & Before Midnight & After Noon & Before Noon \\
\hline Highest Number of Points & 456 & 466 & 340 & 594 \\
\hline Full width at half maximum & 555.0 & 360.0 & 270.0 & 210.0 \\
\hline
\end{tabular}

\subsection{Discussion:}

It was expected from (Harding et al., 2017) there is a lot of asymmetry at night rather than during the day and the greatest asymmetry at sunset and sunrise. However, we could not calculate the asymmetry at the suggested time period by (Harding et al., 2017) due to no data at sunset and sunrise, therefore we calculated asymmetry at After Midnight, Before Midnight, After Noon, Before Noon (Figure 66 and Figure 67). Referring to the table 2, we can interpret that asymmetry is higher at night compared to daytime, as suggested by (Harding et al., 2017). Moreover, we can see the asymmetry does not account for the difference between the wind in the model and WINDII well. 


\section{Chapter 4 Conclusions}

The ionosphere is home of most spacecraft, satellite, International Space Station (ISS) etc., besides for navigation and precise positioning of satellites, aircraft, vehicles, rockets and many other spacecraft's, global positioning system (GPS) signals, radio frequency interference (RFI) pass through the ionosphere. The ionosphere is formed from either process like UV radiation hitting the upper atmosphere, or high energy charged particles hit the upper atmosphere - i.e. in aurora. The charged particles in the ionosphere are very variable as observed from both the ground and space. Some part of that variability comes from the upper atmosphere as the charged particles can be moved around by the neutral atmosphere, and E-fields that result from neutrals hitting charged particles, or through changes in its composition. We have looked at the wind portion of this variability (ICON will look at both). So, it is a matter of importance to understand the variability in the winds in order to understand the ionosphere.

There have been a number of satellite experiments that tried to figure out the variability in the upper atmosphere. However, the (ICON) Ionospheric Connection Explorer is the only recent NASA mission designed to study solely the Ionosphere and answer the what causes the variability in the upper atmosphere. ICON will be launched in a circular orbit at $575 \mathrm{~km}$ altitude, $27^{\circ}$ inclination orbit (Immel et al., 2018) studying the earth's upper atmosphere between 90 and 450 $\mathrm{km}$ above the Earth's surface. One of the key instruments on ICON is called MIGHTI, which measures the winds in the upper atmosphere.

In this thesis we have developed a tool to help us to compare MIGHTI with a model to interpret the MIGHTI observations of the variability of the winds in the thermosphere at low-mid latitudes. We used this tool to account for the geometry of the observation and variations in parameters using technique called ray-tracing approach. Using this technique, we read parameters like $\mathrm{O}_{2} \mathrm{O}_{2}, \mathrm{O}_{+}$, $\mathrm{O}_{2+}$, T, wind, solar F10.7 index, for every point along every ray from a model of the atmosphere. These parameters then were calculated from the model and brightness and Line of Sight (LOS) wind as a function of altitude and time. Besides the wind, another important parameter needed for the calculation of asymmetry (the summation before and after tangent point), green line airglow produced by the atomic oxygen transition $\mathrm{O}\left({ }_{1} \mathrm{D}-1 \mathrm{~S}\right)$ and resulting in photon emission at $557.7 \mathrm{~nm}$, from (Zhang et al., 2005) and red line emission at $630.0 \mathrm{~nm}$ from the $\mathrm{O}\left({ }_{1} \mathrm{D}\right)$ level of atomic oxygen is a prominent feature in the thermosphere between 100 and $400 \mathrm{~km}$, (Zhang et al.,2004). However, we looked at the Red line airglow for this study because for Red line airglow data we had both meridian and zonal winds and has the highest data resolution.

\section{Regarding MIGHTI:}

-We developed a tool able to simulate thermospheric wind profiles, $\mathrm{O}, \mathrm{O}_{2}, \mathrm{O}_{+}, \mathrm{O}_{2+}$ densities, Volume emission rate (VER) of green and red line airglow from measurements on the NASA Ionospheric Connection Explorer (ICON) mission from an instrument on board called MIGHTI.

- ICON is yet to launch so do not have MIGHTI to test our algorithm.

- We chose an instrument which is similar to MIGHTI called Wind Imaging Interferometer (WINDII), from a different mission called Upper Atmosphere Research Satellite (UARS) to test our algorithm. 
- Ultimately, we end up looking at the WINDII data, to try to test our code. But the real purpose of our code is MIGHTI, we just couldn't test it. Our tests with WINDII are incomplete because it doesn't give us the same data as MIGHTI.

Regarding our tests with WINDII:

- We chose to focus on the Redline for the WINDII data set as Harding et al 2017 suggest this has the biggest asymmetry and thus we hoped to find the effect of this in the WINDII winds.

- Comparing the WINDII winds to both a model simulation for the same conditions and a climatology of winds at redline altitudes, we see basic agreement in the overall patterns, but the WINDII winds do not perfectly match the model. This allowed us to inspect where they agree or disagree, and if asymmetry in the redline brightness along the ray plays an important part in this.

- Using the tool, we developed for MIGTHI, we calculated the asymmetry along each ray inspired by (Harding et al., 2017) that there is a lot of asymmetry at night rather than at day and the greatest asymmetry at sunset and sunrise.

- However, we could not calculate the asymmetry at the time period suggested by Harding et al., 2017 to have the largest asymmetry - sunrise and sunset - due to no WINDII data at these times. Therefore, we calculated asymmetry at four local times: After Midnight, Before Midnight, After Noon, Before Noon, but we note this is a significant limitation of our study that could not be overcome.

- Examining the asymmetry plots for the four local times where we have WIDNII data, we can interpret that asymmetry is higher at night compared to the daytime, as suggested by (Harding et al., 2017).

- Moreover, we can see the asymmetry does not account for the difference between the wind in the model and WINDII well.

- We believe there are other things going on such as variability in the winds associated with natural fluctuations in the thermosphere, atmospheric waves, inputs from the sun and the atmosphere below etc., appear to be bigger factor than just asymmetry along the line of sight.

We can summarize, asymmetry along the line of sight does not do a good job for accounting the variability, for the cases with WINDII where we were able to examine. We believe there are other things going on such as variability in the winds etc., that appears to be a bigger factor than just asymmetry along the line of sight. We should note several important limitations to this study, which will be overcome once MIGHTI data is available:

- We took only 400 points of a particular day (Year 1992 Day 015), where we are really only looking at one day. For better results we may need to investigate something like 2030 days to see a real agreement, which we can't do because, one day of simulation took us over weeks to run.

- We need to explore the terminators (sunset and sunrise) according to (Immel et al., 2018; Harding et al., 2017) rather looking at some other local times. When we have the MIGHTI data available, we can run simulations for the terminator (sunset and sunrise) and find if the asymmetry in this region is important in the comparison of the data to the model. 
- The publicly available WINDII data do not provide the line of sight winds, only the vector winds. In addition, they do not provide the observed redline brightness. Both of these are important checks we need to do with our tool, that could not be performed. Again, the MIGHTI data will provide both of these. 


\section{Bibiliography}

1. Coll, M., and J.M. Forbes, 2002, Nonlinear interactions in the upper atmosphere:The s $=1$ and $s=3$ nonmigrating semidiurnal tides, J. Geophys. Res., 107, 1157, doi:10.1029/2001JA900179.

2. Christensen, Andrew \& Yee, Jeng-Hwa \& L. Bishop, Rebecca \& A. Budzien, Scott \& H. Hecht, James \& Sivjee, Gulamabas \& W. Stephan, Andrew. (2012). Observations of molecular oxygen Atmospheric band emission in the thermosphere using the near infrared spectrometer on the ISS/RAIDS experiment. Journal of Geophysical Research (Space Physics). 117. 4315-. 10.1029/2011JA016838.

3. Clynch," Earth Coordinates" February 2006.

4. "Earth-centered inertial", Wikipedia, the free encyclopedia.

5. "ECEF Coordinate System", WRLD3D.

6. Englert, Christoph \& M. Harlander, John \& Brown, Charles \& D. Marr, Kenneth \& J. Miller, Ian \& Eloise Stump, J \& Hancock, Jed \& Q. Peterson, James \& Kumler, Jay \& H. Morrow, William \& A. Mooney, Thomas \& Ellis, Scott \& Mende, S \& E. Harris, Stewart \& H. Stevens, Michael \& Makela, Jonathan \& Harding, Brian \& J. Immel, Thomas. (2017). Michelson Interferometer for Global High-Resolution Thermospheric Imaging (MIGHTI): Instrument Design and Calibration. Space Science Reviews. 212. 1-32. 10.1007/s11214-017-0358-4.

7. Englert, J.M. Harlander, C.M. Brown, K.D. Marr, I.J. Miller, J.E. Stump, J. Hancock, J.Q. Peterson, J. Kumler, W.H. Morrow, T.A. Mooney, S. Ellis, S.B. Mende, S.E. Harris, M.H. Stevens, J.J. Makela, B.J. Harding, T.J. Immel, Michelson Interferometer for Global HighResolution Thermospheric Imaging DOI: 10.1007/s11214-017-0449-2 44 (MIGHTI): Instrument Design and Calibration. Space Sci. Rev. (2017).

8. Fejer, B.G., dePaula, E.R., Gonzalez, S.A., Woodman, R.F.,1991. Average vertical and zonal $F$ region plasma drifts over Jicamarca. Journal of Geophysical Research 96, 13901.

9. Forbes, "Dynamics of the upper mesosphere and thermosphere"J. Meteor. Soc. Jpn., 85B (2007), pp. 193-213.

10. Forbes, J.M., 1995. Tidal and planetary waves. In: Johnson, R.M., Killeen, T.L. (Eds.), The Upper Mesosphere and LowerThermosphere: A Review of Experiment and Theory, Vol. 87, AGU, Washington, DC.

11. GPS-E1 Evaluation Kit for GPS-MS1 and GPS-PS1, July, 1999.

12. Grieger, N., G. Schmitz, and U. Achatz, 2004, The dependence of nonmigrating diurnal tide in the mesosphere and lower thermosphere on stationary planetary waves, J. Atmos. Solar-Terr. Phys., 66, 733-754.

13. Haberle, R.M., Clancy, R.T., Forget, F., Smith, M.D., Zurek, R.W. (Eds.), 2017. The atmosphere and climate of Mars, Cambridge planetary science. Cambridge University Press, Cambridge.

14. Hagan, M.E., and R.G. Roble, 2001, Modeling diurnal tidal variability with the NCAR TIMEGCM, J. Geophys. Res., 106, 24869-24882.

15. Harlander, John \& R. Englert, Christoph \& Brown, Charles \& D. Marr, Kenneth \& J. Miller, lan \& Zastera, Vaz \& W. Bach, Bernhard \& Mende, S. (2017). Michelson Interferometer for Global High-Resolution Thermospheric Imaging (MIGHTI): 
Monolithic Interferometer Design and Test. Space Science Reviews. 212. 1-13. 10.1007/s11214-017-0374-4.

16. Harding, J.J. Makela, C.R. Englert, K.D. Marr, J.M. Harlander, S.L. England, T.J. Immel, The MIGHTI wind finding algorithm: Description and verification. Space Sci. Rev., 1-16 (2017). doi:10.1007/s11214-017-0359-3.

17. Heelis, 2004. Electrodynamics in the low and middle latitude ionosphere: a tutorial. Journal of atmospheric and solar-terrestial physics, Volume 66, Issue 10, July 2004, Pages 825- 838.https://doi.org/10.1016/j.jastp.2004.01.034.

18. Heelis, Kendall, P.C., Moffett, R.J., Windle, D.W., Rishbeth,H., 1974. Electrical coupling of the E- and F-regions and itseffect on F-region drifts and winds. Planetary and Space Science22, 743.

19. Heelis, U.T. Dallas, CEDAR, 2001 'Equatorial Ionospheric Electrodynamics'.

20. Hu, Bin Zhao, Xianze Ao, Yuehong Su, Yunyun Wang, Gang Pei, "Comparative analysis of different surfaces for integrated solar heating and radiative cooling: A numerical study", 2018. https://doi.org/10.1016/j.energy.2018.04.152.

21. Immel, T \& England, Scott \& Mende, S \& Heelis, R \& R. Englert, C \& Edelstein, Jerry \& Frey, H \& Korpela, Eric \& R. Taylor, E \& W. Craig, W \& E. Harris, S \& Bester, Manfred \& Bust, Gary \& Crowley, G \& M. Forbes, J \& Gérard, J.-C \& M. Harlander, J \& Huba, Joseph \& Hubert, B \& Sirk, Martin. (2018). The Ionospheric Connection Explorer Mission: Mission Goals and Design. Space Science Reviews. 214. 10.1007/s11214-017-0449-2.

22. "ICON - The Ionospheric Connection Explorer," UCB/SSL, URL: http://icon.ssl.berkeley.edu/science/

23. Killeen, T. L., Won, Y.-I., Niciejewski, R. J., \& Burns, A. G. (1995). Upper thermosphere winds and temperatures in the geomagnetic polar cap: Solar cycle, geomagnetic activity, and interplanetary magnetic field dependencies. Journal of Geophysical Research, 100(A11), 21,327-21,342. https://doi.org/10.1029/95JA01208

24. Lieberman, R.S., J. Oberheide, M.E. Hagan, E.E. Remsberg, and L.L. Gordley, 2004, Variability of diurnal tides and planetary waves during November 1978 - May 1979, J. Atmos. Solar-Terr. Phys., 66, 517-528, doi:10.1016/j.jastp.2004.01.006.

25. McDade, D.P Murtagh, R.G.H Greer, P.H.G Dickinson, G Witt, J Stegman, E. Llewellyn, L Thomas, D.B Jenkins Planet. Space Sci., 34 (1986), pp. 789-800.

26. Mustafa DǴNÇ,"Ph.D Thesis", Istanbul Technical University, Graduate school of science engineering and technology, 2013.

27. Oberheide, J., and O.A. Gusev, 2002, Observation of migrating and nonmigrating diurnal tides in the equatorial lower thermosphere, Geophys. Res. Lett., 29, 2167, doi:10.1029/2002GL016213.

28. Prolss ,'Physics of the Earth's Space Environment', Chapter 3, Fig. 3.32., Page (134), 2004.Picone, J. M., Hedin, A. E., Drob, D. P., and Aikin, A. C., NRLMSISE-00 empirical model of the atmosphere: Statistical comparisons and scientific issues, J. Geophys. Res., 107( A12), 1468, doi:10.1029/2002JA009430, 2002.

29. "Properties of Earth's Upper Atmosphere", John Emmert/Naval Research Lab.

30. Rishbeth, H., Müller-Wodarg, I. C. F., Zou, L., Fuller-Rowell, T. J., Millward, G. H., Moffett,R. J., Idenden, D. W., and Aylward, A. D., 2000, Annual and semiannual 
variations in the ionospheric F2-layer: II. Physical discussion, Ann. Geophysicae, 18, 945 956.

31. Roger A. Pielke, "Atmosphere GASEOUS ENVELOPE”, Encyclopædia Britannica.

32. Rowell, T. (1995). The dynamics of the lower thermosphere. Washington DC American Geophysical Union Geophysical Monograph Series. 87. 23-36. 10.1029/GM087p0023.

33. Tafon, Sivla \& Mccreadie, Heather. (2012). Lower and Upper thermosphere wind variations during magnetically quiet days.

34. "Thermosphere Ionosphere Electrodynamics General Circulation Model", University Corporation for Atmospheric Research.

35. The Editors of Encyclopaedia Britannica," Airglow", Encyclopaedia Britannica.

36. "Trends in Atmospheric Carbon Dioxide", Global Greenhouse Gas Reference Network, NOAA, 2019, retrieved 2019-05-31

37. "Vectors and the Geometry of Space", Lumen Learning.

38. Yamashita, K., S. Miyahara, Y. Miyoshi, K. Kawano, and J. Ninomiya, 2002, Seasonal variation of non-migrating semidiurnal tide in the polar MLT region in a general circulation model, J. Atmos. Sol.-Terr. Phys., 64, 1083-1094.

39. Zhang, S. P., and Shepherd, G. G. (2004), Solar influence on the O(1D) dayglow emission rate: Global-scale measurements by WINDII on UARS, Geophys. Res. Lett., 31, L07804, doi:10.1029/2004GL019447

40. Zhang, Shengpan \& Shepherd, Gordon. (2005). On the response of the O(1S) dayglow emission rate to the Sun's energy input: An empirical model deduced from WINDII/UARS global measurements. Journal of Geophysical Research. 110. 10.1029/2004JA010887.

41. Yee, R. DeMajistre, F. Morgan, Canadian Journal of Physics, 2012, 90(8): 769784, https://doi.org/10.1139/p2012-073 